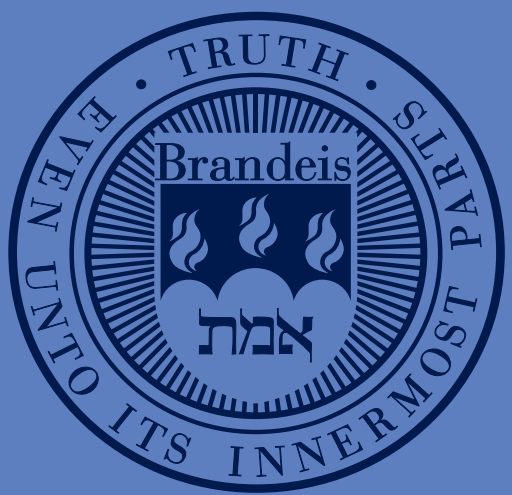

\title{
Factor Price Overshooting with Trade Liberalization: Theory and Evidence
}

Julian Emami Namini, Erasmus University Rotterdam

Ricardo Lopez, Brandeis International Business School

Working Paper Series 


\title{
Factor price overshooting with trade liberalization: theory and evidence*
}

\author{
Julian EMAMI NAMINI†and Ricardo A. LÓPEZ
}

September 17, 2012

\begin{abstract}
This paper develops an intra-industry trade model with skilled and unskilled labor as factors of production, endogenous accumulation of skilled labor and firm heterogeneity in factor intensities to examine the effect of trade reforms on factor prices. Since exporters are more skill intensive than non-exporters, a decrease in trade barriers initially increases wage inequality between skilled and unskilled worker, as a result of an increase in the relative demand for skilled labor. Over time, however, as agents respond to the change in relative wages by investing in skilled labor, the relative wage of skilled labor decreases. Evidence from Chilean plant-level data supports the idea of factor price overshooting with trade liberalization.
\end{abstract}

JEL classification: F12; E22; O41; O54.

Keywords: intra-industry trade; firm heterogeneity in factor intensities; wage inequality; overshooting; impact versus long run effect; Chile.

\footnotetext{
*We would like to thank Giovanni Facchini, Jean-Marie Viaene, Otto Swank, Bruno Merlevede, two anonymous referees and seminar participants at UCLA, the Midwest International Economics Meeting at Indiana University, the Ljubljana Empirical Trade Conference and the European Economic Association Annual Congress in Malaga for very helpful comments. All remaining shortcomings are ours.

${ }^{\dagger}$ Erasmus University Rotterdam, Department of Economics; tel.: +31 10408 1399; fax: +31 10408 9161; e-mail address: emaminamini@ese.eur.nl; Centro Studi Luca d'Agliano, Milan, Italy.

${ }^{\ddagger}$ Brandeis University, International Business School; tel.: +1 781736 4823; fax: +1 781736 2267; e-mail address: rlopez@brandeis.edu.
} 


\section{Introduction}

Relatively high levels of wage inequality between skilled and unskilled workers characterize many developing countries, especially those in Latin America (de Ferranti, et al., 2004). According to the Stolper-Samuelson theorem, increased trade with the rest of the world should decrease wage inequality in developing countries, by increasing the wage of unskilled workers (typically the relatively abundant factor in those countries), both in absolute and real terms. Empirical tests of this prediction, however, have been inclusive. While some studies find that trade reforms decrease wage inequality in certain countries (e.g., Gonzaga, et al., 2006), others find that trade liberalization actually increased wage inequality in many other countries (Goldberg and Pavcnik, 2004, 2007). ${ }^{1}$

This paper argues that the effect of trade liberalization on relative wages crucially depends on whether the country is able to increase its investments in skilled labor. We contend that since exporters are more skilled labor intensive than non-exporters (e.g., Alvarez and López, 2005), a decrease in trade barriers around the world should initially increase the demand for skilled labor in the country, relative to the demand for unskilled labor, thereby initially increasing the relative wage of skilled labor. Over time, however, as economic agents respond to the change in relative wages, investments in skilled labor take place, which increase the relative supply of skilled workers, resulting in a decrease of the relative wage of skilled labor in the long run. This result arises from introducing firm heterogeneity in factor intensities into a dynamic model of trade with endogenous accumulation of skilled labor. This framework allows us to examine the dynamic effects of decreasing trade barriers on wage inequality, and also to reconcile the apparently contradictory findings of the existing empirical studies cited above.

The dynamic model in this paper builds upon the intra-industry trade framework in Emami Namini (2009), and we use it to examine the impact effect and the long-run effect of trade liberalization on relative wages. The model modifies the Krugman (1980) setting of intra-industry trade by incorporating $(i)$ skilled and unskilled labor as factors of production, (ii) endogenous accumulation of skilled labor, (iii) CES production functions, and $(i v)$ firm heterogeneity in factor intensities. We use this framework to analyze how trade liberalization affects relative factor returns and firms' factor input choices, and we explicitly distinguish between the impact effect and the long-run effect of trade. ${ }^{2}$

\footnotetext{
${ }^{1}$ Country-specific studies include Beyer, Rojas and Vergara (1999), Hanson and Harrison (1999), Galiani and Sanguinetti (2003), Attanasio, Goldberg and Pavcnik (2004), and Acosta and Montes-Rojas (2008).

${ }^{2}$ Although our focus is on skilled and unskilled labor, the model can also be applied to a setting with
} 
We start by analyzing the effect of trade liberalization on impact, which refers to the immediate and temporary effect of trade liberalization. It corresponds to the effect of trade liberalization when countries have fixed amounts of skilled labor. The model shows that firms with different factor intensities produce with different levels of marginal costs. Thus, when a country opens up to costly trade, exporters and non-exporters use factors in different intensities. We restrict our analysis to such a constellation of parameters for which exporters are more skilled labor intensive than non-exporters. The reason for this is twofold: first, it is an empirical regularity that exporters are more skilled labor intensive than non-exporters; second, we can show that exporters can be more skilled labor intensive than non-exporters, regardless of a country's relative factor endowments. The model shows that trade liberalization increases the relative return to skilled labor on impact. This induces each single firm to produce less intensively with skilled labor.

We then analyze the long-run effect of trade liberalization. In the long run, the countries' skilled labor stocks are flexible and determined endogenously in a Ramsey growth setting. Due to the increased competition for skilled labor on impact, and the resulting increase of the relative return to skilled labor, households increase their investments into a country's skilled labor stock. Thus, in the long run, a country's skilled labor stock increases. This in turn decreases the relative return to skilled labor, which induces firms to produce more intensively with skilled labor in the long run. Thus, our model identifies an overshooting of the relative return to skilled labor on impact after trade liberalization. The reason for the overshooting is that the supply of skilled labor is fixed and cannot adjust on impact, while, in the long run, the supply of skilled labor reacts to the impact effect of trade liberalization.

Importantly, Heckscher-Ohlin trade seems less relevant to derive testable predictions on how trade affects wage inequality (i.e. the wage of skilled workers relative to the one of unskilled workers) for a country like Chile. Unlike most papers on Latin America, Leamer et al. (1999) argue that the endowment driven part of South American trade is due to a relative abundance of natural resources, not due to a relative abundance of skilled or unskilled labor. Thus, Heckscher-Ohlin trade by South American countries should redistribute income between the owners of natural resources and the aggregate of skilled and unskilled labor, rather than between the different types of labor. ${ }^{3}$ As a physical capital and labor as factors of production. Notice that the terms "skilled labor" and "human capital" have been used interchangeably in the existing literature (e.g., Findlay and Kierzkowski, 1983).

${ }^{3}$ See also Jones and Easton (1983) on the distributional consequences of trade in a three-factor Heckscher-Ohlin framework. 
consequence, an appropriately formulated Heckscher-Ohlin setting for Chile would not generate a testable effect of trade on wage inequality.

In the empirical part, we test the theoretical predictions using a panel dataset of Chilean manufacturing plants for the period 1990-1999. This dataset has information on the employment and the wage payments to skilled and unskilled workers. We find that, on impact, trade liberalization increases the relative wage of skilled workers and decreases the skill intensity of firms. If we look at the long run, we find exactly the opposite: the relative wage of skilled workers decreases and the skill intensity of a sector's average firm increases. These empirical results support the channels highlighted in the theoretical part, and suggest that the time dimension plays an important role when evaluating the impact of trade liberalization on wages in the context of firm heterogeneity in factor intensities.

Our paper is closely related to the literature on the effect of trade liberalization on wage inequality, which can be subdivided into different strands. In the first group, authors such as Findlay and Kierzkowski (1983) consider a setting with Heckscher-Ohlin trade, unskilled and endogenous skilled labor. The authors assume that an educational input is used for the accumulation of skilled labor, while the traded goods are produced only with skilled and unskilled labor. Findlay and Kierzkowski (1983) show that factor price equalization across countries results, i.e. trade liberalization leads to a one-time increase (decrease) of the relative return to skilled labor in the relatively skill abundant (scarce) country. Leamer et al. (1999) explain the high levels of wage inequality in Latin American countries by arguing that the Heckscher-Ohlin trade by these countries is based on relative abundance of natural resources and, thus, does not encourage investments into skills. Other researchers emphasize the potential role of skill-biased technological change in increasing wage inequality (Robbins, 1996; Tokarick, 2005; Gallego, 2006). Unlike these papers, our model does not assume that technological change is biased. Instead, our model generates changes in wage inequality due to factor reallocations between firms, and due to accumulation of skilled labor by households. Authors such as Robertson (2003) and Verhoogen (2008) focus on the role of exchange rate fluctuations on wage inequality. Since changes in exchange rates may generate effects similar to reducing tariffs abroad, our paper complements this line of research.

Another strand of the literature analyzes the effect of trade liberalization on wage inequality within a heterogeneous firms framework. Bernard, et al. (2007) extend the Melitz (2003) setup by including two factors of production and two monopolistically competitive 
sectors that use different capital-labor ratios in production. Within sectors, firms are heterogeneous in terms of total factor productivity (TFP), but are homogeneous in terms of factor input ratios. Their model provides important insights into the inter-industry factor reallocations due to trade liberalization. Since firms are homogeneous in factor intensities within a sector, changes in relative factor returns are due to Heckscher-Ohlin trade in their model.

Vannoorenberghe (2011) and Burstein and Vogel (2012) consider a two-factor setting, in which firms are randomly assigned a skill-specific productivity parameter upon market entry. Vannoorenberghe (2011) uses this setting to illustrate how a reduction in fixed export costs affects the skill premium differently than a reduction in variable export costs. Burstein and Vogel (2012) perform a quantitative analysis and illustrate how the effect of trade liberalization on the skill premium depends on a country's relative size and on its relative factor endowments. Harrigan and Reshef (2012) assume that firms get a TFP parameter as well as the factor share parameters of a Cobb-Douglas production function randomly assigned upon market entry. They calibrate their model with Chilean data to analyze how trade liberalization affects the skill premium. By construction, these papers do not consider the time dimension aspect of trade liberalization and its effects on relative factor returns. We argue in our paper that a distinction between the impact and the long-run effect is, indeed, important when analyzing the effect of trade liberalization on relative factor returns.

Another strand of this literature analyzes the impact of trade liberalization on the skill premium for the case of imperfectly competitive labor markets. Helpman et al. (2010) extend a Melitz (2003) setting by including a search and matching process, in which firms screen workers before hiring them. Due to increasing returns to scale in screening, larger firms have a more productive workforce and pay higher wages since a more productive workforce is more costly to replace. Helpman et al. (2010) show that trade liberalization increases wage inequality as the dispersion in firm size increases, which, in turn, increases the dispersion in wages. Davis and Harrigan (2011) develop a setting in which a worker's effort is imperfectly observable by firms. Thus, firms are willing to pay a higher wage to induce a higher level of effort, while the wage a firm pays decreases with the firm's ability to observe a worker's efforts. Davis and Harrigan (2011) show that trade liberalization reduces the mass of firms which pay high wages since these are the inefficient firms which are driven out of the market. Finally, Amiti and Davis (2012) consider a fair wages setting 
and extend the production side by including trade in intermediate goods. Amiti and Davis (2012) analyze theoretically and empirically how liberalization of final and intermediate goods trade interacts with a firm's mode of globalization to impact the wage the firm pays. Unlike our setting, these authors do not consider the time dimension when evaluating how trade liberalization affects relative wages.

Our paper also belongs to an increasing literature that examines the dynamics of trade liberalization. Ederington and McCalman (2008) construct a dynamic trade model and show that trade liberalization induces firms to adopt an advanced technology earlier. The dynamics in their paper result from an exogenous decline of technology adoption costs over time. Our paper differs from Ederington and McCalman (2008) since in our setting the dynamics result endogenously as trade liberalization increases the relative wage of skilled labor on impact, which triggers the accumulation of skilled labor and, thus, decreases its relative wage in the long run. Also related is the work by Atolia (2007). The author constructs a Heckscher-Ohlin setting with three factors of production, non-traded and traded goods, and uses calibration techniques to study the dynamic impact of trade liberalization on wage inequality. Atolia (2007) provides important insights into the role of capital adjustment costs. Our model differs from his since we consider intra-industry trade with firm heterogeneity in factor intensities. This different setting also allows for analytical results, which we test afterwards. Probably closest to our paper is Chaney (2005). He considers a one-factor Melitz (2003) setting, but assumes that the mass and distribution of firms adjust only sluggishly after trade liberalization. Chaney (2005) shows that such a setting generates an overshooting of aggregate TFP after trade liberalization. In our setting, and in contrast to Chaney (2005), it is the country's endowment of skilled labor that reacts sluggishly to trade liberalization and drives the overshooting of relative factor prices.

The only other papers that focus on firm heterogeneity in factor intensities - and abstract from heterogeneity in TFP or factor specific productivities - are Crozet and Trionfetti (2009), Emami Namini (2009), and Emami Namini et al. (2011). While Crozet and Trionfetti (2009) assume random factor share parameters and analyze how a firm's factor intensities interact with a country's relative factor endowments to determine the firm's market share, Emami Namini (2009) assumes random factor share parameters and analyzes the growth impact of trade liberalization. Emami Namini et al. (2011), on the other hand, assume that firms can choose their technology and analyze the firm selection 
due to trade liberalization. In the present paper, and in contrast to the previous ones, we assume that the distribution and the mass of firms, which are heterogeneous in their factor intensities, are given exogenously. ${ }^{4}$ In addition, we distinguish here between the impact effect and the long-run effect of trade on factor returns, and we test our results empirically.

The structure of the paper is as follows. Section 2 describes the setup of the theoretical model. Section 3 analyzes the autarkic steady state. Section 4 analyzes trade liberalization and distinguishes between its impact effect and its long-run effect on relative wages. Section 5 presents our empirical analysis. Section 6 concludes. All proofs are relegated to the appendix.

\section{The model}

\section{$2.1 \quad$ Overview}

There are two countries, the domestic country $D$ and the foreign country $F$. Households in each country are characterized by Dixit-Stiglitz preferences (Dixit and Stiglitz, 1977) and consume a continuum of imperfectly substitutable varieties of an aggregate consumption good $Q$. Firm behavior can therefore be described by large-group monopolistic competition, i.e. each firm regards the prices of all other varieties and factor prices as given. The production side of each country consists of this single monopolistically competitive sector.

Firms produce with skilled labor $S$ and unskilled labor $L$, and use a CES technology to produce a unique variety of the aggregate good $Q$. Firms are heterogeneous with respect to the factor share parameters of the CES production function.

We show the following: if the relative return to skilled labor differs from the relative productivity of skilled labor, firms with different factor share parameters realize different profit levels. We restrict our analysis to such a parameter constellation, for which a

\footnotetext{
${ }^{4}$ This assumption simplifies the analysis and allows us to focus on the main mechanisms that drive our results. In appendix $\mathrm{H}$, which is available online, we endogenize the mass and distribution of firms, and this does not qualitatively affect our results. If we follow Melitz and Ottaviano (2008), and assume that the mass and distribution of firms does not react on impact with trade liberalization, the impact effect is not affected by endogenizing mass and distribution of firms. However, the long run decrease in the relative return to skilled labor is amplified. The reason for this is the following. Since we choose the parameters such that only the more skilled labor intensive firms export, these firms correspond to the more productive ones in a setting with firm heterogeneity in TFP (e.g., Melitz, 2003). Thus, in our setting the firm distribution shifts towards the more skilled labor intensive ones in the long run after trade liberalization. This amplifies the long run increase in the relative endowment of skilled labor and, as a consequence, the long run decrease in the relative return to skilled labor.
} 
higher skilled labor share parameter leads to higher profits. The reason for this parameter restriction is twofold. First, if trade is also sufficiently costly, our model replicates the stylized fact that exporters are more skilled labor intensive than non-exporters. Second, we highlight that this parameter restriction does not restrict a country's relative endowment of skilled labor to be "large" or "small". Thus, our model can explain a higher skill intensity of exporters, regardless of a country's relative factor endowments.

To keep the analysis simple, and without affecting our general conclusions, we assume that the mass and distribution of firms are given exogenously. Thus, we do not explicitly analyze market entry or exit of firms in this paper. ${ }^{5}$ Furthermore, we make two additional assumptions to keep the model tractable: $(i)$ skilled and unskilled labor are perfectly mobile between firms within a country, but perfectly immobile between countries; $(i i)$ countries $D$ and $F$ are symmetric in every respect.

Finally, we will include a subscript aut or $f t$, to denote autarkic or free trade variables, respectively, only if otherwise confusion would arise.

\subsection{Production}

A single firm produces its unique variety of good $Q$ with the following CES function:

$$
q(\phi)=\left[\phi^{\frac{1}{\sigma}}\left(s A_{S}\right)^{\frac{\sigma-1}{\sigma}}+(1-\phi)^{\frac{1}{\sigma}}\left(l A_{L}\right)^{\frac{\sigma-1}{\sigma}}\right]^{\frac{\sigma}{\sigma-1}}, \quad 0 \leq \phi \leq 1,
$$

where $s$ and $l$ denote the input of skilled and unskilled labor, and $A_{S}$ and $A_{L}$ are factor specific productivity parameters, which are identical across firms. Thus, $s A_{S}$ and $l A_{L}$ represent the effective input of skilled and unskilled labor. $\sigma$ stands for the elasticity of substitution between effective factor inputs $s A_{S}$ and $l A_{L}$. If $\sigma>1$, factors are gross substitute in production, while they are gross complements in production if $1>\sigma>0$.

The number (or mass) of firms active in the market is exogenously given and denoted by $N$. Firms differ with respect to $\phi$ and we assume that the $N$ firms are distributed over the interval $[0,1]$ according to an exogenously given density $g(\phi)$. Thus, the density of firms with skilled labor share parameter $\phi$ is $N g(\phi)$.

Firms minimize production costs for a given $\phi$. Thus, a firm's marginal production

\footnotetext{
${ }^{5}$ As mentioned before and shown in appendix $\mathrm{H}$, which is available online, allowing the mass and distribution of firms to be determined endogenously does not change the main results of our analysis.
} 
cost is:

$$
c(\phi)=\left[\phi\left(\frac{w_{S}}{A_{S}}\right)^{1-\sigma}+(1-\phi)\left(\frac{w_{L}}{A_{L}}\right)^{1-\sigma}\right]^{\frac{1}{1-\sigma}},
$$

where $w_{S}$ and $w_{L}$ are the returns to skilled and unskilled labor, respectively. If $\frac{w_{S}}{A_{S}} \neq \frac{w_{L}}{A_{L}}$, the skilled labor share parameter $\phi$ influences $c(\phi)$.

\subsection{Demand}

Households consume the different varieties of the aggregate good $Q$. Following the existing literature, we assume that good $Q$ results from the following CES function:

$$
Q=\left[\int_{0}^{1} q(\phi)^{\frac{\xi-1}{\xi}} g(\phi) N d \phi\right]^{\frac{\xi}{\xi-1}}, \quad \xi>1
$$

$\xi$ stands for the elasticity of substitution between the varieties of $Q$. To simplify the algebra, without affecting the results in a qualitative sense, we impose assumption 1 for the remainder of the analysis:

Assumption $1 \sigma=\xi>1$. This implies that, in the following, $\sigma$ will denote the elasticity of substitution between skilled and unskilled labor in production and the elasticity of substitution between the varieties in consumption.

Assumption 1 implies that the term $c(\phi)^{1-\xi}$ becomes linear in $\phi .{ }^{6}$ Furthermore, $\sigma>1$ since $\xi>1$ is necessary to generate intra-industry trade (Krugman, 1980).

The price index $P$, which is dual to the CES function in equation 2 , is given by:

$$
P=\left[\int_{0}^{1} p(\phi)^{1-\sigma} g(\phi) N d \phi\right]^{\frac{1}{1-\sigma}}=\left[p(\widetilde{\phi})^{1-\sigma} N\right]^{\frac{1}{1-\sigma}}
$$

with $\widetilde{\phi}=\int_{0}^{1} \phi g(\phi) d \phi$. Since $P$ is the price index which is dual to the aggregate consumption good (equation 2), we can state the following definition:

Definition $1 \widetilde{\phi}$ is the skilled labor share parameter of the aggregate good $Q$.

\footnotetext{
${ }^{6}$ Notice that the results of this paper will depend on $(i)$ how $\phi$ influences $c(\phi)$ and $(i i)$ how $\phi$ and factor prices influence the per unit factor demands by firms. These relationships are not influenced by assumption 1 in a qualitative sense. The proofs for the more general case of $\sigma \neq \xi$ and $\sigma \gtrless 1$ are tedious and, as a consequence, are relegated to appendix I, which is available online.
} 
Applying Shephard's Lemma to the price index $P$, the demand for a single variety can be derived as:

$$
q(\phi)=Y P^{\sigma-1} p(\phi)^{-\sigma}
$$

$Y$ denotes total factor income, i.e. $Y=w_{S} S+w_{L} L=P Q$, with $S$ and $L$ denoting the country's endowments of skilled and unskilled labor. Profit maximizing firms charge the price $p(\phi)=\frac{\sigma}{\sigma-1} c(\phi)$.

\subsection{Profits, the factor share parameter $\phi$ and factor returns $w_{S}$ and $w_{L}$}

Unskilled labor is chosen as numéraire and we set $w_{L}$ equal to unity. Thus, $w_{S}$ will denote the relative return to skilled labor in the following. Later, when we derive the steady state, we will show that the relative return to skilled labor $w_{S}$, which is determined endogenously, can be smaller or larger than $\frac{A_{S}}{A_{L}}$ in the steady state, depending on the parameters of the model. Depending on whether $w_{S}<\frac{A_{S}}{A_{L}}$ or $w_{S}>\frac{A_{S}}{A_{L}}$, the skilled labor share parameter $\phi$ has a positive or a negative influence on a firm's profits $\pi(\phi)$. This is shown by the following equation:

$$
\pi(\phi)=\frac{p(\phi) q(\phi)}{\sigma}=Y P^{\sigma-1} \frac{\phi\left[w_{S}^{1-\sigma}-\left(\frac{A_{S}}{A_{L}}\right)^{1-\sigma}\right] A_{S}^{\sigma-1}+A_{L}^{\sigma-1}}{\sigma^{\sigma}(\sigma-1)^{1-\sigma}} .
$$

$Y$ and $P$ are exogenous for a single firm due to large-group monopolistic competition.

Thus, if $w_{S}<\frac{A_{S}}{A_{L}}$ in the steady state, a more skilled labor intensive firm has larger profits than a more unskilled labor intensive one. If $w_{S}>\frac{A_{S}}{A_{L}}$, in contrast, a more unskilled labor intensive firm has larger profits than a more skilled labor intensive one.

\subsection{Relative factor returns in the steady state}

Households use part of the aggregate consumption good $Q$ for investment purposes. Since the investment technology is not characterized by a "love of variety" property, households do not evaluate each unit of investments in skilled labor with $P$ (see equation 3), but, instead, with $p(\widetilde{\phi})=P N^{\frac{1}{\sigma-1}}$. Households choose their consumption and investment levels each period such that lifetime utility $V$ is maximized. ${ }^{7}$

Denoting the time discount rate as $\rho$ and the instantaneous utility function as $u$, then

\footnotetext{
${ }^{7}$ Since the distribution of $\phi$ on the unit interval is exogenously given, the model remains analytically solvable, even if any variety $q(\phi)$ with $\phi \neq \widetilde{\phi}$ were used for investments.
} 
lifetime utility of the representative household of either country is:

$$
V=\sum_{t=0}^{\infty} \frac{u\left(Q_{t}\right)}{(1+\rho)^{t}}
$$

where $t$ is time and $Q_{t}$ is the aggregate consumption good defined by 2 .

Each country's endowment of unskilled labor is constant over time. Investments increase the stock of skilled labor and compensate for the depreciation of it. If $\delta$ denotes the rate of depreciation of skilled labor, investments in a country's skilled labor stock in any period $t$ of the steady state are given by:

$$
I_{t}=S_{t+1}-(1-\delta) S_{t}=\delta S
$$

where $I_{t}$ is the amount of the aggregate good $Q$ invested in period $t$, while $S_{t}$ and $S_{t+1}$ are the country's stocks of skilled labor in $t$ and $t+1$. Investments in the steady state are given by $I_{t}=\delta S$ where $S$ is the steady state endowment of skilled labor.

Households own the production factors and lend them out to firms for production. Given that households behave perfectly competitively, the steady state of a Ramsey growth setup is characterized by a set of first order conditions, which determine $w_{S}$ in the steady state as a function of the parameters $\rho, \delta, \sigma, A_{S}, A_{L}$ and the average skilled labor share parameter $\widetilde{\phi}$ (see also Baxter, 1992). This is summarized by lemma 1 .

Lemma 1 The relative return to skilled labor in the steady state is given by:

$$
w_{S}=\left[\frac{(1-\widetilde{\phi})(\rho+\delta)^{1-\sigma} A_{L}^{\sigma-1}}{1-\widetilde{\phi}(\rho+\delta)^{1-\sigma} A_{S}^{\sigma-1}}\right]^{\frac{1}{1-\sigma}}
$$

Proof. See appendix A. ${ }^{8}$

The time index $t$ has been removed from equation 6 since it denotes a relationship in the steady state. Equation 6 shows that the parameters $\rho, \delta$ and $A_{S}$ determine whether $w_{S}<\frac{A_{S}}{A_{L}}$ or $w_{S}>\frac{A_{S}}{A_{L}}$ in the steady state. This leads to lemma 2 :

\footnotetext{
${ }^{8}$ Notice that the more familiar expression for $w_{S}$ in the steady state would result if variety $q(\widetilde{\phi})$ were taken as numéraire: $\frac{w_{S}}{p(\widetilde{\phi})}=(\rho+\delta) \frac{\sigma-1}{\sigma}$. Equation 6 shows that $w_{S}$ is defined for all possible values of $\sigma$ only if $\widetilde{\phi}<\left(\frac{A_{S}}{\rho+\delta}\right)^{1-\sigma}$. Since $\widetilde{\phi}$ is exogenous in our setting, we have to assume that $\widetilde{\phi}<\left(\frac{A_{S}}{\rho+\delta}\right)^{1-\sigma}$. However, we show in appendix $H$ that, in a setting in which $\widetilde{\phi}$ is determined endogenously via a market entry procedure like in Melitz (2003) - firms pay market entry costs, afterwards randomly draw their $\phi$ and then decide whether to start production or not-, the equilibrium $\widetilde{\phi}$ is necessarily smaller $\operatorname{than}\left(\frac{A_{S}}{\rho+\delta}\right)^{1-\sigma}$.
} 
Lemma 2 If $\rho+\delta<A_{S}$, then $w_{S}<\frac{A_{S}}{A_{L}}$ in the steady state. Conversely, if $\rho+\delta>A_{S}$, then $w_{S}>\frac{A_{S}}{A_{L}}$ in the steady state.

Thus, if we compare any two firms $i$ and $j$ with skilled labor share parameters $\phi_{i}$ and $\phi_{j}$, with $\phi_{i}>\phi_{j}$, the relationship between $\rho+\delta$ and $A_{S}$, will determine if $i$ has larger profits than firm $j$ (see also subsection 2.4).

Later, when we analyze trade liberalization, we will assume that trade is costly, so that only part of the domestically active firms will export. In order to guarantee that only sufficiently skill intensive firms will export, we impose assumption 2 for the remainder of our analysis:

Assumption 2 The parameters $\rho, \delta$ and $A_{S}$ are such that $\rho+\delta<A_{S}$. This implies that $w_{S}<\frac{A_{S}}{A_{L}}$ in the steady state, i.e. if two firms $i$ and $j$ are characterized by skilled labor share parameters $\phi_{i}$ and $\phi_{j}$ with $\phi_{i}>\phi_{j}$, firm $i$ produces with a lower marginal cost than firm $j$.

Furthermore, it is useful for our further analysis to study how the steady state value of $w_{S}$ depends on $\widetilde{\phi}$. Remember that $\widetilde{\phi}$ reflects the skilled labor share parameter of the aggregate good $Q$ and, thus, equals the average skilled labor share parameter over all varieties that are supplied to the domestic market (see definition 1 ). Thus, $\widetilde{\phi}$ changes with trade liberalization if not all firms, which supply to the domestic market, export as well. The relationship between $\widetilde{\phi}$ and the steady state value of $w_{S}$ is summarized by lemma 3 :

Lemma 3 Given assumption 2, an increase in the average skilled labor share parameter $\widetilde{\phi}$ decreases the steady state value of $w_{S}$.

Proof. See appendix B.

\section{Autarkic steady state}

The autarkic steady state for either country is characterized by the following 3 conditions:

(i) output equals demand for each variety at price $p(\phi)=\frac{\sigma}{\sigma-1} c(\phi)$ (see equation 4);

(ii) $w_{S}=\left[\frac{(1-\widetilde{\phi})(\rho+\delta)^{1-\sigma} A_{L}^{\sigma-1}}{1-\widetilde{\phi}(\rho+\delta)^{1-\sigma} A_{S}^{\sigma-1}}\right]^{\frac{1}{1-\sigma}}($ see equation 6$)$; 
(iii) factor market clearing conditions (see below).

In the steady state, $w_{S}$ is determined by the parameters $\rho, \delta, \sigma, A_{S}, A_{L}$ and by the average skilled labor share parameter $\widetilde{\phi}$, while the stock of skilled labor $S$ is such that demand for skilled labor equals its supply at price $w_{S}$. Thus, in subsection 3.1 we will substitute $w_{S}$ from equation 6 into the factor market clearing conditions to determine the magnitude of $S$ in the autarkic steady state. In subsection 3.2 we will substitute the steady state values of $S$ and $w_{S}$ into equation 4 to determine $q(\phi), \forall \phi \in[0,1]$, in the autarkic steady state.

\subsection{Factor market clearing conditions}

Applying Shephard's Lemma to the marginal cost function (equation 1) leads to the following factor market clearing conditions:

$$
\begin{aligned}
\int_{0}^{1}(1-\phi) A_{L}^{\sigma-1} c(\phi)^{\sigma} \frac{Y p(\phi)^{-\sigma}}{P^{1-\sigma}} N g(\phi) d \phi+(1-\widetilde{\phi}) A_{L}^{\sigma-1} c(\widetilde{\phi})^{\sigma} \delta S & =L \\
w_{S}^{-\sigma} \int_{0}^{1} \phi A_{S}^{\sigma-1} c(\phi)^{\sigma} \frac{Y p(\phi)^{-\sigma}}{P^{1-\sigma}} N g(\phi) d \phi+\widetilde{\phi} A_{S}^{\sigma-1} w_{S}^{-\sigma} c(\widetilde{\phi})^{\sigma} \delta S & =S .
\end{aligned}
$$

Notice that $\delta S$ is the level of investment in the steady state, while $(1-\widetilde{\phi}) A_{L}^{\sigma-1} c(\widetilde{\phi})^{\sigma}$ and $\widetilde{\phi} A_{S}^{\sigma-1} w_{S}^{-\sigma} c(\widetilde{\phi})^{\sigma}$ are the per unit input requirements of unskilled and skilled labor, respectively, for the investment good. $\frac{Y p(\phi)^{-\sigma}}{P^{1-\sigma}}$ is the demand for variety $q(\phi)$.

Dividing equations 7 and 8 by each other, solving for $S$ and $w_{S}$ and, afterwards, considering equation 6 lead to the following autarkic steady state values for $w_{S}$ and $S:{ }^{9}$

$$
\begin{aligned}
w_{S} & =\left[\frac{\widetilde{\phi}}{1-\widetilde{\phi}} \frac{L}{S}\left(\frac{A_{S}}{A_{L}}\right)^{\sigma-1}\right]^{\frac{1}{\sigma}}=\left[\frac{(1-\widetilde{\phi})(\rho+\delta)^{1-\sigma} A_{L}^{\sigma-1}}{1-\widetilde{\phi}(\rho+\delta)^{1-\sigma} A_{S}^{\sigma-1}}\right]^{\frac{1}{1-\sigma}} \\
S & =L \frac{w_{S}^{-\sigma} \widetilde{\phi}}{1-\widetilde{\phi}}\left(\frac{A_{S}}{A_{L}}\right)^{\sigma-1}=L \frac{(1-\widetilde{\phi})^{\frac{1}{\sigma-1}}(\rho+\delta)^{-\sigma} \widetilde{\phi} A_{L} A_{S}^{\sigma-1}}{\left[1-\widetilde{\phi}(\rho+\delta)^{1-\sigma} A_{S}^{\sigma-1}\right]^{\frac{\sigma}{\sigma-1}}} .
\end{aligned}
$$

\subsection{Production and revenue in the autarkic steady state}

Substituting the autarkic steady state values for $w_{S}$ (equation 9) and $S$ (equation 10) into the demand function for each single variety of the aggregate good $Q$ (equation 4 ) leads to

\footnotetext{
${ }^{9}$ See appendix $\mathrm{C}$ for the derivation of equations 9 and 10.
} 
the following production of a variety $q(\phi)$ in the autarkic steady state:

$$
q(\phi)=\frac{L A_{L}(1-\widetilde{\phi}) \frac{\sigma-1}{\sigma} \Omega(\phi)^{\frac{\sigma}{\sigma-1}}}{N\left[1-\widetilde{\phi}(\rho+\delta)^{1-\sigma} A_{S}^{\sigma-1}\right]^{\frac{\sigma}{\sigma-1}}}, \quad \text { with } \quad \Omega(\phi) \equiv(\phi-\widetilde{\phi})\left(\frac{\rho+\delta}{A_{S}}\right)^{1-\sigma}+1-\phi
$$

Revenue $q(\phi) p(\phi)$ of a firm which produces with skilled labor share parameter $\phi$ is:

$$
q(\phi) p(\phi)=\frac{L(1-\widetilde{\phi})^{-1} \Omega(\phi)}{N\left[1-\widetilde{\phi}(\rho+\delta)^{1-\sigma} A_{S}^{\sigma-1}\right]}
$$

The relationship between the term $\Omega(\phi)$ and $\phi$ follows from the following partial derivative:

$$
\frac{\partial \Omega(\phi)}{\partial \phi}=A_{S}^{\sigma-1}(\rho+\delta)^{1-\sigma}-1
$$

Equation 12 implies that a more skilled labor intensive firms has higher revenues than a more unskilled labor intensive one since $\rho+\delta<A_{S}$ due to assumption 2. The reason for this is that $\rho+\delta<A_{S}$ implies $w_{S}<\frac{A_{S}}{A_{L}}$.

\subsection{Properties of the autarkic steady state}

The autarkic steady state value of $w_{S}$ is uniquely determined by equation 6 , while equations 10 and 11 uniquely determine the corresponding values for $S$ and $q(\phi)$. Thus, we can formulate lemma 4 :

Lemma 4 A unique and stable autarkic steady state exists.

Importantly, equations 9 and 10 imply that a country's relative endowment with skilled labor $\frac{S}{L}$ only gives limited information about how $w_{S}$ relates to $\frac{A_{S}}{A_{L}}$, i.e. about whether a more skilled or a more unskilled labor intensive technology leads to higher profits. The reason is that only the parameters $\rho, \delta$ and $A_{S}$ determine whether $w_{S}<\frac{A_{S}}{A_{L}}$ or $w_{S}>\frac{A_{S}}{A_{L}}$ in the steady state (see lemma 2), but the steady state level of $\frac{S}{L}$ also depends on $\widetilde{\phi}$ and $A_{L}$. Thus, assumption 2 is not restrictive concerning a country's relative skilled labor endowment, and we can formulate lemma 5:

Lemma 5 Assumption 2 does not restrict the analysis to countries with "large" relative skilled labor endowments. The relative skilled labor endowment can take any value from 
the interval $[0, \infty)$, depending on the magnitudes of $A_{S}, \rho, \delta, \sigma$ and the distribution of $\phi$ on the unit interval.

Proof. See appendix D.

Thus, it is possible in our setting that a country's relative skilled labor endowment $\frac{S}{L}$ is "small" (for example, $\frac{S}{L}<1$ ), while, at the same time, a more skilled labor intensive firm makes larger profits than less skilled labor intensive one. As a consequence, $w_{S}$ being smaller than $\frac{A_{S}}{A_{L}}$ is not limited to developed economies with "large" relative skilled labor endowments.

\section{Trade liberalization}

We consider the case in which trade liberalization decreases tariffs from an initially prohibitive level to zero. Following the existing literature, we assume that entering the foreign market involves sunk costs. Iceberg transport costs are zero and countries $D$ and $F$ are completely symmetric. Thus, we focus on the equilibrium conditions for a single country.

Since not all firms within a sector export after trade liberalization, we assume that the sunk export costs are sufficiently large so that only the more skill intensive firms have sufficiently low marginal costs (see assumption 2) to find it profitable to export.

When analyzing trade liberalization, we distinguish between the impact effect and the long run effect. To analyze the impact effect of trade liberalization we assume that a country's skilled labor endowment $S$ is still fixed at its autarkic steady state level (see equation 10). This implies that the relative price of skilled labor $w_{S}$ will change on impact after trade liberalization such that factor markets clear. Thus, when analyzing the impact effect of trade liberalization, we characterize a country's general equilibrium by the following 3 conditions:

(i) production equals demand for each variety at price $p(\phi)=\frac{\sigma}{\sigma-1} c(\phi)$; notice that 'demand' is 'worldwide demand' if a firm exports;

(ii) a zero cutoff profit condition for the supply to the foreign market;

(iii) the factor market clearing conditions with the skilled labor endowment $S$ at its autarkic steady state level.

These conditions can be solved for the following variables to analyze the impact effect of trade liberalization: $(i)$ production $q(\phi)$ of each variety, $(i i)$ the relative frequency of 
exporting firms in the firm distribution and (iii) the relative return to skilled labor $w_{S}$. Notice that the zero cutoff profit condition for the supply to the foreign market determines a critical $\phi$, which defines the dividing line between exporters and non-exporters. Once this dividing line is known, the relative frequency of exporting firms can be determined.

In the long run after trade liberalization $S$ becomes flexible and adjusts so that factor markets clear. $w_{S}$, instead, is again given by equation 6 in the long run after trade liberalization. Notice, though, that the skilled labor share parameter of the aggregate good $Q$ changes with trade liberalization if not all firms, which supply to the domestic market, export as well. This impacts the steady state level of $w_{S}$ (see lemma 3).

We first discuss a firm's supply decision to the foreign market, and then continue with analyzing the impact effect and the long-run (steady state) effect of trade liberalization.

\subsection{Supply decision to the foreign market}

Foreign demand for a domestic variety is given by $q_{X}(\phi)=Y P^{\sigma-1} p(\phi)^{-\sigma}$. The subscript $X$ denotes exports. Neither $Y$ nor $P$ have a country index due to symmetry across countries. Since iceberg transport costs are zero, aggregate sales of an exporting firm ceteris paribus double with trade liberalization:

$$
q(\phi)+q_{X}(\phi)=2 Y P^{\sigma-1} p(\phi)^{-\sigma}
$$

Entering the foreign market leads to a sunk input requirement $f_{E x}$, which is in terms of a firm's own variety. Thus, the sunk costs for entering the foreign market for a firm with skilled labor share parameter $\phi$ are given by $F_{E x}(\phi)=c(\phi) f_{E x} \cdot{ }^{10}$ The per period equivalent of the sunk entry costs into the foreign market is then given by $c(\phi) f_{X}$, with $f_{X} \equiv f_{E x} \frac{\rho}{1+\rho}$. Notice that a firm with skilled labor share parameter $\phi$ is indifferent between paying $c(\phi) f_{E x}$ once upon entering the foreign market or paying $c(\phi) f_{X}$ in each period of its remaining life, once it has entered the foreign market.

Furthermore, we make the following assumption concerning the magnitude of $f_{X}$ :

Assumption 3 If $w_{S, a u t}, S_{a u t}$ and $P_{a u t}$, respectively, denote the autarkic steady state values of the return to skilled labor, a country's endowment of skilled labor and the aggregate

\footnotetext{
${ }^{10}$ This structure of fixed costs is common in two-factor trade models, e.g., Markusen and Venables (2000). Alternatively, we could assume that firms have to pay for $f_{E x}$ in terms of unskilled labor, i.e. $F_{E x}=f_{E x}$ or in terms of skilled labor, i.e. $F_{E x}=w_{S} f_{E x}$. Our results are robust to these alternative specifications of $F_{E x}$.
} 
price index, $f_{X}$ is such that the following two conditions hold:

$$
\begin{aligned}
\frac{\left(L+w_{S, a u t} S_{a u t}\right)\left(\frac{\sigma}{\sigma-1}\right)^{-\sigma}}{\sigma P_{a u t}^{1-\sigma} A_{L}^{1-\sigma}-\frac{f_{X}}{A_{L}}} & <0 \\
0 & <\frac{\left(L+w_{S, a u t} S_{a u t}\right)\left(\frac{\sigma}{\sigma-1}\right)^{-\sigma} w_{S, \text { aut }}^{1-\sigma}}{\sigma P_{a u t}^{1-\sigma} A_{S}^{1-\sigma}}-\frac{w_{S, \text { aut }} f_{X}}{A_{S}} .
\end{aligned}
$$

The left hand side of condition 13 denotes the potential export profits, evaluated at autarkic prices, of a firm which produces with $\phi=0$. The right hand side of condition 14 denotes the potential export profits, also evaluated at autarkic prices, of a firm which produces with $\phi=1 .^{11}$ Thus, conditions 13 and 14 ensure that the most unskilled labor intensive firms will not serve the foreign market after trade liberalization, while the most skilled labor intensive ones will.

Thus, we can define a critical skilled labor share parameter $\phi_{X}^{*}$, which leads to zero profits from exporting. Since $f_{X}$ is such that the most skilled labor intensive firms make strictly positive profits from exporting, while the most unskilled labor intensive ones make negative profits, we can conclude that $\phi_{X}^{*}$ is uniquely defined and strictly between 0 and 1 since $\frac{\partial \pi(\phi)}{\partial \phi}>0$ due to assumption 2 . The critical $\phi$ solves the following equation: ${ }^{12}$

$$
q\left(\phi_{X}^{*}\right)\left[p\left(\phi_{X}^{*}\right)-c\left(\phi_{X}^{*}\right)\right]=c\left(\phi_{X}^{*}\right) f_{X}
$$

We are now ready to formulate lemma 6 :

Lemma 6 If $\rho+\delta<A_{S}$ (see assumption 2), and if $f_{X}$ is such that conditions 13 and 14 hold, only firms with a skilled labor share parameter equal or larger than $\phi_{X}^{*}$ will export after trade liberalization.

Thus, the price index in the open economy becomes:

$$
P=\left[\int_{0}^{1} p(\phi)^{1-\sigma} N g(\phi) d \phi+\int_{\phi_{X}^{*}}^{1} \frac{p(\phi)^{1-\sigma} s_{X} N g(\phi)}{1-G\left(\phi_{X}^{*}\right)} d \phi\right]^{\frac{1}{1-\sigma}}=\left[N\left(1+s_{X}\right) p(\widetilde{\widetilde{\phi}})^{1-\sigma}\right]^{\frac{1}{1-\sigma}}
$$

\footnotetext{
${ }^{11}$ Notice that the supply to the domestic market in the autarkic steady state is ceteris paribus identical to the supply to the foreign market since countries are symmetric.

${ }^{12}$ Strictly speaking, $w_{S}$ adjusts with trade liberalization - as we will demonstrate later - and this impacts $\phi_{X}^{*}$. Still, for our purposes it is sufficient to know that a unique $\phi_{X}^{*}$ exists.
} 
with $G$ denoting the cumulative density function for $\phi$ on the unit interval, $\widetilde{\widetilde{\phi}} \equiv \frac{\widetilde{\phi}+s_{X} \widetilde{\phi}_{X}}{1+s_{X}}$, $\widetilde{\phi}_{X}=\int_{\phi_{X}^{*}}^{1} \phi \frac{g(\phi)}{1-G\left(\phi_{X}^{*}\right)} d \phi$ and $s_{X}=1-G\left(\phi_{X}^{*}\right)$ denoting the share of exporters in the firm distribution.

Thus, $\widetilde{\widetilde{\phi}}$ represents the skilled labor share parameter of the aggregate good $Q$ in the open economy equilibrium. Comparing $\widetilde{\widetilde{\phi}}$ with $\widetilde{\phi}$ leads to lemma 7 :

Lemma 7 Trade liberalization increases the skilled labor share parameter of the aggregate $\operatorname{good} Q$, i.e. $\widetilde{\widetilde{\phi}}>\widetilde{\phi}$.

\subsection{Impact effect of trade liberalization}

Notice that, when we evaluate the impact effect of trade liberalization, each country's skilled labor endowment $S$ is still at its autarkic steady state level (see equation 10). The relative return to skilled labor is, instead, variable and adjusts on impact such that factor markets clear. Adding the additional factor demands by the exporting firms to the closed economy factor market clearing conditions leads to:

$$
\begin{array}{r}
c(\widetilde{\phi})^{\sigma} q(\widetilde{\phi}) A_{L}^{\sigma-1}\left[N(1-\widetilde{\phi})+N s_{X}\left(1-\widetilde{\phi}_{X}\right)+\frac{c(\widetilde{\widetilde{\phi}})^{\sigma}(1-\widetilde{\widetilde{\phi}}) \delta S}{c(\widetilde{\phi})^{\sigma} q(\widetilde{\phi})}\right]=L-L_{f_{X}} \\
c(\widetilde{\phi})^{\sigma} q(\widetilde{\phi}) w_{S}^{-\sigma} A_{S}^{\sigma-1}\left[N \widetilde{\phi}+N s_{X} \widetilde{\phi}_{X}+\frac{c(\widetilde{\widetilde{\phi}})^{\sigma} \widetilde{\widetilde{\phi}} \delta S}{c(\widetilde{\phi})^{\sigma} q(\widetilde{\phi})}\right]=S-S_{f_{X}},
\end{array}
$$

with $L_{f_{X}} \equiv \frac{N s_{X} f_{X}}{A_{L}^{1-\sigma}} \int_{\phi_{X}^{*}}^{1} \frac{(1-\phi) c(\phi)^{\sigma} g(\phi)}{1-G\left(\phi_{X}^{*}\right)} d \phi$ and $S_{f_{X}} \equiv \frac{N s_{X} f_{X}}{A_{S}^{1-\sigma}} \int_{\phi_{X}^{*}}^{1} \frac{\phi w_{S}^{-\sigma} c(\phi)^{\sigma} g(\phi)}{1-G\left(\phi_{X}^{*}\right)} d \phi$ denoting the total unskilled and skilled labor demand, respectively, for producing the sunk export costs. $s_{X} \equiv 1-G\left(\phi_{X}^{*}\right)$ stands for the share of exporters in the firm distribution. Dividing equations 16 and 17 by each other and solving for $w_{S}$ leads to: ${ }^{13}$

$$
w_{S}=\left[\frac{L-L_{f_{X}}}{S-S_{f_{X}}}\left(\frac{A_{S}}{A_{L}}\right)^{\sigma-1} \frac{\widetilde{\phi}+s_{X} \widetilde{\phi}_{X}}{1+s_{X}-\widetilde{\phi}-s_{X} \widetilde{\phi}_{X}}\right]^{1 / \sigma} .
$$

Comparing equation 18 with equation 9 shows that $w_{S}$ increases on impact with trade liberalization. This follows from: $(i) \frac{L-L_{f_{X}}}{S-S_{f_{X}}}>\frac{L}{S}$ and $(i i) \frac{\widetilde{\phi}+s_{X} \widetilde{\phi}_{X}}{1+s_{X}-\tilde{\phi}-s_{X} \widetilde{\phi}_{X}}>\frac{\widetilde{\phi}}{1-\widetilde{\phi}} \cdot{ }^{14}$

\footnotetext{
${ }^{13}$ See appendix $\mathrm{E}$ for the derivation of equation 18.

${ }^{14}$ Notice that $\frac{L-L_{f_{X}}}{S-S_{f_{X}}}>\frac{L}{S}$ holds if $\frac{L}{S}>\frac{L_{f_{X}}}{S_{f_{X}}}$. The latter holds since $\frac{L}{S}$ equals the relative unskilled labor demand for aggregate production, while $\frac{L_{f_{X}}}{S_{f_{X}}}$ equals relative unskilled labor demand for producing sunk
} 
Thus, we can formulate proposition 1:

Proposition 1 The relative return to skilled labor $w_{S}$ increases on impact with trade liberalization.

The intuition for proposition 1 is straightforward. Since exporters are more skilled labor intensive than non-exporters, trade liberalization increases the relative demand for skilled labor. Thus, the relative return to skilled labor increases on impact with trade liberalization. Although $w_{S}$ increases on impact with trade liberalization, it does not increase to a level equal or even above $\frac{A_{S}}{A_{L}}$. This leads us to lemma 8:

Lemma 8 If $w_{S}<\frac{A_{S}}{A_{L}}$ in the autarkic steady state, then $w_{S}<\frac{A_{S}}{A_{L}}$ also after the impact effect of trade liberalization.

Proof. See appendix F.

Lemma 8 follows from the fact that, if $w_{S}$ gets closer to $\frac{A_{S}}{A_{L}}$, the influence of the factor share parameter $\phi$ on a firm's profits becomes smaller (see equation 5 ). In the extreme, if $w_{S} \rightarrow \frac{A_{S}}{A_{L}}$, the cost advantage of the more skilled labor intensive firms relative to the less skilled labor intensive firms vanishes. This implies that, if $w_{S} \rightarrow \frac{A_{S}}{A_{L}}$, even the most skilled labor intensive firms could not afford to export and the countries would be back in autarky. Thus, the impact effect increases $w_{S}$ to a level strictly smaller than $\frac{A_{S}}{A_{L}}$.

Applying Shephard's lemma to the marginal cost function (equation 1) implies that the skilled-unskilled labor input ratio of a firm with skilled labor share parameter $\phi$ equals $\left(\frac{A_{S}}{A_{L}}\right)^{\sigma-1} \frac{\phi}{1-\phi} w_{S}^{-\sigma}$. Thus, we can formulate proposition 2 :

Proposition 2 The skilled-unskilled labor input ratio of each firm decreases on impact with trade liberalization.

Proposition 2 follows from the fact that firms use less (more) skilled (unskilled) labor per unit output if skilled labor becomes more expensive relative to unskilled labor.

\subsection{Long-run impact of trade liberalization}

Lemma 7 and lemma 3 immediately lead to proposition 3:

export costs. Since exporting firms are less unskilled labor intensive than the average firm, it follows that $\frac{L}{S}>\frac{L_{f_{X}}}{S_{f_{X}}}$. 
Proposition 3 The relative return to skilled labor $w_{S}$ decreases in the long run after trade liberalization.

Proposition 3 follows from our assumption that households use part of the aggregate consumption good for investment purposes. Thus, the skilled labor share parameter of the investment good increases with trade liberalization from $\widetilde{\phi}$ to $\widetilde{\widetilde{\phi}}$ and, as a consequence, the investment good becomes cheaper. ${ }^{15}$ Since one unit of investment in $t$ leads to one unit of skilled labor in $t+1$, the return to skilled labor decreases as well, compared to the autarkic steady state.

Since the skilled-unskilled labor input ratio of a firm with skilled labor share parameter $\phi$ equals $\frac{A_{S}^{\sigma-1}}{A_{L}^{\sigma-1}} \frac{\phi w_{S}^{-\sigma}}{1-\phi}$, proposition 3 implies proposition 4 :

Proposition 4 The skilled-unskilled labor input ratio of each firm increases in the long run after trade liberalization.

Finally, we can state proposition 5:

Proposition 5 The skilled labor endowment $S$ increases in the long run after trade liberalization.

Proof. See appendix G.

Proposition 5 follows from a twofold positive effect of trade liberalization on the relative demand for skilled labor. On the one hand, since exporters are more skilled labor intensive than non-exporters, trade liberalization increases the relative demand for skilled labor even at unchanged relative factor returns. In addition, the relative return to skilled labor decreases in the long-run after trade liberalization, which further increases the relative demand for skilled labor. Since the steady state endowment of skilled labor adjusts according to demand, $S$ increases in the long-run after trade liberalization.

Figure 1 illustrates the impact effect of trade liberalization for both countries, as well as the adjustment to the long-run trading equilibrium. ${ }^{16}$

\footnotetext{
${ }^{15}$ Notice that the partial derivative $\frac{\partial c(\phi)}{\partial \phi}=c(\phi)^{\sigma} \frac{1}{1-\sigma}\left[w_{S}^{1-\sigma}-\left(\frac{A_{S}}{A_{L}}\right)^{1-\sigma}\right] A_{S}^{\sigma-1}$ is negative since $w_{S}^{1-\sigma}-$ $\left(\frac{A_{S}}{A_{L}}\right)^{1-\sigma}>0$ due to assumption 2 and $\frac{1}{1-\sigma}<0$.

${ }^{16}$ Notice that chart 2 illustrates the relative skilled labor input for a firm which produces with a skilled labor share parameter $\phi \in(0,1)$ - those firms that produce with $\phi=0$ or $\phi=1$ use only unskilled or skilled labor, respectively, regardless of the magnitude of $w_{S}$. Furthermore, the skilled-unskilled labor input ratio will never fall below $\frac{A_{L} \phi}{A_{S}(1-\phi)}$ since $w_{S}$ will never rise above $\frac{A_{S}}{A_{L}}$ on impact with trade liberalization (see lemma 8).
} 
Figure 1: Adjustment to the trading equilibrium

\section{$5 \quad$ Empirical analysis}

This section investigates whether the main predictions identified by the theoretical analysis do indeed get support by the data. The focus is on propositions $1-4$, which summarize the core of our findings. Since the dynamics in our setting are triggered by an increase in the relative demand for skilled labor due to rising exports, we focus on how a decrease in tariffs abroad affects domestic relative wages and factor intensities in production. The analysis uses data on employment and wages of non-production workers and production workers as measures of employment and wages of skilled labor and unskilled labor, respectively. ${ }^{17}$

The analysis uses a well-known plant-level dataset of the manufacturing sector of Chile, which has been employed in several previous studies. ${ }^{18}$ The data come from the Annual Survey of Manufacturing Industries, carried out by the National Institute of Statistics of Chile. This dataset covers all manufacturing plants with 10 or more workers and provides information on the number of non-production and production workers, which are employed by each single plant and several other plant characteristics. ${ }^{19}$ The analysis focuses on the years 1990 throughout 1999, a period in which the Chilean government signed several free trade agreements that significantly reduced the trade barriers faced by Chilean exporters. This provides an excellent opportunity to test the predictions of the theory. ${ }^{20}$

The dataset has information on almost 4,400 manufacturing plants per year. A little over $22 \%$ of the plants are exporters. Exporting plants are more skill intensive than nonexporting plants. This can be seen in Table 1, which reports the estimated export premia for the ratio skilled wage to unskilled wage, and the ratio skilled labor to unskilled labor, controlling for sector and year fixed effects. ${ }^{21}$ Columns (2) and (4) also include plant

\footnotetext{
${ }^{17}$ According to Slaughter (2000) using production and non-production workers gives comparable results as using levels of education as measures of skill.

${ }^{18}$ See, for example, Pavcnik (2002), Pavcnik (2003) and Kasahara and Rodrigue (2008).

${ }^{19}$ All monetary variables are in constant 1985 pesos (annual price deflators are available in the case of Chile at the 4-digit ISIC level).

${ }^{20}$ During the 1990s Chile established free trade agreements with Canada, Central America, Mercosur and Mexico. It also signed partial trade liberalization agreements with Argentina, Bolivia, Colombia, Ecuador and Venezuela.

${ }^{21}$ The export premia are the estimated coefficients $b$ on a regression of the form: skill $_{i j t}=a+b E X_{i j t}+$

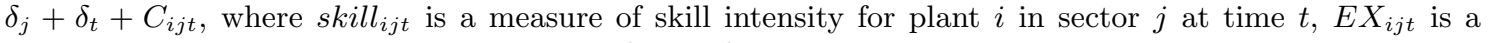
dummy equal to one for plants that export, $\delta_{j}$ and $\delta_{t}$ are year and sector fixed effects, and $C_{i j t}$ is a vector of plant control variables including employment (in $\log$ ) and the percentage of foreign ownership.
} 
controls (the log of employment and the percentage of foreign ownership). As we can see, the estimates for the export premia are all positive and statistically significant. Relative to non-exporters, the relative wage paid to skilled workers is $57 \%$ higher in exporting plants, while the ratio skilled-unskilled labor is $15 \%$ higher in exporting plants, after controlling for year and sector fixed effects, plant size, and foreign ownership.

\section{Table 1: Export premia}

In our model, the effects of trade liberalization are transmitted through its impact on exports, which should increase when foreign tariffs decrease. In order to examine this idea we estimate the following equation:

$$
X_{i j t}=\alpha+\beta \tau_{j t}+\lambda \Omega_{i j t}+\delta_{j}+\delta_{t}+\epsilon_{i j t},
$$

where $X_{i j t}$ corresponds to the ratio exports over sales for firm $i$ operating in sector $j$ at time $t, \tau_{j t}$ is the tariff rate applied on Chilean products of sector $j$ by the rest of the world at time $t, \Omega_{i j t}$ is a vector of control variables at the plant level, which includes total factor productivity (TFP), ${ }^{22}$ size (the log of employment), the percentage share of foreign ownership, the ratio of imported intermediate inputs to total inputs, the ratio of foreign technology licenses fees to total sales, and age (in $\log$ ). The variables $\delta_{j}$ and $\delta_{t}$ are 3-digit sector and year dummy variables that attempt to control for unobserved shocks or characteristics at the sector and year level, respectively.

The tariff data come from the TRAINS database. We use two types of tariffs: the simple average tariff and the trade weighted average tariff for the sector. Both are effectively applied tariff rates. An obvious problem of the simple average is that it treats all commodities identically. ${ }^{23}$ A problem of the weighted tariff is that low duties are likely to carry more imports than high duties, implying that low duties are given more weight than high duties in the weighted average, which introduces a downward bias. For these reasons we opt for using both tariff rates to see if the results are sensitive to the use of either type of tariff.

\footnotetext{
${ }^{22}$ Total factor productivity is the residual of a regression that estimates a Cobb-Douglas production function for each 3-digit sector using the method proposed by Olley and Pakes (1996) and later modified by Levinsohn and Petrin (2003), which corrects the simultaneity bias associated with the fact that productivity is not observed by the econometrician but it may be observed by the firm. In some cases, the production functions were estimated at the 2-digit level due to the small number of observations of some industries at the 3-digit level of disaggregation.

${ }^{23}$ The simple average is also sensitive to changes in goods classification in the tariff code (Anderson and Neary, 2005, chapter 1).
} 
The results of estimating the effect of foreign tariffs on exports are presented in Table 2, column (1) for the simple average tariff and column (2) for the weighted average tariff. First of all, we see that younger and larger plants, as well as those with a higher level of foreign ownership, export a higher fraction of their sales. Second, the estimate for the tariff rate is negative and statistically significant, with either type of tariff, indicating that a decrease in foreign tariffs applied on Chilean products increases the shares of sales that is exported by Chilean plants.

Table 2: Impact effect of foreign tariffs on plant-level variables

We now examine how these tariffs affect relative wages and factor intensities of Chilean firms on impact and in the long run.

\subsection{Impact effect of trade liberalization}

\subsubsection{Basic results}

The model predicts that, on impact after trade liberalization, the aggregate relative wage of skilled labor should increase, while each single firm should produce less skill intensively (propositions 1 and 2). We measure the aggregate relative wage of skilled labor as the average wage paid to skilled workers, relative to the average wage paid to unskilled workers in each 3-digit level sector. ${ }^{24}$ We then investigate the impact effect of declining trade costs abroad by estimating the following equation:

$$
\left(\frac{w_{S}}{w_{L}}\right)_{j t}=\alpha+\beta \tau_{j t}+\lambda Z_{j t}+\delta_{j}+\delta_{t}+\epsilon_{i j t}
$$

where $\left(\frac{w_{S}}{w_{L}}\right)_{j t}$ is the relative wage of skilled labor in sector $j$ at time $t$, and $Z_{j t}$ is a vector of control variables at the 3-digit sector level that includes size (total employment, in log), productivity, ${ }^{25}$ the share of exporters and foreign-owned plants in total employment, the fraction of imported intermediate inputs and the capital-labor ratio of the sector. We estimate 20 with and without sector fixed effects $\left(\delta_{j}\right)$. Since our theory predicts that

\footnotetext{
${ }^{24}$ The average wage of skilled workers is the ratio of total wages paid to non-production workers, divided by the total number of non-production workers which are employed by the sector. Likewise, the average wage of unskilled workers is the ratio of total wages paid to production workers, divided by the total number of production workers which are employed by the sector.

${ }^{25}$ Our measure of sector-level productivity is a weighted average of plant-level productivity levels, where the weights are the share of the plant in sector output: $T F P_{j t}=\sum_{i=1}^{N_{j t}} s_{i j t} T F P_{i j t}$, where $T F P_{j t}$ is total factor productivity of sector $j$ at time $t, s_{i j t}$ is plant $i$ 's share in total output at time $t, T F P_{i j t}$ is total factor productivity of plant $i$ at time $t$, and $N_{j t}$ is the number of plants in sector $j$ at time $t$.
} 
the relative wage of skilled labor should increase when foreign tariffs decrease for a given sector, we expect the estimate for $\beta$ to be negative when sector fixed effects are included. Since the model does not make predictions for cases in which labor is reallocated across sectors, the estimate for $\beta$ when sector fixed effects are not included could be positive, negative, or not statistically significant from zero, as the effect may reflect specialization according to comparative advantage.

The results of estimating 20 are presented in Table 3. Columns (1) and (2) show the results without the sector fixed effects. The estimates for the world tariff rates are positive, but only the simple average is statistically significant. This suggests that when one allows for variation over time and across sectors, the relative wage of skilled labor may decrease when foreign tariffs decrease, which could be consistent with Stolper-Samuelson effects. Columns (3) and (4) present the results with sector fixed effects, which is more appropriate for the purposes of testing our model. We can see that the estimates for foreign tariffs are negative and statistically significant, which indicates that, within sectors, a decrease in foreign trade barriers increases the relative wage of skilled labor, which is consistent with our theoretical model.

Table 3: Impact effect of foreign tariffs on sector-level relative wage

Next, we investigate if the increase in the aggregate relative wage of skilled labor following a decrease in foreign tariffs is reflected in an increase in the relative wage paid by individual plants. ${ }^{26}$ This is done by estimating equation 19 with the relative wage paid by each plant as the dependent variable. In addition to the control variables in 19, the regressions also include a dummy variable for exporters to control for the fact that exporters are more skill intensive than non-exporters. ${ }^{27}$ The results are presented in columns (3) and (4) of Table 2. Plants that are more productive, larger and export tend to pay higher relative wages to skilled workers, on average. The estimate for the tariff rate is negative and statistically significant with either type of tariff, suggesting that a decrease in current foreign tariffs increases the wage of skilled workers relative to the wage of unskilled workers not only at the aggregate level but also at the plant level. The increase in the relative wage both at the aggregate level and also at the plant level is in line with the model's predictions.

\footnotetext{
${ }^{26}$ We measure the relative wage of skilled labor as the average wage paid to skilled workers, relative to the average wage paid to unskilled workers in each plant.

${ }^{27}$ The results are not significantly affected if the dummy for exporters is not included in the regressions.
} 
The model also predicts that, on impact, a reduction in foreign tariffs makes firms less skill intensive in response to the increase in the relative wage of skilled labor. Columns (5) and (6) in Table 2 show the effects of foreign tariffs on skill intensity, measured as the number of skilled workers divided by the number of unskilled workers employed by the plant. As we can see, more productive plants, exporters, and the ones with higher levels of foreign ownership tend to be more skill intensive. The estimates for the tariff variables are positive and statistically significant in both cases, suggesting that firms become less skill intensive following a reduction in foreign tariffs, which is consistent with the model.

\subsubsection{Robustness checks}

We perform a series of tests to check the robustness of our results. First, we re-estimate equation 19 including plant fixed effects to control for unobserved heterogeneity at the plant level. The results are presented in Table $A 1$ in the appendix. We can see that the estimated coefficients are similar to the estimates in Table 2, although a little bit lower in magnitude. We again observe that a lower level of foreign tariffs increases export intensity, and the relative wage of skilled labor paid by each plant, while it reduces the amount of skilled labor relative to unskilled labor used by the plants.

The second robustness check estimates equation 19 without plant controls. This is done because many of the plant-level variables are highly collinear with exporting both in the model and in the data. The results, not presented here to save space, are similar to the results with plant controls. Lower tariffs abroad increase the relative wage of skilled labor and reduce the skill intensity within Chilean plants.

The third robustness check includes the level of world imports at the sector level as an additional control variable in equation 19. It is possible that the increase in Chilean exports is due to an increase in world demand, reflected in a higher level of world imports, rather than the decrease in tariffs faced by Chilean producers. Since foreign tariffs and world imports may be correlated, omitting world imports may potentially introduce a spurious correlation between Chilean exports and foreign tariffs. The results of this exercise are presented in Table $A 2$. We can see that the estimate for world imports is positive in the case of export intensity and skill intensity of Chilean plants, and negative for the relative wage, although in all cases the effects are not statistically significant. More importantly, the estimate for the tariff rates are similar in sign and magnitude than the estimates in Table 2, which gives us confidence that our results are not driven by a spurious correlation 
between Chilean exports and foreign tariffs on Chilean products.

A fourth robustness check estimates directly the effect of exporting on our two variables of interest, the relative wage and the skill intensity in production. Since exporting is endogenous, we use an IV estimation method that instruments exporting with the foreign tariff rate. The results are presented in Table A3. Columns (1) and (2) show the results using the simple average tariff rate, while columns (3) and (4) are based on the weighted average tariff. In both cases we observe that a higher instrumented exports-to-sales ratio increases the relative wage while it decreases skill intensity, as predicted by the model. The estimates for the tariff rates, in the first stage, are as expected negative and statistically significant in both cases, as shown in the table. Moreover, the $F$-test of excluded instruments ranges between 15.03 and 22.66, which are higher than the rule of thumb value of 10 (see Staiger and Stock, 1997). This suggests that the instrument does not lack sufficient relevance to explain the endogenous variable.

Next, we examine the effect of foreign tariffs on variables such as productivity and investment at the plant level. If the effect of tariffs on wages and skill intensity is indeed the result of increasing relative demand for skilled workers rather than the result of intraplant adjustments, such as technological change, then tariffs should not have a significant effect on productivity and investment. ${ }^{28}$ To examine this idea we re-estimate equation 19 with TFP and investment (log of investment and the ratio investment-sales) as dependent variables to proxy for technological change and investments in technology. Our estimates (not presented here), with and without plant fixed effects, for the foreign tariff rates are in all cases not statistically significant, suggesting that at least in the case of manufacturing Chilean plants in the 1990s, lower foreign tariffs did not induce significantly technology adoption. This strongly suggests that increasing demand for skilled labor is the main channel by which the relative wage of skilled labor increases on impact.

Finally, we re-estimate equation 19 including interaction terms between the two measures of tariffs and a dummy variable equal to one for sectors in which tariffs decreased between 1990 and 1999. ${ }^{29}$ This is done because the effect of tariffs may differ across sectors if tariffs are decreasing in some sectors and increasing in others. The results, not presented here, show that the estimate for the interaction term is not significant, indicating that the impact effect does not differ if the sector experienced a decrease in its tariff abroad.

\footnotetext{
${ }^{28}$ It is possible that lower foreign tariffs may induce firms to invest in technological improvements and new capital goods in order to take advantage of the higher export profitability (see Bustos, 2011).

${ }^{29}$ The data show that only 4 out of the 28 sectors experienced a decreased in the simple average tariff between 1990 and 1999 while 14 experienced a decreased in the weighted average.
} 
Summarizing, we find strong evidence that a decrease in foreign tariffs effectively applied on Chilean products increases the relative wage of skilled workers and makes firms less skill intensive. Both effects are in line with the predictions of the theory.

\subsection{Long-run effect of trade liberalization}

\subsubsection{Basic results}

The theory predicts that in the long run after trade liberalization the relative wage of skilled labor should decrease both at the aggregate level as well as at the plant level, while each firm should produce more skill intensively.

We start by examining the long-run effect of foreign tariffs on the aggregate relative wage of skilled labor by estimating three panel regressions that relate tariff rates in the early periods of our sample $(1990,1991$, and 1992) to the relative wage at the 3 -digit sector level 5 to, at most, 10 years later:

$$
\begin{aligned}
& \left(\frac{w_{S}}{w_{L}}\right)_{j t}=\alpha+\sum_{m=1995}^{m=1999} \beta_{m} \tau_{1990} \times \delta_{m}+\lambda Z_{j t}+\delta_{j}+\delta_{t}+\epsilon_{i j t} \\
& \left(\frac{w_{S}}{w_{L}}\right)_{j t}=\alpha+\sum_{m=1996}^{m=1999} \beta_{m} \tau_{1991} \times \delta_{m}+\lambda Z_{j t}+\delta_{j}+\delta_{t}+\epsilon_{i j t} \\
& \left(\frac{w_{S}}{w_{L}}\right)_{j t}=\alpha+\sum_{m=1997}^{m=1999} \beta_{m} \tau_{1992} \times \delta_{m}+\lambda Z_{j t}+\delta_{j}+\delta_{t}+\epsilon_{i j t},
\end{aligned}
$$

where $\left(\frac{w_{S}}{w_{L}}\right)_{j t}$ is the relative wage of skilled labor for the years 1995-1999 (equation 21), 1996-1999 (equation 22) or 1997-1999 (equation 23). $\tau_{1990}, \tau_{1991}$ and $\tau_{1992}$ denote the foreign tariff rate in years 1990, 1991 and 1992, respectively, while $\delta_{m}$ is a dummy variable for year $m$. The parameter $\beta_{m}$ is the coefficient of interest and measures the effect of tariffs that prevailed in 1990, 1991, or 1992 on the relative wage 5 to, at most, 10 years later. $Z_{j t}$ is, again, the vector of control variables at the 3 -digit sector level described earlier. The results are presented in Table 4. To save on space, we omit presentation of the estimates for the control variables, which are similar to the estimates in Table 3. Columns (1)-(3) use the simple average tariff rate, while columns (4)-(6) are based on the weighted average tariff rate. As we can see, most of the estimates for the interaction terms, $\beta_{m}$, are positive and statistically significant, indicating that a decrease in foreign tariffs today decreases the aggregate relative wage of skilled labor between 5 and 10 years 
from now.

Table 4: Long-run effect of foreign tariffs on sector-level relative wage

Next, we check if the decrease in the sector-level relative wage is reflected in a lower relative wage at the plant level and in a higher skill intensity. This is done by estimating panel regressions that relate tariff rates in the early periods $(1990,1991$, and 1992) to the two variables of interest (relative wage and skill intensity) at the plant level 5 to, at most, 10 years later:

$$
\begin{aligned}
Y_{i j t} & =\alpha+\sum_{m=1995}^{m=1999} \beta_{m} \tau_{1990} \times \delta_{m}+\lambda \Omega_{i j t}+\delta_{j}+\delta_{t}+\epsilon_{i j t} \\
Y_{i j t} & =\alpha+\sum_{m=1996}^{m=1999} \beta_{m} \tau_{1991} \times \delta_{m}+\lambda \Omega_{i j t}+\delta_{j}+\delta_{t}+\epsilon_{i j t} \\
Y_{i j t} & =\alpha+\sum_{m=1997}^{m=1999} \beta_{m} \tau_{1992} \times \delta_{m}+\lambda \Omega_{i j t}+\delta_{j}+\delta_{t}+\epsilon_{i j t},
\end{aligned}
$$

where $Y_{i j t}$ is the variable of interest (relative wage or skill intensity) in years 1995-1999 (equation 24), 1996-1999 (equation 25) or 1997-1999 (equation 26). Again, $\beta_{m}$ is the coefficient of interest that measures the effect of tariffs that prevailed in 1990, 1991, or 1992 on the outcomes of interest at the plant level, 5 to, at most, 10 years later. The results are presented in Table 5, where we omit presentation of the estimates for the control variables, which are similar to the estimates in Table 2. The upper panel shows the results for the relative wage of skilled labor, while the lower panel presents the results for the input ratio skilled labor to unskilled labor. As we can see in the upper panel, most of the estimates for the interaction terms are positive and statistically significant, suggesting that a decrease in foreign tariffs today decreases the relative wage of skilled labor at the plant level 5 to 10 years later. For the case of the relative employment of skilled labor, in the lower part of the table, we observe that a decrease in tariffs today increases the relative employment of skilled labor several years later. Both results are consistent with the predictions of the model.

Table 5: Long-run effect of foreign tariffs on plant-level variables

An alternative method to study the long-run effects is to examine the effect of tariffs over a longer period using a cross section of plants or sectors. Since the number of sectors 
is small (29 sectors in total), we focus on the long-run effects of tariffs on the relative wage and skill intensity at the plant level. This is done by first selecting all the plants that stayed in operation during the entire 10-year period and then examining how the tariff rate, averaged over the first half of the period (1990-1994), affected the variables of interest in the second half of the period (1995-1999), controlling for plant characteristics measured as averages over the initial half. Table 6 shows the results of using this technique. Columns (1) and (3) show that initially more productive and larger plants, exporters and those with foreign ownership have a higher ratio of skilled wages relative to unskilled wages during the second part of the period. The estimate for the foreign tariff variable is positive and significant, consistent with the idea that a reduction of foreign tariffs decreases the relative wage of skilled workers in the long run. Columns (2) and (4) show the results for the employment of skilled workers relative to the employment of unskilled workers. The estimates for productivity, size and foreign ownership are positive and significant, while the estimates for tariffs are negative and also significant for the case of the unweighted tariff. This is, again, in line with the predictions of the model.

Table 6: Long-run effect of foreign tariffs — cross section results

\subsubsection{Robustness checks}

The first robustness check estimates equations $24-26$ including plant fixed effects. The results are presented in Table $A 4$ in the appendix, and show that the estimates for tariffs are not significantly affected by the inclusion of plant fixed effects.

Although the evidence in Table 6 is consistent with the predictions of the model, it is possible that the results are essentially driven by the use of this particular group of plants (the ones that survived during the entire sample period). To check this we re-estimate equation 19 to test for the impact effect, but considering only those plants that we use in Table 6. If the long-run estimates are due to the use of this specific sample, we should not observe the impact effects we found earlier with all the plants, when using this reduced sample. The results (not presented here to save space) show that the estimates for the impact effects are similar to what we obtain with the whole sample. In particular, a lower level of foreign tariffs increases the relative wage of skilled labor while it decreases the amount of skilled labor relative to unskilled labor employed by the plants on impact. This suggests that the long-run estimates of table 6 are not the result of using this particular subset of plants. 
The third robustness check introduces world imports as an additional control variable in the estimation of equations 24-26. The results are presented in Table $A 5$ for both the relative wage and the skill intensity at the plant level. The estimate for world imports are not statistically significant in the majority of the cases, and the inclusion of this variable does not significantly affect the estimates for the world tariffs.

In summary, we find that a decrease in foreign tariffs today is correlated with a decrease in the relative wage of skilled labor paid by Chilean plants and with an increase in skill intensity of the same plants several years later. These results are robust to the use of a cross section of plants or the whole sample in a panel estimation, and are in line with the predictions of our model for the long run.

\section{Conclusions}

Previous empirical research examining the effect of trade liberalization on wage inequality in developing countries, especially in Latin America, has found mixed evidence. While some studies find evidence for a decrease in wage inequality, others find the opposite.

In order to reconcile these empirical findings, we have presented an intra-industry trade model with two crucial properties: $(i)$ households can accumulate skilled labor and (ii) firms are heterogeneous in factor intensities. Our theoretical analysis has shown that it is important to distinguish between the impact effect and the long-run effect of globalization on factor returns. If we parameterize the model such that exporters are skilled labor intensive relative to non-exporters - which has been found both for developed and developing countries - , trade liberalization increases relative demand for skilled labor and, on impact with fixed factor endowments, the relative return to skilled labor. The increase in the relative return to skilled labor induces households to raise their investments into the country's skilled labor endowment. As a consequence, the country's skilled labor endowment increases in the long run after trade liberalization, which, in turn, decreases the relative return to skilled labor.

The main result of our theoretical analysis is that the impact effect of globalization for wage inequality is opposite to the long-run effect: while wage inequality increases on impact, it decreases in the long run.

Afterwards, we have tested our theoretical predictions with a panel of Chilean manufacturing firms over the period 1990-1999. We have explicitly distinguished between the impact and the long-run effect of trade liberalization. We have shown that, indeed, trade 
liberalization appears to increase the relative wage of skilled labor on impact after trade liberalization. In the long run, however, the effect of trade liberalization is the opposite: the relative wage of skilled labor goes down. In order to verify these results, we have also tested how Chilean firms correspondingly adjust their factor intensities after trade liberalization.

Thus, our paper argues that policy makers should carefully examine the differential effect of trade reforms on wage inequality on impact versus in the long run. As we have shown in the theory and the empirical analysis, although wage inequality may increase on impact, it is likely to decrease in the long run after trade liberalization, as long as the economy is able to invest into skilled labor. Although the predictions of the theory are observed in the case of Chile, more research is needed to verify whether these predictions also hold for other countries. 


\section{Appendix}

\section{A Proof of lemma 1}

Extending the setup of Baxter (1992) by monopolistic competition between firms, i.e. $p(\phi)=\frac{\sigma}{\sigma-1} c(\phi)$, the steady state of a Ramsey growth model is characterized by four necessary first order conditions:

$$
\begin{aligned}
& w_{S, t}+(1-\delta) p(\widetilde{\phi})=p_{t}^{S} \\
& w_{S, t}=p(\widetilde{\phi})\left[\widetilde{\phi}^{\frac{1}{\sigma}} A_{S}^{\frac{\sigma-1}{\sigma}}+(1-\widetilde{\phi})^{\frac{1}{\sigma}} A_{L}^{\frac{\sigma-1}{\sigma}}\left(\frac{l_{t}}{s_{t}}\right)^{\frac{\sigma-1}{\sigma}}\right]^{\frac{1}{\sigma-1}} \widetilde{\phi}^{\frac{1}{\sigma}} A_{S}^{\frac{\sigma-1}{\sigma}} \\
& w_{L, t}=p(\widetilde{\phi})\left[\widetilde{\phi}^{\frac{1}{\sigma}} A_{S}^{\frac{\sigma-1}{\sigma}}\left(\frac{s_{t}}{l_{t}}\right)^{\frac{\sigma-1}{\sigma}}+(1-\widetilde{\phi})^{\frac{1}{\sigma}} A_{L}^{\frac{\sigma-1}{\sigma}}\right]^{\frac{1}{\sigma-1}}(1-\widetilde{\phi})^{\frac{1}{\sigma}} A_{L}^{\frac{\sigma-1}{\sigma}} \\
& p_{t+1}^{S}=(1+\rho) p(\widetilde{\phi}),
\end{aligned}
$$

where $p_{t}^{S}$ is the price per unit skilled labor in period $t, w_{S, t}$ the return to skilled labor in $t$ and $w_{L, t}$ the return to unskilled labor in $t . p(\widetilde{\phi})$ is the price of the average variety, which is used for investments.

Equation 27 is a zero profit condition for the households' skilled labor lending behavior. Households realize zero profits from lending skilled labor out to firms if $p_{t}^{S}$ equals $w_{S, t}$, plus what is left from the unit of skilled labor in $t+1$; since one unit of $q(\widetilde{\phi})$ in $t$ leads to one unit of skilled labor in $t+1$, the remaining $1-\delta$ units of skilled labor in $t+1$ are evaluated with $p(\widetilde{\phi})$. Equations 28 and 29 imply that, in the steady state, factor returns are equal to the value of the marginal product for each factor. Equation 30 denotes the Euler equation.

The time index is removed now for a steady state analysis. Equations 30 and 28 can be substituted into equation 27 , which is then rearranged to:

$$
\frac{l}{s}=\left\{\frac{\left[\frac{\rho+\delta}{\widetilde{\phi}^{\frac{1}{\sigma}} A_{S}^{\frac{\sigma-1}{\sigma}}}\right]^{\sigma-1}-\widetilde{\phi}^{\frac{1}{\sigma}} A_{S}^{\frac{\sigma-1}{\sigma}}}{(1-\widetilde{\phi})^{\frac{1}{\sigma}} A_{L}^{\frac{\sigma-1}{\sigma}}}\right\}^{\frac{\sigma}{\sigma-1}} .
$$

Substituting equation 31 into equation 29 leads to:

$$
\frac{w_{L}}{p(\widetilde{\phi})}=\left\{\frac{(1-\widetilde{\phi}) A_{L}^{\sigma-1}(\rho+\delta)^{\sigma-1}}{(\rho+\delta)^{\sigma-1}-\widetilde{\phi} A_{S}^{\sigma-1}}\right\}^{\frac{1}{\sigma-1}} .
$$

Combining equations 27 and 30 gives:

$$
\frac{w_{S}}{p(\widetilde{\phi})}=(\rho+\delta)
$$

Dividing equations 33 and 32 by each other leads to equation 6 .

\section{B Proof of lemma 3}

The partial derivative of $w_{S}$ with respect to $\widetilde{\phi}$ is given by:

$$
\frac{\partial w_{S}}{\partial \widetilde{\phi}}=\frac{1}{1-\sigma} w_{S}^{\sigma} \frac{(\rho+\delta)^{1-\sigma} A_{L}^{\sigma-1}\left[(\rho+\delta)^{1-\sigma} A_{S}^{\sigma-1}-1\right]}{\left[1-\widetilde{\phi}(\rho+\delta)^{1-\sigma} A_{S}^{\sigma-1}\right]^{2}} .
$$

$\frac{\partial w_{S}}{\partial \widetilde{\phi}}$ is negative since the squared bracket in the numerator is positive due to assumption 2 , while $\frac{1}{1-\sigma}$ is negative. 


\section{Derivation of equations 9 and $\mathbf{1 0}$}

Using $\left[\frac{c(\phi)}{p(\phi)}\right]^{\sigma}=\left(\frac{\sigma-1}{\sigma}\right)^{\sigma}=\left[\frac{c(\widetilde{\phi})}{p(\phi)}\right]^{\sigma}$, equations 7 and 8 can be simplified:

$$
\begin{gathered}
c(\widetilde{\phi})^{\sigma} q(\widetilde{\phi})(1-\widetilde{\phi}) A_{L}^{\sigma-1}\left[N+\frac{\delta S}{q(\widetilde{\phi})}\right]=L \\
c(\widetilde{\phi})^{\sigma} q(\widetilde{\phi}) w_{S}^{-\sigma} \widetilde{\phi} A_{S}^{\sigma-1}\left[N+\frac{\delta S}{q(\widetilde{\phi})}\right]=S .
\end{gathered}
$$

Dividing equations 34 and 35 by each other, solving for $S$ and $w_{S}$ and, afterwards, considering equation 6 leads to equations 9 and 10 .

\section{Proof of lemma 5}

In order to proof lemma 5, we will construct a numerical example with $\sigma=2$ and $A_{L}=1$. A country's relative skilled labor endowment in the autarkic steady state then becomes $\frac{S}{L}=\frac{(1-\widetilde{\phi}) \widetilde{\phi}}{\left(\frac{\rho+\delta}{A_{S}}-\widetilde{\phi}\right)^{2} A_{S}}$. Notice that we assume $\frac{\rho+\delta}{A_{S}}-\widetilde{\phi}>0$ (see footnote 8 ) and $\frac{\rho+\delta}{A_{S}}<1$ due to assumption 2. If $\widetilde{\phi} \rightarrow 0$, then $\frac{S}{L} \rightarrow 0$. However, if $\widetilde{\phi} \rightarrow \frac{\rho+\delta}{A_{S}}$, then $\frac{S}{L} \rightarrow \infty$. Thus, $\frac{S}{L}$ can reach any value within the interval $[0, \infty)$, despite our parameter restriction $\rho+\delta<A_{S}$ (see assumption 2).

\section{E Derivation of equation 18}

Considering that $\widetilde{\widetilde{\phi}} \equiv \frac{\widetilde{\phi}+s_{X} \widetilde{\phi}_{X}}{1+s_{X}}$, we can simplify equations 16 and 17 to:

$$
\begin{array}{r}
c(\widetilde{\phi})^{\sigma} q(\widetilde{\phi})\left(1+s_{X}-\widetilde{\phi}-s_{X} \widetilde{\phi}_{X}\right) A_{L}^{\sigma-1}\left[N+\frac{c(\widetilde{\widetilde{\phi}})^{\sigma} \frac{1}{1+s_{X}} \delta S}{c(\widetilde{\phi})^{\sigma} q(\widetilde{\phi})}\right]=L-L_{f_{X}} \\
c(\widetilde{\phi})^{\sigma} q(\widetilde{\phi}) w_{S}^{-\sigma}\left(\widetilde{\phi}+s_{X} \widetilde{\phi}_{X}\right) A_{S}^{\sigma-1}\left[N+\frac{c(\widetilde{\widetilde{\phi}})^{\sigma} \frac{1}{1+s_{X}} \delta S}{c(\widetilde{\phi})^{\sigma} q(\widetilde{\phi})}\right]=S-S_{f_{X}} .
\end{array}
$$

Dividing equations 36 and 37 by each other and solving for $w_{S}$ leads equation 18 . Notice that $S$ in equations 36 and 37 is the autarkic steady state endowment of skilled labor since we study here the impact effect of trade liberalization.

\section{F Proof of lemma 8}

We can prove lemma 8 by contradiction. First, notice that $w_{S}$ being smaller than $\frac{A_{S}}{A_{L}}$ is actually necessary for exporters being more skilled labor intensive than non-exporters. In other words, $w_{S}<\frac{A_{S}}{A_{L}}$ is actually necessary for $w_{S}$ to increase on impact with trade liberalization. However, if $w_{S}$ approaches $\frac{A_{S}}{A_{L}}$, then either all firms (if $f_{X}$ is "small") or no firm would export since, if $w_{S}$ approaches $\frac{A_{S}}{A_{L}}$, the skilled labor share parameter does not influence export profits at all. However, if either all firms or if no firm exports after trade liberalization, $w_{S}$ would not change at all and remain at its autarkic level since, if all firms export, $s_{X}=1$ and $\widetilde{\phi}=\widetilde{\phi}_{X}$, while $s_{X}=0$ if no firm exports. Thus, even though $w_{S}$ increases on impact with trade liberalization, it will never become equal or larger than $\frac{A_{S}}{A_{L}}$. 


\section{G Proof of proposition 5}

Solving equation 18 for $\frac{S_{f t}-S_{f_{X}}}{L-L_{f_{X}}}$ in the free trade steady state leads to (in the following, ft will denote variables in the free trade steady state, while aut will denote variables in the autarkic steady state):

$$
\frac{S_{f t}-S_{f_{X}}}{L-L_{f_{X}}}=\frac{w_{S, f t}^{-\sigma}\left(\widetilde{\phi}+s_{X} \widetilde{\phi}_{X}\right)}{1+s_{X}-\widetilde{\phi}-s_{X} \widetilde{\phi}_{X}}\left(\frac{A_{S}}{A_{L}}\right)^{\sigma-1} .
$$

Compared to the autarkic steady state, relative skilled labor demand for producing the varieties $q(\phi)$ has increased since $\frac{w_{S, f t}^{-\sigma}\left(\tilde{\phi}+s_{X} \tilde{\phi}_{X}\right)}{1+s_{X}-\tilde{\phi}-s_{X} \tilde{\phi}_{X}}>\frac{w_{S, a u t}^{-\sigma} \tilde{\phi}}{1-\tilde{\phi}}$. Since the right hand side of equation 38 has decreased with trade liberalization, we can conclude that relative skilled labor supply net of sunk export costs, which is given by $\frac{S_{f t}-S_{f_{X}}}{L-L_{f_{X}}}$, must be larger than $\frac{S_{a u t}}{L}$, i.e. the following must hold:

$$
\frac{S_{f t}-S_{f_{X}}}{L-L_{f_{X}}}>\frac{S_{a u t}}{L} \Rightarrow S_{f t}-S_{a u t}>S_{f_{X}}-\frac{S_{a u t} L_{f_{X}}}{L} .
$$

Furthermore, we know that $\frac{S_{f_{X}}}{L_{f_{X}}}>\frac{S_{a u t}}{L}$, which can be transformed to:

$$
S_{f_{X}}>\frac{S_{a u t} L_{f_{X}}}{L} \Rightarrow S_{f_{X}}-\frac{S_{a u t} L_{f_{X}}}{L}>0
$$

Thus, since $S_{f_{X}}-\frac{S_{a u t} L_{f_{X}}}{L}$ is larger than zero, we can conclude that $S_{f t}-S_{a u t}$ must definitely be larger than zero, i.e. the skilled labor endowment in the free trade steady state is larger than the one in the autarkic steady state. 


\section{Online appendices (appendices $\mathrm{H}$ and $\mathrm{I}$ )}

\section{H The model with an endogenous mass and distribution of firms}

In this appendix we will outline the model for the case of an endogenous mass and distribution of firms. We will show that propositions 1-4, which summarize the main findings of our theoretical model, continue to hold in this appendix.

In order to endogenize the mass and distribution of firms, we extend our model by including a market entry procedure. However, we cannot allow firms to choose their technology upon market entry. The reason is that, if firms were to choose their technology, all firms would choose the most beneficial one. Thus, we consider a market entry procedure, which is comparable to the one in Melitz (2003), i.e. firms get their technology parameter randomly assigned after market entry. However, the technology parameter in our setting will be the factor share parameter of a CES production function, not a parameter of total factor productivity. Thus, we consider a market entry procedure like in Crozet and Trionfetti (2009) and Emami Namini (2009), and it is outlined in the following:

Market entry procedure. An infinitely dividable number of potential entrants into the market exists. By the time of entry, firms do not know their skilled labor share parameter $\phi$ yet, i.e. firms are ex ante identical. ${ }^{30}$ The market entry procedure can be divided into three steps. First, market entry leads to a sunk input requirement $f_{E}$, which is produced with the average skilled labor share parameter over all active firms. Thus, the sunk market entry costs are given by $c(\widetilde{\phi}) f_{E} \cdot{ }^{31}$ Second, after market entry firms draw the factor share parameter $\phi$ of a CES production function from the interval $[0,1]$ according to a probability distribution with density $g(\phi) .{ }^{32}$ A firm's variable costs are then given by $c(\phi)$. The initial uncertainty about the skilled labor share parameter $\phi$ reflects the firms' initial uncertainty about which factor input ratio maximizes profits. Each firm keeps the $\phi$ it has drawn for the rest of its life. Third, after the draw of $\phi$, firms decide whether to start with production or not. Since fixed production $\operatorname{costs} c(\widetilde{\phi}) f$ exist and since we focus here on the case of $w_{S}<\frac{A_{S}}{A_{L}}$, only firms with a $\phi$ from the interval $\left[\phi^{*}, 1\right]$ start with production after entry. Firms with $\phi<\phi^{*}$ immediately exit. Notice that all firms with a $\phi$ from the interval $[0,1]$ are active in the main part of this paper, while only firms with a $\phi$ from the interval $\left[\phi^{*}, 1\right]$, $\phi^{*} \geq 0$, are active in this appendix. A firm's profits are zero if it produces with $\phi=\phi^{*}$. The threshold skilled labor share parameter $\phi^{*}$ solves the following equation:

$$
\pi\left(\phi^{*}\right)=\frac{q\left(\phi^{*}\right) p\left(\phi^{*}\right)}{\sigma}-c(\widetilde{\phi}) f=0 .
$$

Considering $p(\phi)=\frac{\sigma}{\sigma-1} c(\phi)$ and $\frac{q\left(\phi^{*}\right)}{q(\widetilde{\phi})}=\left[\frac{c\left(\phi^{*}\right)}{c(\widetilde{\phi})}\right]^{-\sigma}$, equation 39 can be transformed to:

$$
q(\widetilde{\phi})=(\sigma-1)\left[\frac{c(\widetilde{\phi})}{c\left(\phi^{*}\right)}\right]^{1-\sigma} f .
$$

Fourth, in each period a firm may be hit by a negative shock with probability $\theta, 0<\theta<1$. The shock forces the firm to exit the market. Due to the shock, a constant amount of sunk entry costs arises in each period of the steady state.

Thus, with an endogenous mass and distribution of firms, the average capital share parameter is defined as $\widetilde{\phi}=\int_{\phi^{*}}^{1} \phi \frac{g(\phi)}{1-G\left(\phi^{*}\right)} . g$ denotes the density of the distribution of $\phi$ on the unit interval, while $G$ denotes the corresponding cumulative density. Importantly, except for the fact that the active firms in this

\footnotetext{
${ }^{30}$ Like in Bernard et al. (2003) and Melitz (2003), the firms' ex-ante uncertainty about their technology reflects the firms' ex-ante uncertainty about, e.g., their workers' "quality".

${ }^{31}$ Notice that we cannot assume here that fixed costs are in terms of a firm's own variety. The reason is that firms do not know their technology yet by the time of market entry. We could likewise assume that the sunk market entry costs are in terms of skilled labor, i.e. $w_{S} f_{E}$, or in terms of unskilled labor, i.e. $f_{E}$, without affecting the results in a qualitative sense. For reasons of consistency, we assume that all fixed costs are produced with the average skilled labor share parameter in this appendix.

${ }^{32}$ Crozet and Trionfetti (2009), Emami Namini (2009) and Harrigan and Reshef (2012) also consider random factor share parameters in their settings. Harrigan and Reshef (2012) assume that firms get, in addition, a TFP parameter randomly assigned upon market entry. Notice that, without sunk market entry costs, firms could repeatedly enter the market and draw their factor share parameter until they have received the most preferred one.
} 
appendix have their $\phi$ from the interval $\left[\phi^{*}, 1\right]$ —instead of $[0,1]$ 一, the equations from subsections $2.2,2.3$, 2.4 and 2.5 do not change due to endogenizing the mass and distribution of firms.

Autarkic steady state. The autarkic steady state is characterized by five conditions. The first three of them are the same as those that characterize the autarkic steady state in the main part of the text:

(i) output equals demand for each variety at price $p(\phi)=\frac{\sigma}{\sigma-1} c(\phi)$;

(ii) $w_{S}=\left[\frac{(1-\widetilde{\phi})(\rho+\delta)^{1-\sigma} A_{L}^{\sigma-1}}{1-\widetilde{\phi}(\rho+\delta)^{1-\sigma} A_{S}^{\sigma-1}}\right]^{\frac{1}{1-\sigma}}$ since countries are in their steady state;

(iii) the factor market clearing conditions.

However, since the mass and distribution of firms are endogenous, two additional variables add to the model: the mass of firms $N$ and the threshold skilled labor share parameter $\phi^{*}$. Thus, we need two additional equations to describe the autarkic steady state:

(iv) the zero cutoff profit condition (equation 39) and

$(v)$ a free entry condition.

The free entry condition (FEC) mirrors the firms' market entry decision, and it is given by:

$$
c(\widetilde{\phi}) f_{E}=\left[1-G\left(\phi^{*}\right)\right] \sum_{t=t^{\prime}}^{\infty} E\left[\pi(\phi) \mid \phi \geq \phi^{*}\right]\left(\frac{1-\theta}{1+\rho}\right)^{t} .
$$

The left-hand side of equation 41 denotes the sunk market entry costs, while the right hand side denotes expected discounted lifetime profits. Period $t^{\prime}$ denotes the period in which a firm enters the market. The term $(1-\theta)^{t}$ accounts for the risk of death in each period and the term $(1+\rho)^{-t}$ discounts future profits to current period values. Since firms are active after entry only if their $\phi$ belongs to the interval $\left[\phi^{*}, 1\right]$, $1-G\left(\phi^{*}\right)$ denotes the probability for a successful entry and $E\left[\pi(\phi) \mid \phi \geq \phi^{*}\right]$ denotes the expected profits, given that the firm is active. ${ }^{33}$

Firms ex ante expect that a successful market entry will bring them the average profits over all active firms. Therefore:

$$
\begin{aligned}
E\left[\pi(\phi) \mid \phi \geq \phi^{*}\right] & =\int_{\phi^{*}}^{1} \frac{q(\phi) p(\phi)}{\sigma} \frac{g(\phi)}{1-G\left(\phi^{*}\right)} d \phi-c(\widetilde{\phi}) f \\
& =\int_{\phi^{*}}^{1} \frac{Y \frac{1}{\sigma}}{P^{1-\sigma}}\left\{\frac{\sigma}{\sigma-1}\left[\frac{\phi}{A_{S}^{1-\sigma}} w_{S}^{1-\sigma}+\frac{1-\phi}{A_{L}^{1-\sigma}}\right]^{\frac{1}{1-\sigma}}\right\}^{1-\sigma} \frac{g(\phi)}{1-G\left(\phi^{*}\right)} d \phi-c(\widetilde{\phi}) f \\
& =\frac{p(\widetilde{\phi}) q(\widetilde{\phi})}{\sigma}-c(\widetilde{\phi}) f .
\end{aligned}
$$

Using the formula for an infinite geometric series and dividing by $c(\widetilde{\phi})$, the $F E C$ (equation 41 ) can accordingly be transformed to:

$$
f_{E} \frac{\rho+\theta}{1+\rho}=\left[1-G\left(\phi^{*}\right)\right]\left[\frac{q(\widetilde{\phi})}{\sigma-1}-f\right] .
$$

Substituting $q(\widetilde{\phi})$ from the zero cutoff profit condition (equation 40 ) into equation 43 leads to:

$$
\frac{f_{E}}{f} \frac{\rho+\theta}{1+\rho}=\left[1-G\left(\phi^{*}\right)\right]\left[\frac{\widetilde{\phi} w_{S}^{1-\sigma} A_{S}^{\sigma-1}+(1-\widetilde{\phi}) A_{L}^{\sigma-1}}{\phi^{*} w_{S}^{1-\sigma} A_{S}^{\sigma-1}+\left(1-\phi^{*}\right) A_{L}^{\sigma-1}}-1\right] \equiv \Xi\left(\phi^{*}, w_{S}\right) .
$$

${ }^{33}$ Notice that, with an endogenous $\widetilde{\phi}$, we cannot simply assume that $\widetilde{\phi}<\left(\frac{A_{S}}{\rho+\delta}\right)^{1-\sigma}$; remember that this condition has to hold so that the steady state value for $w_{S}$ is defined for all possible values of $\sigma$ (see footnote 8). However, we can argue that, with an endogenous $\widetilde{\phi}, \widetilde{\phi} \rightarrow\left(\frac{A_{S}}{\rho+\delta}\right)^{1-\sigma}$ cannot result in general equilibrium. The argument is as follows. Assume for the moment that $\widetilde{\phi} \rightarrow\left(\frac{A_{S}}{\rho+\delta}\right)^{1-\sigma}$. This implies $w_{S} \rightarrow 0$ and $\phi^{*}=\widetilde{\phi}=1$ since no firm would employ unskilled labor in this case. However, if $\phi^{*}=\widetilde{\phi}$, all firms are identical, implying that the zero cutoff profit condition (equation 39) holds for the average firm. Thus, the FEC does not hold and less firms will enter the market. Less entry ceteris paribus increases sales for each firm, and, thus, reduces $\widetilde{\phi}$ so that $\widetilde{\phi}$ becomes strictly smaller than $\left(\frac{A_{S}}{\rho+\delta}\right)^{1-\sigma}$. 
Remember that, on impact with trade liberalization, the relative return to skilled labor $w_{S}$ may deviate from its steady state level as given by equation 6 . Thus, to study the impact effect of trade liberalization, we need lemma 9:

Lemma 9 Equation 44 establishes a negative relationship between $\widetilde{\phi}$ and $w_{S}$.

Proof. In order to prove lemma 9, we differentiate equation 44 totally, apply Leibniz rule to the partial derivative $\frac{\partial \widetilde{\phi}}{\partial \phi^{*}}$, and simplify the outcome to arrive at:

$$
\begin{gathered}
0=\underbrace{\frac{\left[1-G\left(\phi^{*}\right)\right]\left[\widetilde{\phi}\left(\frac{w_{S}}{A_{S}}\right)^{1-\sigma}+(1-\widetilde{\phi}) A_{L}^{\sigma-1}\right] A_{S}^{\sigma-1}}{\left[\phi^{*}\left(\frac{w_{S}}{A_{S}}\right)^{1-\sigma}+\left(1-\phi^{*}\right) A_{L}^{\sigma-1}\right]^{2}\left[\left(\frac{A_{S}}{A_{L}}\right)^{1-\sigma}-w_{S}^{1-\sigma}\right]^{-1}}}_{=\frac{\partial \Xi\left(\phi^{*}, w_{S}\right)}{\partial \phi^{*}}} d \phi^{*} \\
+\underbrace{\left[1-G\left(\phi^{*}\right)\right] \frac{\left(\widetilde{\phi}-\phi^{*}\right)(1-\sigma) w_{S}^{-\sigma} A_{S}^{\sigma-1} A_{L}^{\sigma-1}}{\left[\phi^{*}\left(\frac{w_{S}}{A_{S}}\right)^{1-\sigma}+\left(1-\phi^{*}\right) A_{L}^{\sigma-1}\right]^{2}}}_{=\frac{\partial \Xi\left(\phi^{*}, w_{S}\right)}{\partial w_{S}}} d w_{S} .
\end{gathered}
$$

Notice that $\frac{\partial \Xi\left(\phi^{*}, w_{S}\right)}{\partial \phi^{*}}<0$ since we focus here on the case of $w_{S}<\frac{A_{S}}{A_{L}}$, i.e. the term $\left(\frac{A_{S}}{A_{L}}\right)^{1-\sigma}-w_{S}^{1-\sigma}$ is negative. We can transform equation 45 to the following:

$$
\frac{d \phi^{*}}{d w_{S}}=\frac{\left(\widetilde{\phi}-\phi^{*}\right)(\sigma-1) w_{S}^{-\sigma} A_{S}^{\sigma-1} A_{L}^{\sigma-1}}{\left[\widetilde{\phi}\left(\frac{w_{S}}{A_{S}}\right)^{1-\sigma}+(1-\widetilde{\phi}) A_{L}^{\sigma-1}\right] A_{S}^{\sigma-1}\left[\left(\frac{A_{S}}{A_{L}}\right)^{1-\sigma}-w_{S}^{1-\sigma}\right]}<0
$$

Since $\frac{\partial \widetilde{\phi}}{\partial \phi^{*}}>0$ due to the Leibniz rule, it follows that equation 44 establishes a negative relationship between $\widetilde{\phi}$ and $w_{S}$. We illustrate the negative relationship between $\widetilde{\phi}$ and $w_{S}$ with the $F E C$-curve in figure A1 below.

Notice that, if $w_{S} \rightarrow \frac{A_{S}}{A_{L}}$, then $\phi^{*}$ approaches its lower bound since all firms can afford to produce, regardless of their $\phi$. As soon as $\phi^{*}$ has reached its lower bound, the $F E C$-curve has a kink and becomes horizontal. We have left out that part of the $F E C$-curve in figure $A 1$.

Equation 6 from the main part of this paper and equation 44 constitute a system of two equations, which can be jointly solved for $\widetilde{\phi}$ and $w_{S}$ in the autarkic steady state. Figure $A 1$ illustrates equations 6 and 44. We call the curve, which illustrates equation 6 , the steady state-curve, and we call the curve, which illustrates equation 44 , the $F E C$ - curve. $^{34}$

\section{[figure $A 1$ about here]}

The negative slope of the steady state-curve follows from lemma 3, while the negative slope of the $F E C$ curve follows from lemma 9 . We can now state lemma 10:

Lemma 10 If $\phi$ follows a Pareto distribution on the interval $\left[\phi_{L}, 1\right]$, with the lower bound $\phi_{L}$ being strictly larger than zero, the steady state-curve and the FEC-curve intersect only once. Furthermore, the steady state curve is steeper than the FEC-curve.

Proof. First, we prove that the steady state-curve and the FEC-curve intersect only once if $\phi$ follows a Pareto-distribution. To do so, we substitute the steady state value of $w_{S}$ (equation 6 ) into equation 44 and obtain after some simplification:

$$
\frac{\frac{f_{E}}{f}(\rho+\theta)}{1+\rho}=\underbrace{\frac{\left[1-G\left(\phi^{*}\right)\right]\left[1-(\rho+\delta)^{1-\sigma} A_{S}^{\sigma-1}\right]}{(\rho+\delta)^{1-\sigma} A_{S}^{\sigma-1}+\frac{1-\phi^{*}}{\phi^{*}-\widetilde{\phi}}}}_{\equiv \Psi\left(\phi^{*}\right)} .
$$

\footnotetext{
${ }^{34}$ Notice that we have drawn the steady state-curve and the FEC-curve linearly in order to keep the exposition neat.
} 
We will now show that the right hand side of equation 47 , which we denote by $\Psi\left(\phi^{*}\right)$, depends monotonously negatively on $\phi^{*}$ if $\phi$ follows a Pareto-distribution. The first order partial derivative of the function $\Psi\left(\phi^{*}\right)$ with respect to $\phi^{*}$ results as:

$$
\frac{\partial \Psi\left(\phi^{*}\right)}{\partial \phi^{*}}=\frac{\left[\frac{A_{S}^{1-\sigma}}{(\rho+\delta)^{1-\sigma}}-1\right]\left\{\left[1-G\left(\phi^{*}\right)\right] \frac{1-\widetilde{\phi}}{(\rho+\delta)^{1-\sigma} A_{S}^{\sigma-1}}-g\left(\phi^{*}\right)\left(\phi^{*}-\widetilde{\phi}\right)^{2}\right\}}{\left[\left(\phi^{*}-\widetilde{\phi}\right)(\rho+\delta)^{1-\sigma} A_{S}^{\sigma-1}+1-\phi^{*}\right]^{2}\left[(\rho+\delta)^{\sigma-1} A_{S}^{\sigma-1}\right]^{2}} .
$$

Since we focus here on the case of $\frac{A_{S}^{1-\sigma}}{(\rho+\delta)^{1-\sigma}}<1$, the partial derivative $\frac{\partial \Psi\left(\phi^{*}\right)}{\partial \phi^{*}}$ is negative as long as:

$$
\frac{A_{S}^{1-\sigma}}{(\rho+\delta)^{1-\sigma}}>\frac{g\left(\phi^{*}\right)\left(\phi^{*}-\widetilde{\phi}\right)^{2}}{\left[1-G\left(\phi^{*}\right)\right](1-\widetilde{\phi})} .
$$

We have argued in footnote 33 that, in general equilibrium, $(\rho+\delta)^{\sigma-1}-\widetilde{\phi} A_{S}^{\sigma-1}>0$, i.e. $\frac{A_{S}^{1-\sigma}}{(\rho+\delta)^{1-\sigma}}>\widetilde{\phi}$ Thus, condition 49 definitely holds if:

$$
\widetilde{\phi}>\frac{g\left(\phi^{*}\right)\left(\phi^{*}-\widetilde{\phi}\right)^{2}}{\left[1-G\left(\phi^{*}\right)\right](1-\widetilde{\phi})} .
$$

Assuming a Pareto distribution with finite mean and variance for $\phi$ on $\left[\phi_{L}, 1\right]$, we get:

$$
\frac{g\left(\phi^{*}\right)}{1-G\left(\phi^{*}\right)}=\frac{k\left(\phi^{*}\right)^{-1}}{1-\left(\phi^{*}\right)^{k}} \quad \text { and } \quad \widetilde{\phi}=\frac{k}{k-1} \phi^{*} \frac{1-\left(\phi^{*}\right)^{k-1}}{1-\left(\phi^{*}\right)^{k}}, \quad \text { with } k>2 .
$$

Thus, condition 50 can be transformed to:

$$
\left[1-\left(\phi^{*}\right)^{k}\right]\left[1-\left(\phi^{*}\right)^{k-1}\right] \geq \frac{\left\{(k-1)\left[1-\left(\phi^{*}\right)^{k}\right]-k\left[1-\left(\phi^{*}\right)^{k-1}\right]\right\}^{2}}{(k-1)\left[1-\left(\phi^{*}\right)^{k}\right]-k \phi^{*}\left[1-\left(\phi^{*}\right)^{k-1}\right]}
$$

Since $1>\phi^{*}>0$, condition 51 definitely holds if:

$$
\underbrace{2-\left(\phi^{*}\right)^{k-1}(1+k)-2\left(\phi^{*}\right)^{k}+k\left(\phi^{*}\right)^{k}+\left(\phi^{*}\right)^{2 k-1}}_{\equiv \Delta} \geq 0 .
$$

Evaluating $\Delta$ at $\phi^{*}=0$ and $\phi^{*}=1$ leads to: $\left.\Delta\right|_{\phi^{*}=0}=2$ and $\left.\Delta\right|_{\phi^{*}=1}=0$. Furthermore:

$$
\frac{\partial \Delta}{\partial \phi^{*}}=\left(\phi^{*}\right)^{k-2} \underbrace{\left[1-k^{2}-2 k \phi^{*}+k^{2} \phi^{*}+(2 k-1)\left(\phi^{*}\right)^{k}\right]}_{\equiv \Gamma} .
$$

Evaluating $\Gamma$ at $\phi^{*}=0$ and $\phi^{*}=1$ leads to: $\left.\Gamma\right|_{\phi^{*}=0}=1-k^{2}<0$ and $\left.\Gamma\right|_{\phi^{*}=1}=0$. Finally:

$$
\frac{\partial \Gamma}{\partial \phi^{*}}=-2 k+k^{2}+k(2 k-1)\left(\phi^{*}\right)^{k-1}>0 \quad \text { since } k>2 .
$$

Since $\Gamma$ is negative for all $\phi^{*} \in\left[\phi_{L}, 1\right]$, it follows that $\Delta$ is positive for all $\phi^{*} \in\left[\phi_{L}, 1\right]$. Thus, condition 52 holds, implying that $\frac{\partial \Psi\left(\phi^{*}\right)}{\partial \phi^{*}}<0$, i.e. the right hand side of equation 47 depends monotonously negatively on $\phi^{*}$, implying that equation 47 holds for a unique level of $\phi^{*}$.

Second, we prove that the steady state curve is steeper than the $F E C$-curve in figure $A 1$ if $\phi$ follows a Pareto distribution on the interval $\left[\phi_{L}, 1\right]$. Consider an exogenous decrease in the term $\frac{f_{E}}{f}$ on the left hand side of equation 47 . This shifts the $F E C$-curve upward since the term $\Xi\left(\phi^{*}, w_{S}\right)$ depends negatively on $\phi^{*}$ (see equation 45 ), i.e. an increase in $\phi^{*}$ guarantees that equation 47 holds again after the decrease in $\frac{f_{E}}{f}$. The new equilibrium level of $\widetilde{\phi}$, which is determined by the intersection point between the steady state-curve and the $F E C$-curve, is larger (smaller) than the old one if the steady state-curve is steeper (flatter) than the $F E C$-curve. However, we have shown that the right hand side of equation 47 depends 
negatively on $\phi^{*}$ if we consider the dependency of $w_{S}$ on $\widetilde{\phi}$ in the steady state. ${ }^{35}$ Thus, if we consider the steady state-curve and the $F E C$-curve simultaneously, a decrease in $\frac{f_{E}}{f}$ leads to an increase in $\phi^{*}$. As a consequence, the steady state-curve must be steeper than the $F E C$-curve in figure $A 1$ if $\phi$ follows a Pareto-distribution on $\left[\phi_{L}, 1\right]$.

Figure $A 1$ and equation 47 lead to proposition 6 :

Proposition 6 If $\phi$ follows a Pareto distribution on $\left[\phi_{L}, 1\right]$, with the lower bound $\phi_{L}$ being strictly larger than zero, the average skilled labor share parameter $\widetilde{\phi}$ and the relative return to skilled labor $w_{S}$ in the autarkic steady state are uniquely determined by: $\sigma$ (elasticity of substitution), $\rho$ (time discount rate), $\delta$ (rate of depreciation of skilled labor), $\theta$ (death probability), $A_{S}$ and $A_{L}$ (productivity parameters) and $f$ and $f_{E}$ (fixed costs parameters).

Once the steady state values of $\widetilde{\phi}$ and $w_{S}$ have been determined, the steady state magnitude of $q(\widetilde{\phi})$ can be derived with the help of equation 40 .

Finally, the factor market clearing conditions in the autarkic steady state are given by:

$$
\begin{aligned}
(1-\tilde{\phi}) A_{L}^{\sigma-1} c(\widetilde{\phi})^{\sigma}\{N[q(\widetilde{\phi})+\tilde{f}]+\delta S\} & =L \\
\widetilde{\phi} A_{S}^{\sigma-1} w_{S}^{-\sigma} c(\widetilde{\phi})^{\sigma}\{N[q(\widetilde{\phi})+\tilde{f}]+\delta S\} & =S,
\end{aligned}
$$

with $N \tilde{f}$ denoting total fixed input requirements in general equilibrium and $\tilde{f}=f+\frac{f_{E} \theta}{1-G\left(\phi^{*}\right)} \cdot{ }^{36}$ Dividing equations 54 and 55 by each other leads to:

$$
\frac{(1-\widetilde{\phi}) A_{L}^{\sigma-1}}{\widetilde{\phi} A_{S}^{\sigma-1} w_{S}^{-\sigma}}=\frac{L}{S} .
$$

Equation 56 is illustrated by an upward sloping curve in figure $A 1$ and we call this curve $\frac{L}{S}$-curve. Notice that $S$ is flexible in the long-run and always adjusts such that, in the steady state, the $\frac{L}{S}$-curve goes through the intersection point between the steady state-curve and the $F E C$-curve.

Substituting $q(\widetilde{\phi})$ (equation 40) and the steady state level for $w_{S}$ (equation 6) into equations 54 and 55 , the resulting equations can be solved for $S$ and $N$ as functions of $\widetilde{\phi}$ :

$$
\begin{aligned}
S & =L \frac{\widetilde{\phi} A_{S}^{\sigma-1}(1-\widetilde{\phi})^{\frac{1}{\sigma-1}} A_{L}(\rho+\delta)^{-\sigma}}{\left[1-\widetilde{\phi}(\rho+\delta)^{1-\sigma} A_{S}^{\sigma-1}\right]^{\frac{\sigma}{\sigma-1}}} \\
N & =\frac{(1-\widetilde{\phi})^{\frac{1}{\sigma-1}}\left[1-\widetilde{\phi} A_{S}^{\sigma-1}(\rho+\delta)^{-\sigma} \delta\right]\left[1-\widetilde{\phi}(\rho+\delta)^{1-\sigma} A_{S}^{\sigma-1}\right]^{\frac{\sigma}{1-\sigma}}}{\frac{(1-\widetilde{\phi}) A_{L}^{-1}(\sigma-1) f}{\left(\phi^{*}-\tilde{\phi}\right)(\rho+\delta)^{1-\sigma} A_{S}^{\sigma-1}+\left(1-\phi^{*}\right)}+A_{L}^{-1}\left[f+\frac{f_{E} \theta}{1-G\left(\phi^{*}\right)}\right]} L .
\end{aligned}
$$

Thus, in summary, equations 6 and 44 can be jointly solved for $\widetilde{\phi}$ and $w_{S}$ in the autarkic steady state. Once $\widetilde{\phi}$ and $w_{S}$ are known, the autarkic equilibrium quantities of all other variables can be determined.

Open economy. Considering the open economy, we again assume that serving the foreign market leads to fixed costs, which are in terms of the average variety: $c(\widetilde{\phi}) f_{X}$. The threshold skilled labor share parameter $\phi_{X}^{*}$, which separates exporters from non-exporters solves the following zero cutoff profit condition for the supply to the foreign market:

$$
\pi_{X}\left(\phi_{X}^{*}\right)=\frac{q\left(\phi_{X}^{*}\right) p\left(\phi_{X}^{*}\right)}{\sigma}-c(\widetilde{\phi}) f_{X}=0 .
$$

\footnotetext{
${ }^{35}$ Remember that equation 47 results from substituting the term for $w_{S}$ (equation 6 ) into equation 44 , i.e. equation 47 results from considering the steady state-curve and the $F E C$-curve simultaneously.

${ }^{36} f_{E}$ is divided by $1-G\left(\phi^{*}\right)$ in order to account for the fact that only the share $1-G\left(\phi^{*}\right)$ of the entering firms becomes active. Thus, if $N$ firms are active in general equilibrium, $\frac{N}{1-G\left(\phi^{*}\right)}$ firms had entered. Since unsuccessful entry also leads to entry costs, $f_{E}$ is divided by $1-G\left(\phi^{*}\right)$. Furthermore, $f_{E}$ is multiplied by $\theta$ in order to account for the fact that the share $\theta$ of the active firms is replaced by new firms in each period of the steady state.
} 
Equations 39 and 59 can be jointly solved for $\phi_{X}^{*}$ :

$$
\phi_{X}^{*}=\phi^{*} \frac{f_{X}}{f}+\frac{\frac{f_{X}}{f}-1}{\left[w_{S}^{1-\sigma}-\left(\frac{A_{S}}{A_{L}}\right)^{1-\sigma}\right]\left(\frac{A_{S}}{A_{L}}\right)^{\sigma-1}} .
$$

Since we focus here on the case of $w_{S}<\frac{A_{S}}{A_{L}}$, it follows from equation 60 that $\phi_{X}^{*}>\phi^{*}$, i.e. not all domestically active firms export, if $f_{X}>f$.

As in the main part of the text, we assume that on impact with trade liberalization, a country's skilled labor stock $S$ is constant and still given by its autarkic steady state level. In addition, we follow Melitz and Ottaviano (2008) and assume that, on impact with trade liberalization, the mass and distribution of firms is fixed. Thus, except for the fact that the active firms are distributed on the interval $\left[\phi^{*}, 1\right]$-instead of $[0,1]$ - the impact effect of trade liberalization in this appendix is identical to the one in the main part of the text. As a consequence, propositions 1 and 2 also hold with an endogenous mass and distribution of firms. The impact effect of trade liberalization is illustrated by the clock-wise turn of the $\frac{L}{S}$-curve in chart 1 of figure $A 2$. The $\frac{L}{S}$-curve turns clock-wise since the relative return to skilled labor $w_{S}$ increases on impact with trade liberalization (see proposition 1), and the increase in $w_{S}$ becomes larger, the larger is the autarkic $\widetilde{\phi}$ (see equation 18). Notice that $\widetilde{\phi}$ stays at its autarkic level since the distribution of firms is fixed on impact with trade liberalization.

In order to determine the long-run effect of trade liberalization, we consider that the skilled labor stock $S$ and the mass and distribution of firms become endogenous again. Thus, in order to determine the long-run effect of trade liberalization, we also have to consider how trade liberalization shifts the $F E C$ curve and the steady state-curve. First, the free entry condition (equation 43) has to be extended by the ex-ante expected export profits:

$$
\frac{f_{E}(\theta+\rho)}{1+\rho}=\left[1-G\left(\phi^{*}\right)\right]\left[\frac{q(\widetilde{\phi})}{\sigma-1}-f\right]+\frac{1-G\left(\phi_{X}^{*}\right)}{c(\widetilde{\phi})}\left[\frac{q\left(\widetilde{\phi}_{X}\right) p\left(\widetilde{\phi}_{X}\right)}{\sigma}-c(\widetilde{\phi}) f_{X}\right],
$$

with $\widetilde{\phi}_{X}=\int_{\phi_{X}^{*}}^{1} \phi \frac{g(\phi)}{1-G\left(\phi_{X}^{*}\right)} d \phi$ denoting the average skilled labor share parameter over the exporting firms. The term $\frac{q\left(\widetilde{\phi}_{X}\right) p\left(\widetilde{\phi}_{X}\right)}{\sigma}-c(\widetilde{\phi}) f_{X} \equiv \pi_{X}\left(\widetilde{\phi}_{X}\right)$ stands for the average export profits over the exporting firms, while the term $1-G\left(\phi_{X}^{*}\right)$ denotes the probability that an entrant will be an exporting firm. $\pi_{X}\left(\widetilde{\phi}_{X}\right) \geq 0$ since firms export only due to additional profit opportunities abroad. Thus, the expected profits from market entry increase with trade liberalization, i.e. without any adjustment of $\phi^{*}$, the right hand side of equation 61 would be larger than the left hand side of equation 61 . Both sides of equation 61 are equalized again by an increase in $\phi^{*}$. Notice that the proof of lemma 10 has shown that the term $\left[1-G\left(\phi^{*}\right)\right]\left[\frac{q(\tilde{\phi})}{\sigma-1}-f\right]$ depends negatively on $\phi^{*}$, i.e. an increase of $\phi^{*}$ is necessary to compensate for the additional expected export profits. Thus, the $F E C$-curve shifts upward in the long run after trade liberalization, and this is illustrated by chart 2 of figure $A 2$.

\section{[figure $A 2$ about here]}

Second, the skilled labor share parameter of the investment good increases due to trade liberalization. Including subscripts aut and $f t$ to denote variables in the autarkic and the free trade steady state, it increases from $\widetilde{\phi}_{\text {aut }}$ to $\underset{\widetilde{\phi}}{\widetilde{\tilde{\phi}}}=\frac{\widetilde{\phi}_{f t}+s_{X} \widetilde{\phi}_{X}}{1+s_{X}}$. Notice that $\widetilde{\widetilde{\phi}}$ in this appendix with an endogenous distribution of firms is larger than $\widetilde{\widetilde{\phi}}$ in the main part of the text. The reason is that $\widetilde{\phi}$ increases from $\widetilde{\phi}_{\text {aut }}$ to $\widetilde{\phi}_{f t}$ in this appendix. Thus, $w_{S}$ decreases for each given level of $\widetilde{\phi}$, but the decrease in $w_{S}$ becomes stronger due to endogenizing the distribution of firms. ${ }^{37}$ Thus, the steady state-curve moves to the left, as illustrated by chart 2 of figure $A 2$. Notice that the steady state-curve might also change its slope due to trade liberalization. However, for our current purposes it is sufficient to know that the steady state-curve moves to the left.

\footnotetext{
${ }^{37}$ Lemma 3 has shown that, given assumption 2, $w_{S}$ decreases with an increase of $\widetilde{\phi}$. The increase of the skilled labor share parameter of the investment good from $\widetilde{\phi}_{a u t}$ to $\widetilde{\widetilde{\phi}}=\frac{\widetilde{\phi}_{f t}+s_{X} \widetilde{\phi}_{X}}{1+s_{X}}$ has the same impact on $w_{S}$ as an increase of $\widetilde{\phi}$.
} 
Finally, the country's skilled labor stock adjusts in the long-run after trade liberalization so that the $\frac{L}{S}$-curve in the open economy steady state runs through the intersection point between the steady statecurve and the $F E C$-curve. Thus, as illustrated by chart 2 of figure $A 2$, the $\frac{L}{S}$-curve turns anti-clockwise due to the long-run adjustment to trade liberalization.

Thus, comparing the impact effect with the long run effect of trade liberalization on $w_{S}$ reveals that propositions 3 and 4 continue to hold with an endogenous mass and distribution of firms.

\section{The model with $\sigma \neq \xi$ and $\sigma \gtrless 1$}

In this appendix we will outline the model for the case of $\sigma \neq \xi$, i.e. we will drop assumption 1 in this appendix. Furthermore, we will also allow for $\sigma$ to be smaller than unity.

The marginal cost function and the definition of the aggregate consumption good do not change with this adjustment and are still given by equations 1 and 2, respectively. Thus, the aggregate price index still results as:

$$
P=\left[\int_{0}^{1} p(\phi)^{1-\xi} g(\phi) N d \phi\right]^{\frac{1}{1-\xi}} .
$$

If we define the average skilled labor share parameter as

$$
\widetilde{\phi}=\frac{\left\{\int_{0}^{1}\left[\phi w_{S}^{1-\sigma} A_{S}^{\sigma-1}+(1-\phi) A_{L}^{\sigma-1}\right]^{\frac{1-\xi}{1-\sigma}} g(\phi) d \phi\right\}^{\frac{1-\sigma}{1-\xi}}-A_{L}^{\sigma-1}}{w_{S}^{1-\sigma} A_{S}^{\sigma-1}-A_{L}^{\sigma-1}},
$$

we can express the aggregate price index $P$ in terms of the average variety, and this is illustrated by equation $64:^{38}$

$$
P=\left[\int_{0}^{1} p(\phi)^{1-\xi} \mu(\phi) N d \phi\right]^{\frac{1}{1-\xi}}=\left[p(\widetilde{\phi})^{1-\xi} N\right]^{\frac{1}{1-\xi}}
$$

Notice that the average capital share parameter, as defined by equation 63 , becomes $\widetilde{\phi}=\int_{0}^{1} \phi g(\phi) d \phi$ if $\sigma=\xi$ as in the main part of this paper. Again, we assume that the average variety, i.e. the variety which is produced with the skilled labor share parameter $\widetilde{\phi}$, is used for investment purposes. This is equivalent to assuming that households use part of the aggregate consumption good for investment purposes, but that the investment technology is not characterized by a "love of variety" property.

Demand for a single variety of the aggregate consumption good $Q$ now becomes:

$$
q(\phi)=Y P^{\xi-1} p(\phi)^{-\xi},
$$

and the profit maximizing price results as $p(\phi)=\frac{\xi}{\xi-1} c(\phi)$. Profits of a single firm with skilled labor share parameter $\phi$ are given by:

$$
\pi(\phi)=\frac{p(\phi) q(\phi)}{\xi}=Y P^{\xi-1} \frac{\left\{\phi\left[w_{S}^{1-\sigma}-\left(\frac{A_{S}}{A_{L}}\right)^{1-\sigma}\right] A_{S}^{\sigma-1}+A_{L}^{\sigma-1}\right\}^{\frac{1-\xi}{1-\sigma}}}{\xi^{\xi}(\xi-1)^{1-\xi}} .
$$

\footnotetext{
${ }^{38}$ In fact, the average capital share parameter, as defined by equation 63 , results from solving the following equation for $\widetilde{\phi}$ :

$$
=\left\{\left[\frac{\xi}{\xi-1}\left(\widetilde{\phi} w_{S}^{1-\sigma} A_{S}^{\sigma-1}+(1-\widetilde{\phi}) A_{L}^{\sigma-1}\right)^{\frac{1}{1-\sigma}}\right]^{1-\xi} N\right\}^{\frac{1}{1-\xi}} .
$$$$
\left\{\int_{0}^{1}\left[\frac{\xi}{\xi-1}\left(\phi w_{S}^{1-\sigma} A_{S}^{\sigma-1}+(1-\phi) A_{L}^{\sigma-1}\right)^{\frac{1}{1-\sigma}}\right]^{1-\xi} g(\phi) N d \phi\right\}^{\frac{1}{1-\xi}}
$$ 
The partial derivative of $\pi(\phi)$ with respect to $\phi$ results as:

$$
\frac{\partial \pi(\phi)}{\partial \phi}=\frac{p(\phi) q(\phi) \frac{1-\xi}{1-\sigma}}{\xi\left\{\phi\left[w_{S}^{1-\sigma}-\left(\frac{A_{S}}{A_{L}}\right)^{1-\sigma}\right] A_{S}^{\sigma-1}+A_{L}^{\sigma-1}\right\}}\left[w_{S}^{1-\sigma}-\left(\frac{A_{S}}{A_{L}}\right)^{1-\sigma}\right] A_{S}^{\sigma-1} .
$$

Equation 66 shows the following: also if $\sigma \neq \xi$ and if $1>\sigma>0$, a more skilled labor intensive firm realizes larger profits than a more unskilled labor intensive one if $w_{S}<\frac{A_{S}}{A_{L}}$ (notice that the term $\frac{1-\xi}{1-\sigma}$ is negative if $1>\sigma>0)$.

The relative return to skilled labor in the steady state is still given by:

$$
w_{S}=\left[\frac{(1-\widetilde{\phi})(\rho+\delta)^{1-\sigma} A_{L}^{\sigma-1}}{1-\widetilde{\phi}(\rho+\delta)^{1-\sigma} A_{S}^{\sigma-1}}\right]^{\frac{1}{1-\sigma}} .
$$

Notice, though, that $\widetilde{\phi}$ is not equal to $\int_{0}^{1} \phi g(\phi) d \phi$ if $\sigma \neq \xi$, but it follows from equation 63 in this case. Equation 67 implies that lemma 2 still holds, regardless of whether $\sigma>1$ or $1>\sigma>0$ : if $\rho+\delta<A_{S}$, then $w_{S}<\frac{A_{S}}{A_{L}}$ in the steady state. Thus, the parameter restriction from assumption 2 still applies in this appendix.

Importantly, if $\sigma \neq \xi$, the average skilled labor share parameter $\widetilde{\phi}$ is a function of $w_{S}$, while $w_{S}$ is a function of $\widetilde{\phi}$, as highlighted by equations 68 and 69 :

$$
\begin{aligned}
\widetilde{\phi} & =\frac{\left\{\int_{0}^{1}\left[\phi w_{S}^{1-\sigma} A_{S}^{\sigma-1}+(1-\phi) A_{L}^{\sigma-1}\right]^{\frac{1-\xi}{1-\sigma}} g(\phi) d \phi\right\}^{\frac{1-\sigma}{1-\xi}}-A_{L}^{\sigma-1}}{w_{S}^{1-\sigma} A_{S}^{\sigma-1}-A_{L}^{\sigma-1}} \\
w_{S} & =\left[\frac{(1-\widetilde{\phi})(\rho+\delta)^{1-\sigma} A_{L}^{\sigma-1}}{1-\widetilde{\phi}(\rho+\delta)^{1-\sigma} A_{S}^{\sigma-1}}\right]^{\frac{1}{1-\sigma}} .
\end{aligned}
$$

Still, we can formulate lemma 11:

Lemma 11 Both $\widetilde{\phi}$ and $w_{S}$ are uniquely defined if $\sigma \neq \xi$ and $1 \gtrless \sigma>0$, i.e. equations 68 and 69 define a unique combination of $\widetilde{\phi}$ and $w_{S}$.

Proof. (Notice that the proof ends on page 43.) First, consider the case of $\sigma>1$. The proof goes as follows: substituting equation 69 into equation 68 and rearranging terms leads to:

$$
\underbrace{(1-\widetilde{\phi})^{\frac{1-\xi}{1-\sigma}}}_{\equiv \psi(\widetilde{\phi})}=\underbrace{\int_{0}^{1}\left\{\phi\left[\left(\frac{\rho+\delta}{A_{S}}\right)^{1-\sigma}-1\right]+1-\widetilde{\phi}\left(\frac{\rho+\delta}{A_{S}}\right)^{1-\sigma}\right\}^{\frac{1-\xi}{1-\sigma}} g(\phi) d \phi}_{\equiv \chi(\widetilde{\phi})} .
$$

Equations 68 and 69 define a unique combination of $\widetilde{\phi}$ and $w_{S}$ if equation 70 holds for a unique level of $\widetilde{\phi}$. To prove that this is the case, we take the first and second order partial derivatives of the terms $\psi(\widetilde{\phi})$ and $\chi(\widetilde{\phi})$ with respect to $\widetilde{\phi}$ :

$$
\begin{aligned}
\frac{\partial \psi(\widetilde{\phi})}{\partial \widetilde{\phi}} & =\frac{1-\xi}{1-\sigma}(1-\widetilde{\phi})^{\frac{\sigma-\xi}{1-\sigma}}(-1)<0 \\
\frac{\partial^{2} \psi(\widetilde{\phi})}{(\partial \widetilde{\phi})^{2}} & =\frac{(1-\xi)(\sigma-\xi)}{(1-\sigma)^{2}}(1-\widetilde{\phi})^{\frac{\sigma-\xi}{1-\sigma}-1} \lessgtr 0 \\
\frac{\partial \chi(\widetilde{\phi})}{\partial \widetilde{\phi}} & =-\frac{1-\xi}{1-\sigma}\left[\left(\frac{\rho+\delta}{A_{S}}\right)^{1-\sigma}\right] \int_{0}^{1} \Omega(\phi)^{\frac{\sigma-\xi}{1-\sigma}} g(\phi) d \phi<0 \\
\frac{\partial^{2} \chi(\widetilde{\phi})}{(\partial \widetilde{\phi})^{2}} & =-\frac{(1-\xi)(\sigma-\xi)}{(1-\sigma)^{2}}\left[\left(\frac{\rho+\delta}{A_{S}}\right)^{1-\sigma}\right]^{2} \int_{0}^{1} \Omega(\phi)^{\frac{\sigma-\xi}{1-\sigma}-1} g(\phi) d \phi \lessgtr 0,
\end{aligned}
$$

with $\Omega(\phi)=(\phi-\widetilde{\phi})\left(\frac{\rho+\delta}{A_{S}}\right)^{1-\sigma}+1-\phi$. Equations 71 and 73 show that both $\psi(\widetilde{\phi})$ and $\chi(\widetilde{\phi})$ decrease with 
an increase of $\widetilde{\phi}$. Furthermore, if $\sigma-\xi>0$, then $\frac{\partial^{2} \psi(\widetilde{\phi})}{(\partial \widetilde{\phi})^{2}}<0$ and $\frac{\partial^{2} \chi(\widetilde{\phi})}{(\partial \widetilde{\phi})^{2}}<0$, implying that $\psi(\widetilde{\phi})$ and $\chi(\widetilde{\phi})$ are downward convex in $\widetilde{\phi}$. However, if $\sigma-\xi<0$, then $\frac{\partial^{2} \psi(\widetilde{\phi})}{(\partial \widetilde{\phi})^{2}}>0$ and $\frac{\partial^{2} \chi(\widetilde{\phi})}{(\partial \tilde{\phi})^{2}}>0$, implying that $\psi(\widetilde{\phi})$ and $\chi(\widetilde{\phi})$ are downward concave in $\widetilde{\phi}$. Furthermore, evaluating the functions $\psi(\widetilde{\phi})$ and $\chi(\widetilde{\phi})$ at $\widetilde{\phi}=1$ and $\widetilde{\phi}=0$, respectively, leads to:

(i) $\left.\psi(\widetilde{\phi})\right|_{\widetilde{\phi}=1}=0$

(ii) $\left.\psi(\widetilde{\phi})\right|_{\tilde{\phi}=0}=1$

(iii) $\left.\chi(\widetilde{\phi})\right|_{\tilde{\phi}=1}=\int_{0}^{1}(1-\phi)^{\frac{1-\xi}{1-\sigma}} g(\phi) d \phi\left[1-\left(\frac{\rho+\delta}{A_{S}}\right)^{1-\sigma}\right]^{\frac{1-\xi}{1-\sigma}}<0 \quad$ since $1-\left(\frac{\rho+\delta}{A_{S}}\right)^{1-\sigma}<0$

(iv) $\left.\chi(\widetilde{\phi})\right|_{\tilde{\phi}=0}=\int_{0}^{1}\left\{1-\phi\left[1-\left(\frac{\rho+\delta}{A_{S}}\right)^{1-\sigma}\right]\right\}^{\frac{1-\xi}{1-\sigma}} g(\phi) d \phi>1 \quad$ since $1-\left(\frac{\rho+\delta}{A_{S}}\right)^{1-\sigma}<0$.

Notice, though, that the term $\left[1-\left(\frac{\rho+\delta}{A_{S}}\right)^{1-\sigma}\right]^{\frac{1-\xi}{1-\sigma}}$ is defined for all possible magnitudes of $1-\left(\frac{\rho+\delta}{A_{S}}\right)^{1-\sigma}$ only if the exponent $\frac{1-\xi}{1-\sigma}$ is an integer. Otherwise, the function $\chi(\widetilde{\phi})$ is defined only up to such a magnitude of $\widetilde{\phi}$, at which it approaches zero. Thus, illustrating the functions $\psi(\widetilde{\phi})$ and $\chi(\widetilde{\phi})$ by a corresponding curve leads to charts 1 and 2 of figure $A 3$.

[figure $A 3$ about here]

Charts 1 and 2 of figure $A 3$ show that, regardless of whether $\sigma-\xi>0$ or $\sigma-\xi<0$, the curves illustrating the functions $\psi(\widetilde{\phi})$ and $\chi(\widetilde{\phi})$ intersect exactly once. Thus, in summary, equations 68 and 69 define a unique combination of $\widetilde{\phi}$ and $w_{S}$ if $\sigma>1$.

Second, consider the case of $1>\sigma>0$. In order to prove that equations 68 and 69 still define a unique combination of $\widetilde{\phi}$ and $w_{S}$, we rewrite equation 68 :

$$
\left[\widetilde{\phi} w_{S}^{1-\sigma} A_{S}^{\sigma-1}+(1-\widetilde{\phi}) A_{L}^{\sigma-1}\right]^{\frac{1-\xi}{1-\sigma}}=\int_{0}^{1}\left[\phi w_{S}^{1-\sigma} A_{S}^{\sigma-1}+(1-\phi) A_{L}^{\sigma-1}\right]^{\frac{1-\xi}{1-\sigma}} g(\phi) d \phi .
$$

Substituting the steady state level of $w_{S}$ (equation 69) into equation 75 and simplification leads to:

$$
\underbrace{\frac{(1-\widetilde{\phi})^{\frac{1-\xi}{1-\sigma}} A_{L}^{\xi-1}}{\left[1-\widetilde{\phi}(\rho+\delta)^{1-\sigma} A_{S}^{\sigma-1}\right]^{\frac{1-\xi}{1-\sigma}}}}_{\equiv \Pi(\widetilde{\phi})}=\underbrace{A_{L}^{\xi-1} \int_{0}^{1}\left[\frac{\Omega(\phi)}{1-\widetilde{\phi}(\rho+\delta)^{1-\sigma} A_{S}^{\sigma-1}}\right]^{\frac{1-\xi}{1-\sigma}} g(\phi) d \phi}_{\equiv \Phi(\tilde{\phi})} .
$$

Again, equations 68 and 69 define a unique combination of $\widetilde{\phi}$ and $w_{S}$ if equation 76 holds for a unique level of $\widetilde{\phi}$. In order to prove that this is the case, we will evaluate the left and right hand side of equation 76 separately. First, the left hand side. The first order partial derivative of the function $\Pi(\widetilde{\phi})$ with respect to $\widetilde{\phi}$ is given by: ${ }^{39}$

$$
\frac{\partial \Pi(\widetilde{\phi})}{\partial \widetilde{\phi}}=\frac{\frac{(\rho+\delta)^{1-\sigma}}{A_{S}^{1-\sigma}}-1}{\left[1-\widetilde{\phi}(\rho+\delta)^{1-\sigma} A_{S}^{\sigma-1}\right]^{\frac{2-\xi-\sigma}{1-\sigma}}} A_{L}^{\xi-1}(1-\widetilde{\phi})^{\frac{1-\xi}{1-\sigma}-1} \frac{1-\xi}{1-\sigma}>0
$$

\footnotetext{
${ }^{39}$ Notice that the condition $\rho+\delta<A_{S}$ implies $\frac{(\rho+\delta)^{1-\sigma}}{A_{S}^{1-\sigma}}>1$ in this part of the proof since $1>\sigma>0$.
} 
The second order partial derivative of the function $\Pi(\widetilde{\phi})$ with respect to $\widetilde{\phi}$ results as:

$$
\begin{gathered}
\frac{\partial^{2} \Pi(\widetilde{\phi})}{(\widetilde{\phi})^{2}}=\frac{\left[\frac{(\rho+\delta)^{1-\sigma}}{A_{S}^{1-\sigma}}-1\right] \frac{1-\xi}{(1-\sigma)^{2}} \gamma(\widetilde{\phi})}{A_{L}^{1-\xi}\left[1-\widetilde{\phi} \frac{(\rho+\delta)^{1-\sigma}}{A_{S}^{1-\sigma}}\right]^{\frac{3-\xi-2 \sigma}{1-\sigma}}(1-\widetilde{\phi})^{\frac{2 \sigma-\xi-1}{\sigma-1}}} \\
\text { with } \gamma(\widetilde{\phi})=[2-\xi-\sigma+2 \widetilde{\phi}(\sigma-1)] \frac{(\rho+\delta)^{1-\sigma}}{A_{S}^{1-\sigma}}-(\sigma-\xi) .
\end{gathered}
$$

In order to evaluate the sign of $\frac{\partial^{2} \Pi(\widetilde{\phi})}{(\widetilde{\phi})^{2}}$, we first consider the partial derivative of the function $\gamma(\widetilde{\phi})$ with respect to $\widetilde{\phi}$ :

$$
\frac{\partial \gamma(\widetilde{\phi})}{\partial \widetilde{\phi}}=2 A_{S}^{\sigma-1}(\sigma-1)(\rho+\delta)^{1-\sigma}<0
$$

Furthermore, $\left.\gamma(\widetilde{\phi})\right|_{\tilde{\phi}=1}=-(\sigma-\xi)\left[1-\frac{(\rho+\delta)^{1-\sigma}}{A_{S}^{1-\sigma}}\right]>0$. Thus, the function $\gamma(\widetilde{\phi})$ on the right hand side of equation 78 is positive also for all $\widetilde{\phi}<1$, i.e. the function $\Pi(\widetilde{\phi})$ is upward convex in $\widetilde{\phi}$. Finally, $\left.\Pi(\widetilde{\phi})\right|_{\widetilde{\phi}=0}=A_{L}^{\xi-1}$ and $\left.\Pi(\widetilde{\phi})\right|_{\widetilde{\phi}=1}=\infty$.

Concerning the right hand side of equation 76 , its first and second order partial derivatives with respect to $\widetilde{\phi}$ are given by:

$$
\begin{aligned}
\frac{\partial \Phi(\widetilde{\phi})}{\partial \widetilde{\phi}} & =A_{L}^{\xi-1} \frac{1-\xi}{1-\sigma} \int_{0}^{1} \frac{\Omega(\phi)^{\frac{\sigma-\xi}{1-\sigma}}}{\left[1-\widetilde{\phi} \frac{(\rho+\delta)^{1-\sigma}}{A_{S}^{1-\sigma}}\right]^{\frac{2-\xi-\sigma}{1-\sigma}}} \frac{(\rho+\delta)^{1-\sigma}}{A_{S}^{1-\sigma}} \phi\left[\frac{(\rho+\delta)^{1-\sigma}}{A_{S}^{1-\sigma}}-1\right] g(\phi) d \phi>0 \\
\frac{\partial^{2} \Phi(\widetilde{\phi})}{(\partial \widetilde{\phi})^{2}} & =\left[\frac{(\rho+\delta)^{1-\sigma}}{A_{S}^{1-\sigma}}-1\right] \frac{(1-\xi)(\xi-\sigma)}{A_{L}^{1-\xi}(1-\sigma)^{2}}\left[\frac{(\rho+\delta)^{1-\sigma}}{A_{S}^{1-\sigma}}\right]^{2} \frac{\int_{0}^{1} \phi \Omega(\phi)^{\frac{2 \sigma-\xi-1}{1-\sigma}} g(\phi) d \phi}{\left[1-\widetilde{\phi} \frac{(\rho+\delta)^{1-\sigma}}{A_{S}^{1-\sigma}}\right]^{\frac{2-\xi-\sigma}{1-\sigma}}>0 .}
\end{aligned}
$$

Remember that $\Omega(\phi) \equiv(\phi-\widetilde{\phi}) \frac{(\rho+\delta)^{1-\sigma}}{A_{S}^{1-\sigma}}+1-\phi$. Thus, the function $\Phi(\widetilde{\phi})$ is upward convex in $\widetilde{\phi}$ as well. Finally, $\left.\Phi(\widetilde{\phi})\right|_{\widetilde{\phi}=0}=A_{L}^{\xi-1} \int_{0}^{1}\left\{1+\left[\frac{(\rho+\delta)^{1-\sigma}}{A_{S}^{1-\sigma}}-1\right] \phi\right\}^{\frac{1-\xi}{1-\sigma}} g(\phi) d \phi>A_{L}^{\xi-1}$ and $\left.\Phi(\widetilde{\phi})\right|_{\widetilde{\phi}=1}=A_{L}^{\xi-1} \int_{0}^{1}(1-$ $\phi)^{\frac{1-\xi}{1-\sigma}} g(\phi) d \phi$.

Thus, illustrating the functions $\Pi(\widetilde{\phi})$ and $\Phi(\widetilde{\phi})$ by a corresponding curve leads to chart 3 of figure $A 3$. Chart 3 shows that the two curves intersect only once. Thus, also if $1>\sigma>0$, equations 68 and 69 define a unique combination of $\widetilde{\phi}$ and $w_{S}$.

Lemma 3 does not change due to dropping assumption 1 and it does not depend on whether $\sigma>1$ or $1>\sigma>0$. If $\rho+\delta<\underset{\widetilde{\sim}}{A_{S}}$, a ceteris paribus increase of the skilled labor share parameter of the average variety, e.g., from $\widetilde{\phi}$ to $\widetilde{\phi}$, decreases $w_{S}$.

The autarkic steady state is, like in the main part of this paper, characterized by the following three conditions: $(i)$ output equals demand for each variety at price $p(\phi)=\frac{\xi}{\xi-1} c(\phi) ;(i i) w_{S}=\left[\frac{(1-\widetilde{\phi})(\rho+\delta)^{1-\sigma} A_{L}^{\sigma-1}}{1-\widetilde{\phi}(\rho+\delta)^{1-\sigma} A_{S}^{\sigma-1}}\right]^{\frac{1}{1-\sigma}}$ since the country is in its steady state; (iii) the factor market clearing conditions.

If $\sigma \neq \xi$, the factor market clearing conditions become:

$$
\begin{gathered}
\int_{0}^{1}(1-\phi) A_{L}^{\sigma-1} c(\phi)^{\sigma} \frac{Y\left(\frac{\xi}{\xi-1}\right)^{-\xi}}{P^{1-\xi} c(\phi)^{\xi}} N g(\phi) d \phi+(1-\widetilde{\phi}) A_{L}^{\sigma-1} c(\widetilde{\phi})^{\sigma} \delta S=L \\
w_{S}^{-\sigma} \int_{0}^{1} \phi A_{S}^{\sigma-1} c(\phi)^{\sigma} \frac{Y\left(\frac{\xi}{\xi-1}\right)^{-\xi}}{P^{1-\xi} c(\phi)^{\xi}} N g(\phi) d \phi+\widetilde{\phi} A_{S}^{\sigma-1} w_{S}^{-\sigma} c(\widetilde{\phi})^{\sigma} \delta S=S .
\end{gathered}
$$

Notice that the terms $c(\phi)^{\sigma}$ and $c(\phi)^{-\xi}$ do not cancel out if $\sigma \neq \xi$. Substituting the term for $w_{S}$ into 
equations 81 and 82 (remember that the marginal cost functions $c(\phi)$ are also functions of $w_{S}$ ) and solving afterwards for $S$ leads to:

$$
S=\frac{A_{L}\left[1-\widetilde{\phi}(\rho+\delta)^{1-\sigma} A_{S}^{\sigma-1}\right]^{\frac{\sigma}{1-\sigma}} L}{\frac{(1-\tilde{\phi})^{\frac{\sigma}{1-\sigma}}}{A_{L}^{\sigma-1}}\left[(\rho+\delta)^{\sigma}-\widetilde{\phi} A_{S}^{\sigma-1} \delta\right] \Lambda+(1-\widetilde{\phi})^{\frac{1}{1-\sigma}} \delta},
$$

with $\Lambda=\frac{\int_{0}^{1}(1-\phi) A_{L}^{\sigma-1} \Omega(\phi)^{\frac{\sigma-\xi}{1-\sigma}} g(\phi) d \phi}{\int_{0}^{1} \phi A_{S}^{\sigma-1} \Omega(\phi)^{\frac{\sigma-\xi}{1-\sigma}} g(\phi) d \phi}$ and $\Omega(\phi)=(\phi-\widetilde{\phi})\left(\frac{\rho+\delta}{A_{S}}\right)^{1-\sigma}+1-\phi$. Equation 83 shows that lemma 5 continues to hold if $\sigma \neq \xi$ : despite the parameter restriction $\rho+\delta<A_{S}$ (see assumption 2), the relative skilled labor stock $\frac{S}{L}$ can take any value from the interval $[0, \infty)$, depending on the magnitudes of $\sigma, \xi, A_{S}, A_{L}, \rho, \delta$ and the distribution of $\phi$ on the unit interval. The proof is as follows: on the one hand, equation 83 shows that $S \rightarrow \infty$ if $\sigma>1$ and $\widetilde{\phi}\left(\frac{A_{S}}{\rho+\delta}\right)^{\sigma-1} \rightarrow 1$. On the other hand, if the distribution of $\phi$ on the unit interval is such that $\Lambda \rightarrow \infty$, then $S \rightarrow 0$.

Total factor income now results as:

$$
L+w_{S} S=L+L \frac{(1-\widetilde{\phi})(\rho+\delta)\left[1-\widetilde{\phi}(\rho+\delta)^{1-\sigma} A_{S}^{\sigma-1}\right]^{-1}}{A_{L}^{-1}\left[(\rho+\delta)^{\sigma}-\widetilde{\phi} A_{S}^{\sigma-1} \delta\right] \Lambda+(1-\widetilde{\phi}) \delta} .
$$

Thus, we can derive the steady state production $q(\phi)$ and revenue $q(\phi) p(\phi)$, respectively, by a firm which produces with skilled labor share parameter $\phi$ :

$$
\begin{gathered}
q(\phi)=\frac{\xi-1}{\xi N L^{-1}}\left\{1+\frac{\frac{(1-\widetilde{\phi})(\rho+\delta)}{\left[1-\widetilde{\phi}(\rho+\delta)^{1-\sigma} A_{S}^{\sigma-1}\right]}}{\left[(\rho+\delta)^{\sigma}-\widetilde{\phi} A_{S}^{\sigma-1} \delta\right] \frac{\Lambda}{A_{L}^{\sigma-1}}+(1-\widetilde{\phi}) \delta}\right\} \frac{A_{L} \Omega(\phi)^{\frac{\xi}{\sigma-1}}(1-\widetilde{\phi})^{\frac{\xi-1}{1-\sigma}}}{\left[1-\widetilde{\phi}\left(\frac{\rho+\delta}{A_{S}}\right)^{1-\sigma}\right]^{\frac{1}{\sigma-1}}} \\
q(\phi) p(\phi)=\frac{\xi-1}{\xi N L^{-1}}\left\{1+\frac{\frac{(1-\widetilde{\phi})(\rho+\delta)}{\left[1-\widetilde{\phi}(\rho+\delta)^{1-\sigma} A_{S}^{\sigma-1}\right]}}{\left[(\rho+\delta)^{\sigma}-\widetilde{\phi} A_{S}^{\sigma-1} \delta\right] \frac{\Lambda}{A_{L}^{\sigma-1}}+(1-\widetilde{\phi}) \delta}\right\} \frac{A_{L} \Omega(\phi)^{\frac{\xi-1}{\sigma-1}}(1-\widetilde{\phi})^{\frac{\xi-1}{1-\sigma}}}{\left[1-\widetilde{\phi}\left(\frac{\rho+\delta}{A_{S}}\right)^{1-\sigma}\right]^{\frac{1}{\sigma-1}}} .
\end{gathered}
$$

Equations 85 and 86 show that an individual firm's $\phi$ influences $q(\phi)$ and $q(\phi) p(\phi)$ only via its influence on $\Omega(\phi)$. The first order partial derivative of $\Omega(\phi)$ with respect to $\phi$ results as $\frac{\partial \Omega(\phi)}{\partial \phi}=A_{S}^{\sigma-1}(\rho+\delta)^{1-\sigma}-1>0$ if $\sigma>1$, which implies that a more skilled labor intensive firm has a higher level of production and revenue than a less skilled labor intensive one. Notice that $\frac{\partial \Omega(\phi)}{\partial \phi}<0$ if $1>\sigma>0$, but the exponent of $\Omega(\phi)$ in equations 85 and 86 is negative as well if $1>\sigma>0$. Thus, also if $1>\sigma>0$ production and revenue are higher, the larger is $\phi$.

Considering the open economy, aggregate sales of an exporting firm result as:

$$
q(\phi)+q_{X}(\phi)=2 Y P^{\xi-1} p(\phi)^{-\xi} .
$$

If $\sigma \neq \xi$, assumption 3 on the fixed export costs is modified to the following:

$$
\begin{aligned}
\frac{\left(L+w_{S, a u t} S_{\text {aut }}\right)\left(\frac{\xi}{\xi-1}\right)^{-\xi} A_{L}^{\xi-1}}{\xi P_{\text {aut }}^{1-\xi}}-\frac{f_{X}}{A_{L}} & <0 \\
0 & <\frac{\left(L+w_{S, a u t} S_{a u t}\right)\left(\frac{\xi}{\xi-1}\right)^{-\xi} w_{S, \text { aut }}^{1-\xi} A_{S}^{\xi-1}}{\xi P_{\text {aut }}^{1-\xi}}-\frac{w_{S, a u t} f_{X}}{A_{S}} .
\end{aligned}
$$

Due to conditions 88 and 89 the most unskilled labor intensive firms cannot afford to export, while the most skilled labor intensive ones can. The price index in the open economy becomes:

$$
P=\left[\int_{0}^{1} p(\phi)^{1-\xi} g(\phi) d \phi N+\int_{\phi_{X}^{*}}^{1} \frac{p(\phi)^{1-\xi} g(\phi)}{1-G\left(\phi_{X}^{*}\right)} s_{X} N d \phi\right]^{\frac{1}{1-\xi}}=\left[p(\widetilde{\widetilde{\phi}})^{1-\xi} N\left(1+s_{X}\right)\right]^{\frac{1}{1-\xi}},
$$


with:

$$
\widetilde{\widetilde{\phi}}=\frac{\left\{\frac{1}{1+s_{X}} \int_{0}^{1} c(\phi)^{1-\xi} g(\phi) d \phi+\frac{s_{X}}{1+s_{X}} \int_{\phi_{X}^{*}}^{1} c(\phi)^{1-\xi} \frac{g(\phi)}{1-G\left(\phi_{X}^{*}\right)} d \phi\right\}^{\frac{1-\sigma}{1-\xi}}-A_{L}^{\sigma-1}}{w_{S}^{1-\sigma} A_{S}^{\sigma-1}-A_{L}^{\sigma-1}} .
$$

$G$ denotes the cumulative density for $\phi$ on the unit interval and $s_{X}=\frac{1-G\left(\phi_{X}^{*}\right)}{1-G\left(\phi^{*}\right)}$. Equation 91 leads to lemma 12

Lemma 12 Trade liberalization increases the skilled labor share parameter of the aggregate good $Q$, i.e. $\widetilde{\widetilde{\phi}}>\widetilde{\phi}$.

Proof. First, consider the case of $\sigma>1$. If we substitute the term $w_{S}=\left[\frac{(1-\widetilde{\phi})(\rho+\delta)^{1-\sigma} A_{L}^{\sigma-1}}{1-\widetilde{\phi}(\rho+\delta)^{1-\sigma} A_{S}^{\sigma-1}}\right]^{\frac{1}{1-\sigma}}$ into equation 91 and rearrange the resulting term we arrive at:

$$
\underbrace{(1-\widetilde{\phi})^{\frac{1-\xi}{1-\sigma}}}_{\equiv \psi(\tilde{\phi})}=\underbrace{\frac{1}{1+s_{X}} \int_{0}^{1} \Omega(\phi)^{\frac{1-\xi}{1-\sigma}} g(\phi) d \phi+\frac{s_{X}}{1+s_{X}} \int_{\phi_{X}^{*}}^{1} \Omega(\phi)^{\frac{1-\xi}{1-\sigma}} \frac{g(\phi)}{1-G\left(\phi_{X}^{*}\right)} d \phi}_{\equiv \chi_{X}(\tilde{\phi})} .
$$

Remember that $\Omega(\phi)=(\phi-\widetilde{\phi})\left(\frac{\rho+\delta}{A_{S}}\right)^{1-\sigma}+1-\phi$. Comparing equation 92 with equation 70 shows the following: $\chi(\widetilde{\phi})<\chi_{X}(\widetilde{\phi})$, i.e. the $\chi(\widetilde{\phi})$-curves in charts 1 and 2 of figure $A 3$ shift upward due to trade liberalization. The new curves are labeled " $\chi_{x}(\widetilde{\phi})$-curve". Thus, the intersection point between the $\psi(\widetilde{\phi})$-curve and the $\chi_{X}(\widetilde{\phi})$-curve yields larger value for the skilled labor share parameter of the average variety, as compared to the autarkic equilibrium. We denote the skilled labor share parameter of the average variety in the trading equilibrium by $\widetilde{\widetilde{\phi}}$.

Second, consider the case of $1>\sigma>0$. The open economy equivalent to equation 75 is given by:

$$
\begin{aligned}
& {\left[\widetilde{\phi} w_{S}^{1-\sigma} A_{S}^{\sigma-1}+(1-\widetilde{\phi}) A_{L}^{\sigma-1}\right]^{\frac{1-\xi}{1-\sigma}}} \\
& =\frac{\int_{0}^{1}\left[\phi w_{S}^{1-\sigma} A_{S}^{\sigma-1}+(1-\phi) A_{L}^{\sigma-1}\right]^{\frac{1-\xi}{1-\sigma}} g(\phi) d \phi}{1+s_{X}}+\frac{s_{X} \int_{\phi_{X}^{*}}^{1}\left[\phi w_{S}^{1-\sigma} A_{S}^{\sigma-1}+(1-\phi) A_{L}^{\sigma-1}\right]^{\frac{1-\xi}{1-\sigma}} \frac{g(\phi)}{1-G\left(\phi_{X}^{*}\right)} d \phi}{1+s_{X}} .
\end{aligned}
$$

Substituting the steady state level of $w_{S}$ (equation 69) into equation 93 and simplification leads to:

$$
\frac{(1-\widetilde{\phi})^{\frac{1-\xi}{1-\sigma}} A_{L}^{\xi-1}}{\left[1-\widetilde{\phi} \frac{(\rho+\delta)^{1-\sigma}}{A_{S}^{1-\sigma}}\right]^{\frac{1-\xi}{1-\sigma}}}=\frac{\int_{0}^{1} \Omega(\phi)^{\frac{1-\xi}{1-\sigma}} g(\phi) d \phi A_{L}^{\xi-1}}{\left(1+s_{X}\right)\left[1-\widetilde{\phi} \frac{(\rho+\delta)^{1-\sigma}}{A_{S}^{1-\sigma}}\right]^{\frac{1-\xi}{1-\sigma}}}+\frac{s_{X} \int_{\phi_{X}^{*}}^{1} \Omega(\phi)^{\frac{1-\xi}{1-\sigma}} \frac{g(\phi)}{1-G\left(\phi_{X}^{*}\right)} d \phi A_{L}^{\xi-1}}{\left(1+s_{X}\right)\left[1-\widetilde{\phi} \frac{(\rho+\delta)^{1-\sigma}}{A_{S}^{1-\sigma}}\right]^{\frac{1-\xi}{1-\sigma}}}
$$

Notice that $\frac{\partial \Omega(\phi)}{\partial \phi}=\frac{(\rho+\delta)^{1-\sigma}}{A_{S}^{1-\sigma}}-1<0$ and $\frac{1-\xi}{1-\sigma}<0$ if $1>\sigma>0$. Thus, we can conclude that

$$
\int_{0}^{1} \Omega(\phi)^{\frac{1-\xi}{1-\sigma}} d(\phi) d \phi<\int_{\phi_{X}^{*}}^{1} \Omega(\phi)^{\frac{1-\xi}{1-\sigma}} \frac{g(\phi)}{1-G\left(\phi_{X}^{*}\right)} d \phi
$$

which implies that the right hand side of equation 94 is ceteris paribus larger than the right hand side of equation 76. Thus, trade liberalization shifts the $\Phi(\widetilde{\phi})$-curve in chart 3 of figure $A 3$ upward, so that the $\Pi(\widetilde{\phi})$-curve and the $\Phi_{X}(\widetilde{\phi})$-curve intersect at a larger value for the skilled labor share parameter of the average variety, as compared to the autarkic equilibrium. Again, we denote the skilled labor share parameter of the average variety in the trading equilibrium by $\widetilde{\widetilde{\phi}}$.

Finally, extending the factor market clearing conditions (equations 81 and 82) by factor demands for producing exports and the fixed export costs, rearranging the resulting factor market clearing conditions 
and division by each other leads to:

$$
\begin{array}{r}
\int_{0}^{1} \frac{1-\phi}{A_{L}^{1-\sigma}} c(\phi)^{\sigma} \frac{Y p(\phi)-\xi}{P^{1-\xi}} N g(\phi) d \phi+\int_{\phi_{X}^{*}}^{1} \frac{1-\phi}{A_{L}^{1-\sigma}} c(\phi)^{\sigma} N s_{X}\left[\frac{Y p(\phi)^{-\xi}}{P^{1-\xi}}+f_{X}\right] \frac{g(\phi)}{1-G\left(\phi_{X}^{*}\right)} d \phi \\
w_{S}^{-\sigma} \int_{0}^{1} \frac{\phi}{A_{S}^{1-\sigma}} c(\phi)^{\sigma} \frac{Y p(\phi)^{-\xi}}{P^{1-\xi}} N g(\phi) d \phi+w_{S}^{-\sigma} \int_{\phi_{X}^{*}}^{1} \frac{\phi}{A_{S}^{1-\sigma}} c(\phi)^{\sigma} N s_{X}\left[\frac{Y p(\phi)-\xi}{P^{1-\xi}}+f_{X}\right] \frac{g(\phi)}{1-G\left(\phi_{X}^{*}\right)} d \phi \\
=\frac{L-(1-\widetilde{\widetilde{\phi}}) A_{L}^{\sigma-1} c(\widetilde{\widetilde{\phi}})^{\sigma} \delta S}{S-w_{S}^{-\sigma} \widetilde{\widetilde{\phi}} A_{S}^{\sigma-1} c(\widetilde{\widetilde{\phi}})^{\sigma} \delta S} .
\end{array}
$$

The left hand side of equation 95 stands for the relative unskilled labor demand for producing the varieties of the aggregate good $Q$ and fixed export costs, while the right hand side of equation 95 stands for relative unskilled labor supply, net of factor demands for investing into the country's skilled labor stock. Equation 95 leads to lemma 13:

Lemma 13 Trade liberalization decreases relative unskilled labor demand, while it increases relative unskilled labor supply, net of factor demands for investing into the skilled labor stock.

Proof. In order to prove that the left hand side of equation 95 decreases with trade liberalization, we first divide the interval $[0,1]$ into $n$ neighboring subintervals $\left[\phi_{1}, \phi_{2}\right],\left[\phi_{2}, \phi_{3}\right], \ldots,\left[\phi_{n-1}, \phi_{n}\right]$, with $0=\phi_{1}<\phi_{2}<\ldots<\phi_{X}^{*}<\ldots<\phi_{n-1}<\phi_{n}$. Furthermore, we assume that each subinterval has the same length, i.e. $\phi_{2}-\phi_{1}=\phi_{3}-\phi_{2}=\ldots=\phi_{n}-\phi_{n-1}$. Thus, we can approximate the left hand side of equation 95 by the ratio of two sums, as it is illustrated in the following: ${ }^{40}$

$$
\begin{aligned}
& \frac{\int_{0}^{1} \frac{1-\phi}{A_{L}^{1-\sigma}} c(\phi)^{\sigma} \frac{Y p(\phi)^{-\xi}}{P^{1-\xi}} N g(\phi) d \phi+\int_{\phi_{X}^{*}}^{1} \frac{1-\phi}{A_{L}^{1-\sigma}} c(\phi)^{\sigma} N s_{X}\left[\frac{Y p(\phi)^{-\xi}}{P^{1-\xi}}+f_{X}\right] \frac{g(\phi)}{1-G\left(\phi_{X}^{*}\right)} d \phi}{\int_{0}^{1} \frac{\phi}{A_{S}^{1-\sigma}} c(\phi)^{\sigma} \frac{Y p(\phi)^{-\xi}}{P^{1-\xi}} N g(\phi) d \phi+\int_{\phi_{X}^{*}}^{1} \frac{\phi}{A_{S}^{1-\sigma}} c(\phi)^{\sigma} N s_{X}\left[\frac{Y p(\phi)^{-\xi}}{P^{1-\xi}}+f_{X}\right] \frac{g(\phi)}{1-G\left(\phi_{X}^{*}\right)} d \phi}
\end{aligned}
$$

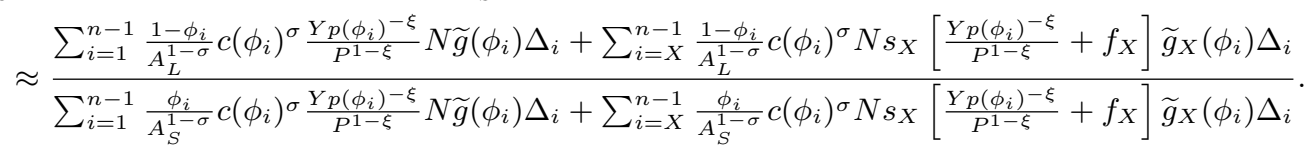

The subscript $i$ indexes the starting value for each subinterval, i.e. the index $i$ runs from $i=1$ to $i=n-1$. Each firm with a $\phi$ equal or larger than $\phi_{X}^{*}$ is an exporting firm. Furthermore, $\widetilde{g}\left(\phi_{i}\right) \equiv G\left(\phi_{i}\right)-G\left(\phi_{i-1}\right)$ stands for the relative frequency of firms within the subinterval $\left[\phi_{i-1}, \phi_{i}\right], \widetilde{g}_{X}\left(\phi_{i}\right) \equiv \frac{G\left(\phi_{j}\right)-G\left(\phi_{j-1}\right)}{1-G\left(\phi_{X}^{*}\right)}$ stands for the relative frequency of firms within the subinterval $\left[\phi_{j-1}, \phi_{j}\right]$, with $\phi_{j-1} \geq \phi_{X}^{*}$, and $\Delta_{i}$ stands for the length of a single subinterval. Notice that the approximation in 96 holds as an equality if $n$ approaches infinity, i.e. if all subintervals have a length of zero. Furthermore, notice that, if $s_{X}=0$ the countries are in autarky, while $s_{X}>0$ reflects the open economy case. We can now show that the following holds for any given level of $w_{S}:^{41}$

$$
\frac{\sum_{i=1}^{n-1} \frac{\left(1-\phi_{i}\right) \widetilde{g}\left(\phi_{i}\right)}{c\left(\phi_{i}\right)^{\xi-\sigma} A_{L}^{1-\sigma}}}{\sum_{i=1}^{n-1} \frac{\phi_{i} \widetilde{g}\left(\phi_{i}\right)}{c\left(\phi_{i}\right)^{\xi-\sigma} A_{S}^{1-\sigma}}}>\frac{\sum_{i=1}^{n-1} \frac{\left(1-\phi_{i}\right) \widetilde{g}\left(\phi_{i}\right)}{c\left(\phi_{i}\right)^{\xi-\sigma} A_{L}^{1-\sigma}}+\sum_{i=X}^{n-1} \frac{\left(1-\phi_{i}\right) \widetilde{g}_{X}\left(\phi_{i}\right) s_{X}}{c\left(\phi_{i}\right)^{\xi-\sigma} A_{L}^{1-\sigma}}\left[1+\frac{f_{X} P^{1-\xi}}{p\left(\phi_{i}\right)^{-\xi} Y}\right]}{\sum_{i=1}^{n-1} \frac{\phi_{i} \widetilde{g}\left(\phi_{i}\right)}{c\left(\phi_{i}\right)^{\xi-\sigma} A_{S}^{1-\sigma}}+\sum_{i=X}^{n-1} \frac{\phi_{i} \widetilde{g}_{X}\left(\phi_{i}\right) s_{X}}{c\left(\phi_{i}\right)^{\xi-\sigma} A_{S}^{1-\sigma}}\left[1+\frac{f_{X} P^{1-\xi}}{p\left(\phi_{i}\right)^{-\xi} Y}\right]}
$$

Notice that the marginal cost terms on both sides of inequality 97 are evaluated at the same level for $w_{S}$, which we denote $\bar{w}_{S}$ for the time being. Thus, the left hand side of inequality 97 stands for the relative unskilled labor demand in the autarkic equilibrium at price $\bar{w}_{S}$, while the right hand side of inequality 97 stands for the relative unskilled labor demand in the open economy equilibrium at price $\bar{w}_{S}$. The terms $\Delta_{i}$ have dropped out from inequality 97 since we have subdivided the unit interval into subintervals of an

\footnotetext{
${ }^{40}$ Notice that the term $w_{S}^{-\sigma}$ has canceled out in this approximation.

${ }^{41}$ Notice that the term $\frac{Y}{P^{1-\xi}}$ has canceled out on the left hand side of inequality 97. Furthermore, since $p\left(\phi_{i}\right)^{-\xi}=\left(\frac{\xi}{\xi-1}\right)^{-\xi} c\left(\phi_{i}\right)^{-\xi}$, we have merged the term $c\left(\phi_{i}\right)^{\sigma} p\left(\phi_{i}\right)^{-\xi}$ to $c\left(\phi_{i}\right)^{\sigma-\xi}\left(\frac{\xi}{\xi-1}\right)^{-\xi}$ and have canceled out the term $\left(\frac{\xi}{\xi-1}\right)^{-\xi}$ on the left hand side of inequality 97 .
} 
identical length. Inequality 97 can be rearranged to:

$$
\sum_{k=1}^{X-1}\left[\frac{\left(1-\phi_{k}\right) \widetilde{g}\left(\phi_{k}\right)}{c\left(\phi_{k}\right)^{\xi-\sigma} A_{L}^{\sigma-1}} \sum_{l=X}^{n-1} \frac{\phi_{l} \widetilde{g}_{X}\left(\phi_{l}\right) s_{X}}{c\left(\phi_{l}\right)^{\xi-\sigma} A_{S}^{\sigma-1}}\right]>\sum_{k=1}^{X-1}\left[\frac{\phi_{k} \widetilde{g}\left(\phi_{k}\right)}{c\left(\phi_{k}\right)^{\xi-\sigma} A_{S}^{\sigma-1}} \sum_{l=X}^{n-1} \frac{\left(1-\phi_{l}\right) \widetilde{g}_{X}\left(\phi_{l}\right) s_{X}}{c\left(\phi_{l}\right)^{\xi-\sigma} A_{L}^{\sigma-1}}\right] .
$$

Notice that inequality 98 holds since $\frac{1-\phi_{k}}{\phi_{k}}>\frac{1-\phi_{l}}{\phi_{l}}$ for all $k \in\{1, \ldots, X-1\}$ and for all $l \in\{X, \ldots, n-1\}$. Thus, trade liberalization ceteris paribus decreases relative unskilled labor demand. This result is also quite intuitive as only the more skilled labor intensive firms increase their production due to trade liberalization.

Finally, since $\frac{1-\tilde{\phi}}{\tilde{\phi}}>\frac{1-\tilde{\widetilde{\phi}}}{\tilde{\tilde{\phi}}}$, it follows that relative unskilled labor supply net of factor demands for investing into the skilled labor stock ceteris paribus increases with trade liberalization:

$$
\frac{L-(1-\widetilde{\phi}) c(\widetilde{\phi})^{\sigma} A_{L}^{\sigma-1} \delta S}{S-w_{S}^{-\sigma} \widetilde{\phi} c(\widetilde{\phi})^{\sigma} A_{S}^{\sigma-1} \delta S}<\frac{L-(1-\widetilde{\widetilde{\phi}}) c(\widetilde{\widetilde{\phi}})^{\sigma} A_{L}^{\sigma-1} \delta S}{S-w_{S}^{-\sigma} \widetilde{\widetilde{\phi}} c(\widetilde{\widetilde{\phi}})^{\sigma} A_{S}^{\sigma-1} \delta S}
$$

Thus, the relative return skilled labor increases on impact after trade liberalization, which implies that per unit unskilled (skilled) labor input of each single firm increases (decreases) and relative unskilled labor demand and supply are equalized again. Thus, proposition 1 continues to hold with $\sigma \neq \xi$.

Finally, the relative return to skilled labor decreases in the long run after trade liberalization since $\widetilde{\widetilde{\phi}}>\widetilde{\phi}$ and proposition 3 continues to hold with $\sigma \neq \xi$. 


\section{References}

Acosta, P., Montes-Rojas, G. V., 2008. Trade reform and inequality: The case of Mexico and Argentina in the 1990s. The World Economy 31, 763-780.

Alvarez, R., López, R. A., 2005. Exporting and performance: Evidence from Chilean plants. Canadian Journal of Economics 38, 1384-1400.

Amiti, M., Davis, D. R., 2012. Trade, firms, and wages: Theory and evidence. Review of Economic Studies 79, 1-36.

Anderson, J. E., Neary, P., 2005. Measuring the restrictiveness of international trade policy. Cambridge, MA: MIT Press.

Atolia, M., 2007. Trade liberalization and rising wage inequality in Latin America: Reconciliation with HOS theory. Journal of International Economics 71, 467-494.

Attanasio, O., Goldberg, P. K., Pavcnik, N., 2004. Trade reforms and wage inequality in Colombia. Journal of Development Economics 74, 331-366.

Baxter, M., 1992. Fiscal policy, specialization, and trade in the two-sector model: The return of Ricardo? Journal of Political Economy 100, 713-744.

Bernard, A. B., Redding, S., Schott, P. K., 2007. Comparative advantage and heterogeneous firms. Review of Economic Studies 74, 31-66.

Beyer, H., Rojas, P., Vergara, R., 1999. Trade liberalization and wage inequality. Journal of Development Economics 59, 103-123.

Burstein, A., Vogel, J., 2010. International trade, technology, and the skill premium. Mimeo, UCLA.

Bustos P., 2011. Trade liberalization, exports, and technology upgrading: Evidence on the impact of MERCOSUR on Argentinian firms. American Economic Review 101, 304-340.

Davis, D. R., Harrigan, J., 2011. Good jobs, bad jobs, and trade liberalization. Journal of International Economics 84, 26-36.

de Ferranti, D., Perry, G.E., Ferreira, F., Walton, M., 2004. Inequality in Latin America: Breaking with history? Washington, DC: The World Bank.

Dixit, A. K., Stiglitz, J. E., 1977. Monopolistic competition and optimum product diversity. American Economic Review 67, 297-308.

Chaney, 2005. Productivity overshooting: The dynamic impact of trade opening with heterogeneous firms. Mimeo, University of Chicago.

Crozet, M., Trionfetti, F., 2009. Comparative advantage and within-industry firms performance. Mimeo, Paris School of Economics.

Ederington, J., McCalman, P., 2008. Endogenous firm heterogeneity and the dynamics of trade liberalization. Journal of International Economics 74, 422-440. 
Emami Namini, J., 2009. International trade with firm heterogeneity in factor shares. Tinbergen Institute DP 2009-020/1.

Emami Namini, J., Facchini, G., and López, R. A., 2011. Export growth and factor market competition. CEPR Working Paper No. 8256.

Findlay, R., Kierzkowski, H., 1983. International trade and human capital: A simple general equilibrium model. Journal of Political Economy 91, 957-978.

Galiani, S., Sanguinetti, P., 2003. The impact of trade liberalization on wage inequality: Evidence from Argentina. Journal of Development Economics 72, 497-513.

Gallego, F., 2006. Skill premium in Chile: Studying the skill bias technical change hypothesis in the South. Central Bank of Chile Working Paper No. 363.

Goldberg, P. K., Pavcnik, N., 2004. Trade, inequality, and poverty: What do we know? Evidence from recent trade liberalization episodes in developing countries. Brookings Trade Forum, $223-269$.

Goldberg, P. K., Pavcnik, N., 2007. Distributional effects of globalization in developing countries. Journal of Economic Literature 45, 39-82.

Gonzaga, G., Menezes-Filho, N., Terra, C., 2006. Trade liberalization and the evolution of skill earnings in Brazil. Journal of International Economics 68, 345-367.

Hanson, G., Harrison, A., 1999. Trade liberalization and wage inequality in Mexico. Industrial and Labor Relations Review 52, 271-288.

Harrigan, J., Reshef, A., 2011. Skill biased heterogeneous firms, trade liberalization, and the skill premium. NBER Working Paper No. 17604.

Helpman, E., Itskhoki, O., Redding, S., 2010. Inequality and unemployment in a global economy. Econometrica 78, 1239-1283.

Jones, R. W., Easton, S. T., 1983. Factor intensities and factor substitution in general equilibrium. Journal of International Economics 15, 65-99.

Kasahara, H., Rodrigue, J., 2008. Does the use of imported intermediates increase productivity? Plant-level evidence. Journal of Development Economics 87, 106-118.

Krugman, P. R., 1980. Scale economies, product differentiation, and the pattern of trade. American Economic Review 70, 950-959.

Leamer, E. E., Maul, H., Rodriguez, S., Schott, P., 1999. Does natural resource abundance increase Latin American income inequality? Journal of Development Economics 59, 3-42.

Levinsohn, J., Petrin, A., 2003. Estimating production functions using inputs to control for unobservables. Review of Economic Studies 70, 317-341.

Markusen, J. R., Venables, A. J., 2000. The theory of endowment, intra-industry and multinational trade. Journal of International Economics 52, 209-235. 
Melitz, M. J., 2003. The impact of trade on intra-industry reallocations and aggregate industry productivity. Econometrica 71, 1695-1725.

Melitz, M. J., Ottaviano, G., 2008. Market size, trade, and productivity. Review of Economic Studies 75, 295-316.

Olley, G. S., Pakes, A., 1996. The dynamics of productivity in the telecommunications equipment industry. Econometrica 64, 1263-1297.

Pavcnik, N., 2002. Trade liberalization, exit, and productivity improvements: Evidence from Chilean plants. Review of Economic Studies 69, 245-76.

Pavcnik, N., 2003. What explains skill upgrading in less developed countries? Journal of Development Economics 71, 311-328.

Robbins, D., 1996. HOS hits facts: Facts win; Evidence on trade and wages in the developing world. Development Discussion Paper No. 484, Harvard Institute for International Development.

Robertson, R., 2003. Exchange rates and relative wages: Evidence from Mexico. North American Journal of Economics and Finance 14, 25-48.

Staiger, R., Stock, J., 1997. Instrumental variables regression with weak instruments. Econometrica $65,1055-1096$.

Slaughter, M. J., 2000. What are the results of product price studies and what can we learn from their differences? In R. C. Feenstra (ed.), The Impact of International Trade on Wages, NBER Conference Volume. Chicago, IL: University of Chicago Press.

Tokarick, S., 2005. Quantifying the impact of trade on wages: The role of nontraded goods. Review of International Economics 13, 841-860.

Verhoogen, E., 2008. Trade, quality upgrading and wage inequality in the Mexican manufacturing sector. Quarterly Journal of Economics 123, 489-530.

Vannoorenberghe, G., 2011. Trade between symmetric countries, heterogeneous firms, and the skill premium. Canadian Journal of Economics 44, 148-170. 
$\underline{\text { Figures }}$

Figure 1: Adjustment to the trading equilibrium

Chart 1: Relative factor returns and trade liberalization

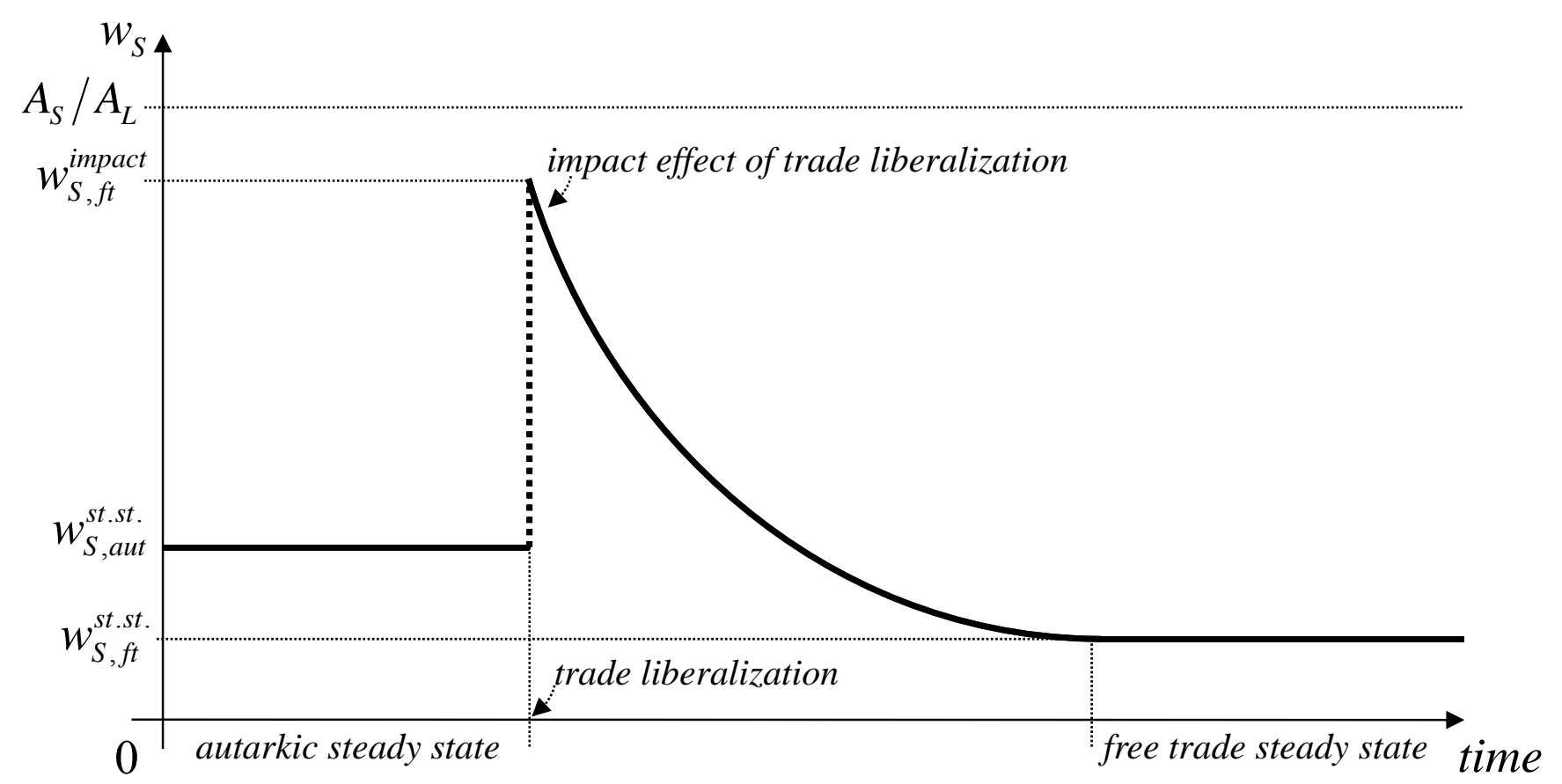

Chart 2: Relative skilled labor input and trade liberalization

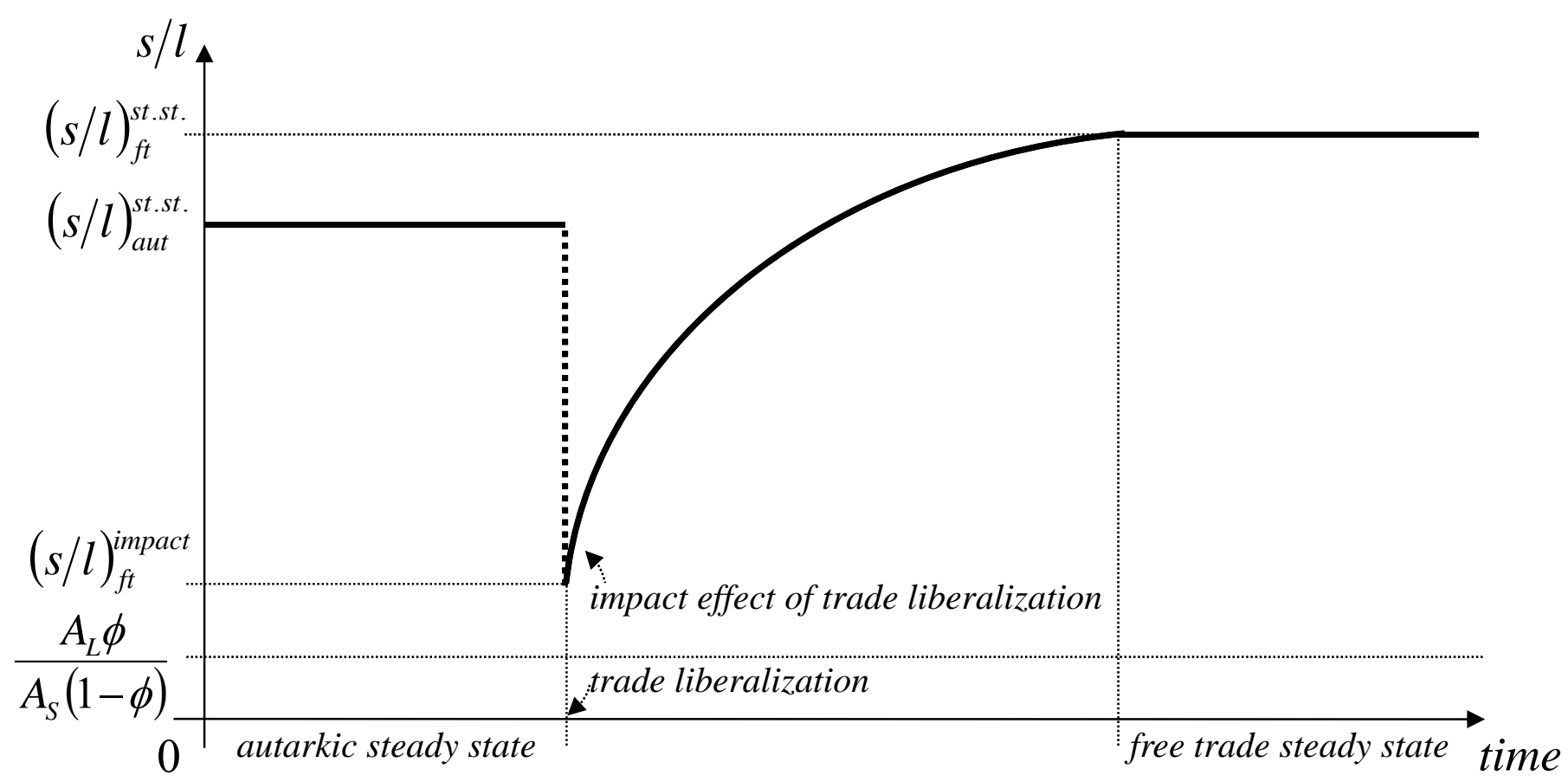

st. st. $\equiv$ steady state 
Figure A1: Autarkic steady state [for online appendix H]

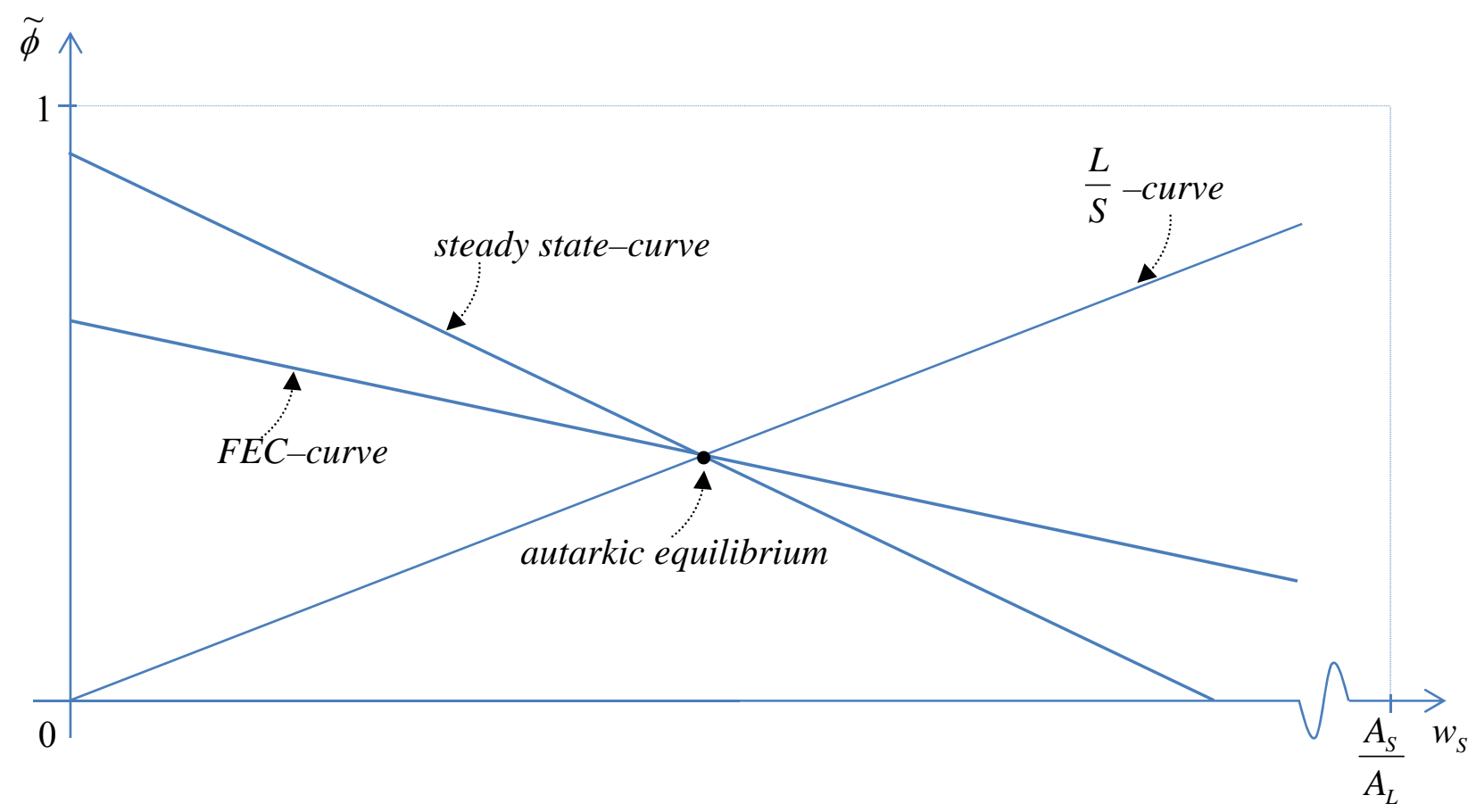

Figure A2: Open economy [ for online appendix H]

chart 1: Impact effect of trade liberalization

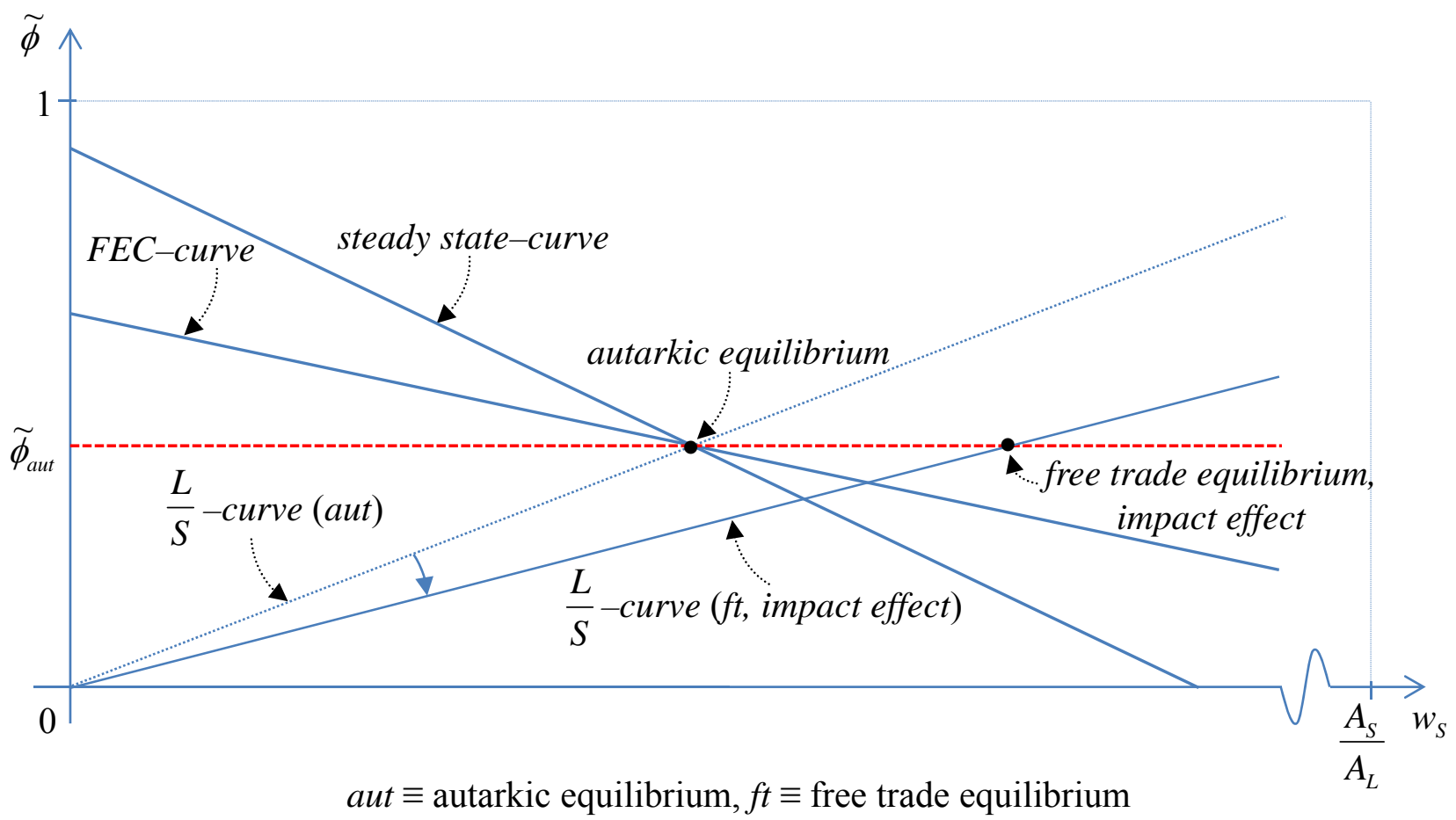


Figure A2: Open economy [for online appendix H] chart 2: Long-run effect of trade liberalization

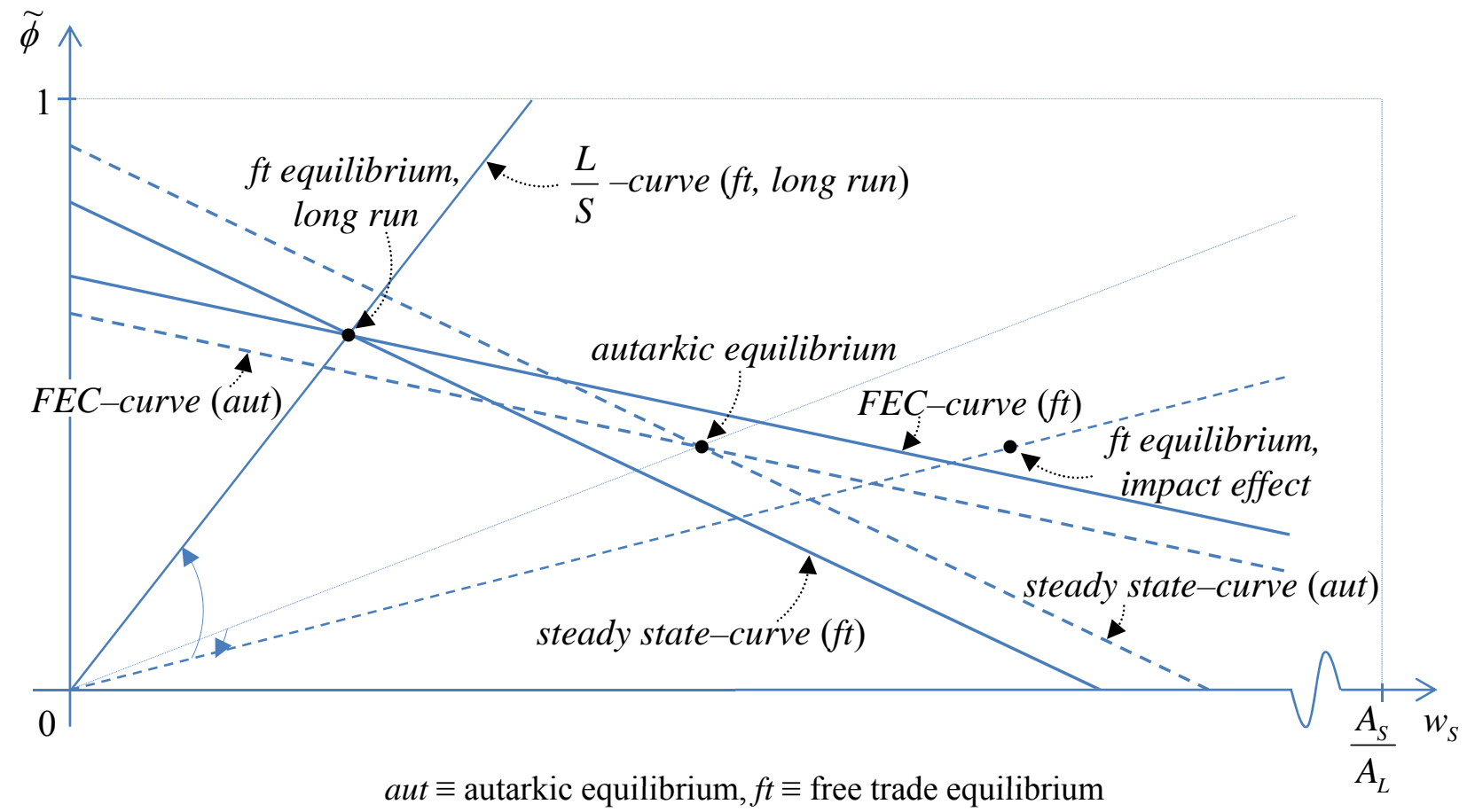


Figure A3 [ for online appendix I]

chart 1: $\sigma-\xi>0$

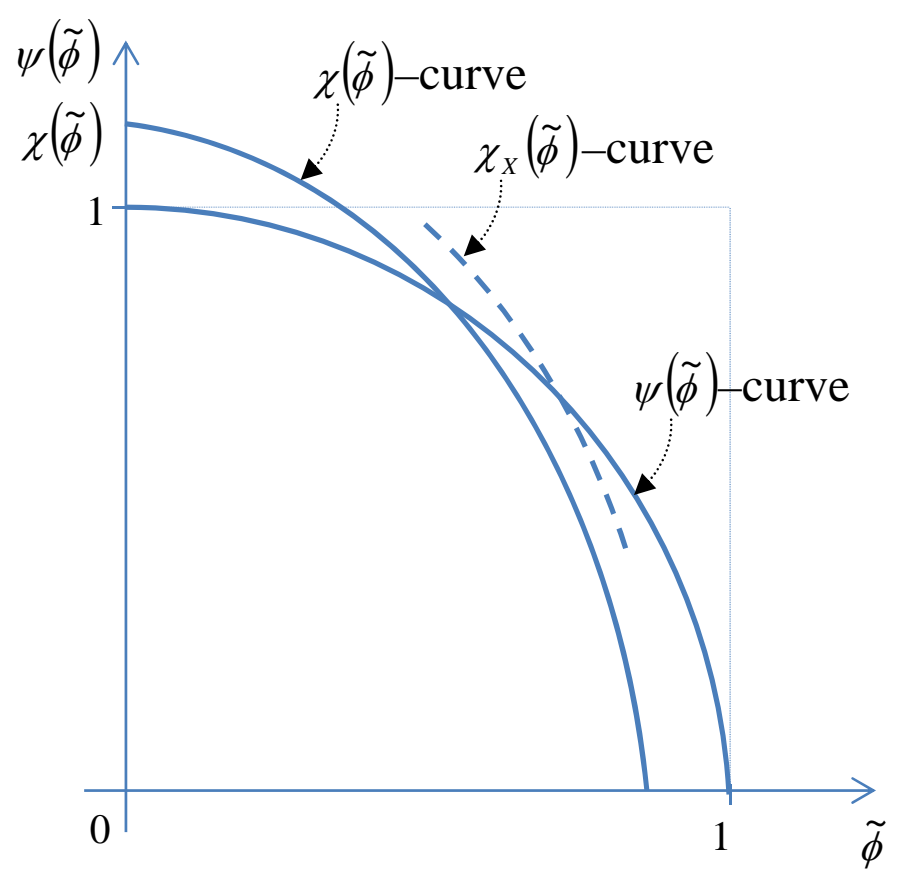

chart 2: $\sigma-\xi<0$

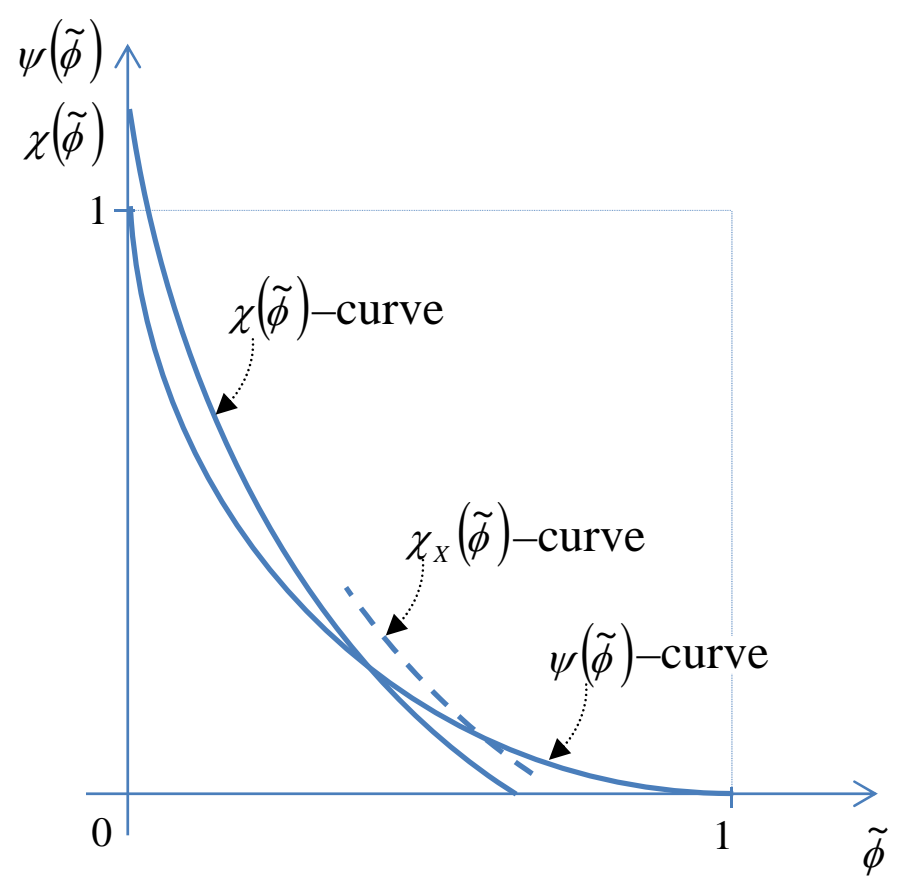

chart 3: $1>\sigma>0$

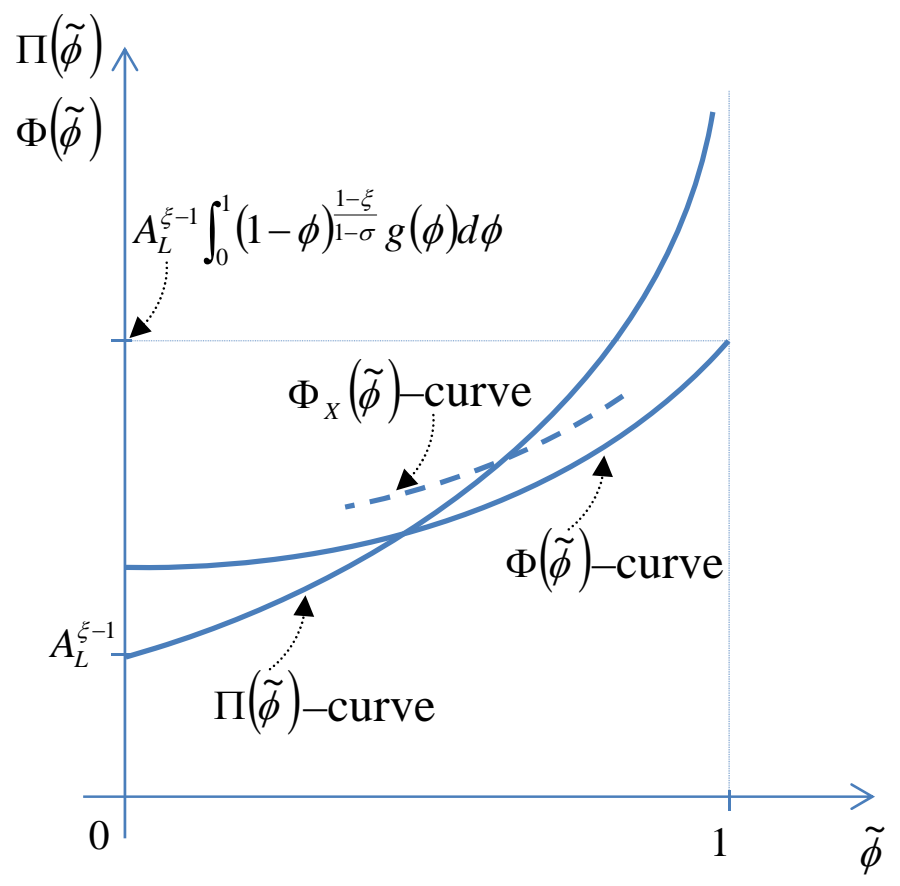


$\underline{\text { Tables }}$

TABLE 1: Export premia

\begin{tabular}{|c|c|c|c|c|}
\hline & \multicolumn{2}{|c|}{ Wage Skilled / Wage Unskilled } & \multicolumn{2}{|c|}{ Skilled Labor / Unskilled Labor } \\
\hline & (1) & (2) & (3) & (4) \\
\hline Export Premia & $\begin{array}{c}1.1697 * * \\
(0.380)\end{array}$ & $\begin{array}{c}0.5702 * \\
(0.238)\end{array}$ & $\begin{array}{c}0.2808^{* *} \\
(0.072)\end{array}$ & $\begin{array}{c}0.1498 * \\
(0.070)\end{array}$ \\
\hline Year FE & Yes & Yes & Yes & Yes \\
\hline Sector FE & Yes & Yes & Yes & Yes \\
\hline Plant Controls & No & Yes & No & Yes \\
\hline
\end{tabular}


TABLE 2: Impact effect of foreign tariffs on plant-level variables

\begin{tabular}{|c|c|c|c|c|c|c|}
\hline & \multicolumn{2}{|c|}{ Exports / Sales } & \multicolumn{2}{|c|}{ Wage Skilled / Wage Unskilled } & \multicolumn{2}{|c|}{ Skilled / Unskilled Labor } \\
\hline & (1) & (2) & (3) & (4) & (5) & (6) \\
\hline World Tariff: Simple Average & $\begin{array}{c}-0.0007 * * \\
(0.000)\end{array}$ & & $\begin{array}{c}-0.0061^{*} \\
(0.003)\end{array}$ & & $\begin{array}{l}0.0052 * \\
(0.002)\end{array}$ & \\
\hline World Tariff: Weighted Average & & $\begin{array}{c}-0.0015^{* *} \\
(0.000)\end{array}$ & & $\begin{array}{c}-0.0223^{* *} \\
(0.008)\end{array}$ & & $\begin{array}{c}0.0161+ \\
(0.009)\end{array}$ \\
\hline TFP & $\begin{array}{l}0.0026 \\
(0.002)\end{array}$ & $\begin{array}{l}0.0027 \\
(0.002)\end{array}$ & $\begin{array}{c}0.2820^{* *} \\
(0.031)\end{array}$ & $\begin{array}{c}0.2825^{* *} \\
(0.031)\end{array}$ & $\begin{array}{c}0.2287 * * \\
(0.037)\end{array}$ & $\begin{array}{c}0.2283^{* *} \\
(0.037)\end{array}$ \\
\hline Employment & $\begin{array}{c}0.0552^{* *} \\
(0.005)\end{array}$ & $\begin{array}{c}0.0551^{* *} \\
(0.005)\end{array}$ & $\begin{array}{c}0.3438 * * \\
(0.030)\end{array}$ & $\begin{array}{c}0.3436^{* * *} \\
(0.030)\end{array}$ & $\begin{array}{l}0.0004 \\
(0.023)\end{array}$ & $\begin{array}{l}0.0006 \\
(0.023)\end{array}$ \\
\hline Export Dummy & & & $\begin{array}{c}0.3039 * * \\
(0.054)\end{array}$ & $\begin{array}{c}0.3030 * * \\
(0.054)\end{array}$ & $\begin{array}{c}0.1096^{*} \\
(0.045)\end{array}$ & $\begin{array}{c}0.1101^{*} \\
(0.045)\end{array}$ \\
\hline Foreign Ownership (\%) & $\begin{array}{c}0.0006^{* *} \\
(0.000)\end{array}$ & $\begin{array}{c}0.0006^{* *} \\
(0.000)\end{array}$ & $\begin{array}{l}0.0019 \\
(0.001)\end{array}$ & $\begin{array}{l}0.0019 \\
(0.001)\end{array}$ & $\begin{array}{c}0.0041^{* *} \\
(0.001)\end{array}$ & $\begin{array}{c}0.0041^{* *} \\
(0.001)\end{array}$ \\
\hline Imported Inputs / Total Inputs & $\begin{array}{c}-0.0019+ \\
(0.001)\end{array}$ & $\begin{array}{c}-0.0019+ \\
(0.001)\end{array}$ & $\begin{array}{c}-0.0109 \\
(0.010)\end{array}$ & $\begin{array}{r}-0.0112 \\
(0.010)\end{array}$ & $\begin{array}{l}-0.0023 \\
(0.006)\end{array}$ & $\begin{array}{l}-0.0020 \\
(0.006)\end{array}$ \\
\hline Age & $\begin{array}{c}-0.0293 * * \\
(0.004)\end{array}$ & $\begin{array}{c}-0.0293 * * \\
(0.004)\end{array}$ & $\begin{array}{l}-0.0315 \\
(0.027)\end{array}$ & $\begin{array}{c}-0.0318 \\
(0.027)\end{array}$ & $\begin{array}{l}-0.0117 \\
(0.019)\end{array}$ & $\begin{array}{l}-0.0115 \\
(0.019)\end{array}$ \\
\hline Foreign Technology Licenses / Sales & $\begin{array}{l}0.1016 \\
(0.185)\end{array}$ & $\begin{array}{l}0.1063 \\
(0.185)\end{array}$ & $\begin{array}{l}1.0000 \\
(4.067)\end{array}$ & $\begin{array}{l}1.0828 \\
(4.064)\end{array}$ & $\begin{array}{c}4.8961+ \\
(2.700)\end{array}$ & $\begin{array}{c}4.8389+ \\
(2.703)\end{array}$ \\
\hline Constant & $\begin{array}{c}-0.1012 * * \\
(0.021)\end{array}$ & $\begin{array}{c}-0.1014 * * \\
(0.020)\end{array}$ & $\begin{array}{l}-0.2372 \\
(0.222)\end{array}$ & $\begin{array}{l}-0.1927 \\
(0.227)\end{array}$ & $\begin{array}{c}-0.9721^{* *} \\
(0.280)\end{array}$ & $\begin{array}{c}-0.9941 * * \\
(0.287)\end{array}$ \\
\hline Number of Observations & 38,359 & 38,359 & 38,359 & 38,359 & 38,359 & 38,359 \\
\hline R-squared & 0.184 & 0.185 & 0.059 & 0.059 & 0.029 & 0.029 \\
\hline
\end{tabular}

Robust standard errors, clustered at the 3-digit sector-year level, in parentheses. ** significant at 1\%, * significant at 5\%, + significant at 10\%. Year and 3-digit sector dummy variables were included but not reported. TFP, Employment, and Age are in logs. 
TABLE 3: Impact effect of foreign tariffs on sector-level relative wage

\begin{tabular}{|c|c|c|c|c|}
\hline & $(1)$ & $(2)$ & $(3)$ & (4) \\
\hline World Tariff: Simple Average & $\begin{array}{c}0.0087 * \\
(0.004)\end{array}$ & & $\begin{array}{c}-0.0051^{*} \\
(0.002)\end{array}$ & \\
\hline World Tariff: Weighted Average & & $\begin{array}{c}0.0004 \\
(0.010)\end{array}$ & & $\begin{array}{c}-0.0230+ \\
(0.012)\end{array}$ \\
\hline Employment Sector & $\begin{array}{c}0.0401 \\
(0.059)\end{array}$ & $\begin{array}{l}0.0431 \\
(0.056)\end{array}$ & $\begin{array}{c}-0.2680 \\
(0.247)\end{array}$ & $\begin{array}{l}-0.2587 \\
(0.241)\end{array}$ \\
\hline Average TFP Sector & $\begin{array}{c}0.0867 \\
(0.065)\end{array}$ & $\begin{array}{l}0.0976 \\
(0.066)\end{array}$ & $\begin{array}{r}-0.0515 \\
(0.092)\end{array}$ & $\begin{array}{l}-0.0464 \\
(0.095)\end{array}$ \\
\hline Share of Exporters in Employment & $\begin{array}{l}0.2280 \\
(0.477)\end{array}$ & $\begin{array}{c}0.2393 \\
(0.485)\end{array}$ & $\begin{array}{l}-0.1389 \\
(0.472)\end{array}$ & $\begin{array}{r}-0.1552 \\
(0.434)\end{array}$ \\
\hline Share of Foreign Owned in Employment & $\begin{array}{l}1.4043^{*} \\
(0.610)\end{array}$ & $\begin{array}{l}1.3222 * \\
(0.600)\end{array}$ & $\begin{array}{c}1.6254^{* *} \\
(0.549)\end{array}$ & $\begin{array}{c}1.6338^{* *} \\
(0.547)\end{array}$ \\
\hline Imported Inputs / Total Inputs & $\begin{array}{l}0.2709 \\
(0.354)\end{array}$ & $\begin{array}{c}0.2675 \\
(0.379)\end{array}$ & $\begin{array}{l}0.0466 \\
(0.376)\end{array}$ & $\begin{array}{l}0.0271 \\
(0.371)\end{array}$ \\
\hline Capital-Labor Ratio & $\begin{array}{c}-0.0000^{* *} \\
(0.000)\end{array}$ & $\begin{array}{c}-0.0000 * * \\
(0.000)\end{array}$ & $\begin{array}{c}-0.0000+ \\
(0.000)\end{array}$ & $\begin{array}{c}-0.0000 * \\
(0.000)\end{array}$ \\
\hline Constant & $\begin{array}{l}1.1918 \\
(0.829)\end{array}$ & $\begin{array}{l}1.2116 \\
(0.779)\end{array}$ & $\begin{array}{c}5.8912 * * \\
(1.943)\end{array}$ & $\begin{array}{c}5.6759 * * \\
(1.894)\end{array}$ \\
\hline Number of Observations & 278 & 278 & 278 & 278 \\
\hline R-squared & 0.322 & 0.311 & 0.237 & 0.254 \\
\hline Year Fixed Effects & Yes & Yes & Yes & Yes \\
\hline Sector Fixed Effects & No & No & Yes & Yes \\
\hline
\end{tabular}


TABLE 4: Long-run effect of foreign tariffs on sector-level relative wage

\begin{tabular}{|c|c|c|c|c|c|c|}
\hline & \multicolumn{3}{|c|}{ World Tariff: Simple Average } & \multicolumn{3}{|c|}{ World Tariff: Weighted Average } \\
\hline & Tariff 1990 & Tariff 1991 & Tariff 1992 & Tariff 1990 & Tariff 1991 & Tariff 1992 \\
\hline & $(1)$ & $(2)$ & (3) & (4) & (5) & (6) \\
\hline World Tariff * Year 1995 & $\begin{array}{l}-0.0078 \\
(0.012)\end{array}$ & & & $\begin{array}{l}-0.0109 \\
(0.021)\end{array}$ & & \\
\hline World Tariff * Year 1996 & $\begin{array}{l}0.0230 \\
(0.024)\end{array}$ & $\begin{array}{c}0.0101 * * \\
(0.001)\end{array}$ & & $\begin{array}{l}0.0099 \\
(0.022)\end{array}$ & $\begin{array}{c}0.0419 * \\
(0.019)\end{array}$ & \\
\hline World Tariff * Year 1997 & $\begin{array}{c}0.0556+ \\
(0.028)\end{array}$ & $\begin{array}{c}0.0178^{* *} \\
(0.002)\end{array}$ & $\begin{array}{c}0.0772 * \\
(0.029)\end{array}$ & $\begin{array}{c}0.0477+ \\
(0.027)\end{array}$ & $\begin{array}{c}0.0700^{* *} \\
(0.025)\end{array}$ & $\begin{array}{l}0.0214 \\
(0.020)\end{array}$ \\
\hline World Tariff * Year 1998 & $\begin{array}{c}0.0322+ \\
(0.016)\end{array}$ & $\begin{array}{c}0.0101 * * \\
(0.002)\end{array}$ & $\begin{array}{c}0.0521^{* *} \\
(0.018)\end{array}$ & $\begin{array}{l}0.0256 \\
(0.016)\end{array}$ & $\begin{array}{c}0.0483^{* *} \\
(0.016)\end{array}$ & $\begin{array}{l}0.0209 \\
(0.018)\end{array}$ \\
\hline World Tariff * Year 1999 & $\begin{array}{l}0.0197 \\
(0.020)\end{array}$ & $\begin{array}{c}0.0089 * * \\
(0.002)\end{array}$ & $\begin{array}{l}0.0348 \\
(0.024)\end{array}$ & $\begin{array}{l}0.0157 \\
(0.020)\end{array}$ & $\begin{array}{c}0.0429 * \\
(0.018)\end{array}$ & $\begin{array}{l}0.0079 \\
(0.021)\end{array}$ \\
\hline Number of Observations & 278 & 278 & 278 & 278 & 278 & 278 \\
\hline R-squared & 0.275 & 0.329 & 0.289 & 0.266 & 0.327 & 0.244 \\
\hline
\end{tabular}

Dependent variable: Wage Skilled Labor / Wage Unskilled Labor. Robust standard errors, clustered at the 3-digit sector level, in parentheses. ** significant at $1 \%, *$ significant at $5 \%,+$ significant at $10 \%$. Year and 3-digit sector dummy variables were included but not reported. Controls at the sector level (same as in Table 3) were included but not reported. 
TABLE 5: Long-run effect of foreign tariffs on plant-level variables

\begin{tabular}{|c|c|c|c|c|c|c|}
\hline & \multicolumn{3}{|c|}{ World Tariff: Simple Average } & \multicolumn{3}{|c|}{ World Tariff: Weighted Average } \\
\hline & Tariff 1990 & Tariff 1991 & Tariff 1992 & Tariff 1990 & Tariff 1991 & Tariff 1992 \\
\hline & $(1)$ & $(2)$ & (3) & (4) & (5) & (6) \\
\hline \multicolumn{7}{|c|}{ Wage Skilled / Wage Unskilled } \\
\hline World Tariff * Year 1995 & $\begin{array}{l}-0.0120 \\
(0.009)\end{array}$ & & & $\begin{array}{l}0.0009 \\
(0.012)\end{array}$ & & \\
\hline World Tariff * Year 1996 & $\begin{array}{l}0.0011 \\
(0.018)\end{array}$ & $\begin{array}{c}0.0086 * * \\
(0.003)\end{array}$ & & $\begin{array}{l}0.0159 \\
(0.017)\end{array}$ & $\begin{array}{c}0.0220+ \\
(0.012)\end{array}$ & \\
\hline World Tariff * Year 1997 & $\begin{array}{l}-0.0020 \\
(0.014)\end{array}$ & $\begin{array}{c}0.0076 * * \\
(0.002)\end{array}$ & $\begin{array}{l}0.0038 \\
(0.028)\end{array}$ & $\begin{array}{c}0.0444 * * \\
(0.016)\end{array}$ & $\begin{array}{l}0.0168 \\
(0.013)\end{array}$ & $\begin{array}{c}-0.0023 \\
(0.017)\end{array}$ \\
\hline World Tariff * Year 1998 & $\begin{array}{c}0.0269 * * \\
(0.010)\end{array}$ & $\begin{array}{c}0.0104 * * \\
(0.003)\end{array}$ & $\begin{array}{c}0.0373^{*} \\
(0.015)\end{array}$ & $\begin{array}{c}0.0527 * * \\
(0.014)\end{array}$ & $\begin{array}{c}0.0431^{* *} \\
(0.011)\end{array}$ & $\begin{array}{l}0.0067 \\
(0.015)\end{array}$ \\
\hline World Tariff * Year 1999 & $\begin{array}{c}0.0423 \\
(0.028)\end{array}$ & $\begin{array}{c}0.0280 * * \\
(0.002)\end{array}$ & $\begin{array}{c}0.0901+ \\
(0.048)\end{array}$ & $\begin{array}{c}0.0531+ \\
(0.032)\end{array}$ & $\begin{array}{c}0.0501+ \\
(0.026)\end{array}$ & $\begin{array}{l}0.0081 \\
(0.014)\end{array}$ \\
\hline Observations & 38,359 & 38,359 & 38,359 & 38,359 & 38,359 & 38,359 \\
\hline R-squared & 0.059 & 0.060 & 0.059 & 0.059 & 0.059 & 0.059 \\
\hline \multicolumn{7}{|c|}{ Skilled Labor / Unskilled Labor } \\
\hline World Tariff * Year 1995 & $\begin{array}{c}-0.0018 \\
(0.007)\end{array}$ & & & $\begin{array}{c}-0.0012 \\
(0.011)\end{array}$ & & \\
\hline World Tariff * Year 1996 & $\begin{array}{l}0.0019 \\
(0.010)\end{array}$ & $\begin{array}{l}-0.0037 \\
(0.002)\end{array}$ & & $\begin{array}{l}-0.0246 \\
(0.019)\end{array}$ & $\begin{array}{l}-0.0148 \\
(0.016)\end{array}$ & \\
\hline World Tariff * Year 1997 & $\begin{array}{c}-0.0140+ \\
(0.007)\end{array}$ & $\begin{array}{c}-0.0069 * * \\
(0.001)\end{array}$ & $\begin{array}{c}-0.0316+ \\
(0.017)\end{array}$ & $\begin{array}{c}-0.0284^{*} \\
(0.012)\end{array}$ & $\begin{array}{c}-0.0079 \\
(0.011)\end{array}$ & $\begin{array}{l}0.0004 \\
(0.009)\end{array}$ \\
\hline World Tariff * Year 1998 & $\begin{array}{c}-0.0419^{* *} \\
(0.011)\end{array}$ & $\begin{array}{c}-0.0073^{* *} \\
(0.002)\end{array}$ & $\begin{array}{c}-0.0609 * \\
(0.028)\end{array}$ & $\begin{array}{c}-0.0504 * * \\
(0.018)\end{array}$ & $\begin{array}{l}-0.0017 \\
(0.018)\end{array}$ & $\begin{array}{l}0.0094 \\
(0.019)\end{array}$ \\
\hline World Tariff * Year 1999 & $\begin{array}{c}-0.0413^{* *} \\
(0.010)\end{array}$ & $\begin{array}{c}-0.0082 * * \\
(0.002)\end{array}$ & $\begin{array}{c}-0.0590 * \\
(0.029)\end{array}$ & $\begin{array}{c}-0.0501 * * \\
(0.018)\end{array}$ & $\begin{array}{l}-0.0224 \\
(0.017)\end{array}$ & $\begin{array}{l}0.0018 \\
(0.018)\end{array}$ \\
\hline Number of Observations & 38,359 & 38,359 & 38,359 & 38,359 & 38,359 & 38,359 \\
\hline R-squared & 0.030 & 0.029 & 0.030 & 0.030 & 0.029 & 0.029 \\
\hline
\end{tabular}

Robust standard errors, clustered at the 3-digit sector-year level, in parentheses. ** significant at 1\%, * significant at 5\%, + significant at 10\%. Year and 3-digit sector dummy variables were included but not reported. TFP, Employment, and Age are in logs. 
TABLE 6: Long-run effect of foreign tariffs - cross section results

\begin{tabular}{|c|c|c|c|c|}
\hline & $\begin{array}{c}\text { Wage Skilled / Wage } \\
\text { Unskilled }\end{array}$ & $\begin{array}{l}\text { Skilled Labor / Unskilled } \\
\text { Labor }\end{array}$ & $\begin{array}{c}\text { Wage Skilled / Wage } \\
\text { Unskilled }\end{array}$ & $\begin{array}{c}\text { Skilled Labor / Unskilled } \\
\text { Labor }\end{array}$ \\
\hline & (1) & (2) & (3) & (4) \\
\hline World Tariff: Simple Average & $\begin{array}{l}0.0219 * \\
(0.009)\end{array}$ & $\begin{array}{c}-0.0327 * * \\
(0.013)\end{array}$ & & \\
\hline World Tariff: Weighted Average & & & $\begin{array}{l}0.0299 * \\
(0.013)\end{array}$ & $\begin{array}{l}-0.0115 \\
(0.018)\end{array}$ \\
\hline TFP & $\begin{array}{c}0.0903+ \\
(0.050)\end{array}$ & $\begin{array}{c}0.2430 * * \\
(0.071)\end{array}$ & $\begin{array}{l}0.1146^{*} \\
(0.048)\end{array}$ & $\begin{array}{c}0.1931^{* *} \\
(0.068)\end{array}$ \\
\hline Employment & $\begin{array}{c}0.3721^{* *} \\
(0.053)\end{array}$ & $\begin{array}{l}0.1903^{*} \\
(0.075)\end{array}$ & $\begin{array}{c}0.3672^{* *} \\
(0.053)\end{array}$ & $\begin{array}{c}0.1951^{* *} \\
(0.075)\end{array}$ \\
\hline Export Dummy & $\begin{array}{c}0.3256^{* *} \\
(0.126)\end{array}$ & $\begin{array}{c}-0.2990+ \\
(0.177)\end{array}$ & $\begin{array}{c}0.3370^{* *} \\
(0.126)\end{array}$ & $\begin{array}{c}-0.2974+ \\
(0.178)\end{array}$ \\
\hline Foreign Ownership (\%) & $\begin{array}{c}0.0048+ \\
(0.003)\end{array}$ & $\begin{array}{l}0.0090^{*} \\
(0.004)\end{array}$ & $\begin{array}{c}0.0048+ \\
(0.003)\end{array}$ & $\begin{array}{l}0.0093^{*} \\
(0.004)\end{array}$ \\
\hline Imported Inputs / Total Inputs & $\begin{array}{l}0.2215 \\
(0.173)\end{array}$ & $\begin{array}{l}0.1547 \\
(0.243)\end{array}$ & $\begin{array}{l}0.1218 \\
(0.175)\end{array}$ & $\begin{array}{l}0.2239 \\
(0.247)\end{array}$ \\
\hline Age & $\begin{array}{l}0.0163 \\
(0.098)\end{array}$ & $\begin{array}{l}0.0407 \\
(0.138)\end{array}$ & $\begin{array}{l}0.0258 \\
(0.098)\end{array}$ & $\begin{array}{l}0.0219 \\
(0.138)\end{array}$ \\
\hline Foreign Technology Licenses / Sales & $\begin{array}{c}6.3531 \\
(10.688)\end{array}$ & $\begin{array}{l}19.9129 \\
(15.057)\end{array}$ & $\begin{array}{c}4.7574 \\
(10.685)\end{array}$ & $\begin{array}{l}21.6569 \\
(15.073)\end{array}$ \\
\hline Constant & $\begin{array}{l}0.3684 \\
(0.397)\end{array}$ & $\begin{array}{c}-1.2286^{*} \\
(0.559)\end{array}$ & $\begin{array}{l}0.2266 \\
(0.401)\end{array}$ & $\begin{array}{c}-1.1683^{*} \\
(0.566)\end{array}$ \\
\hline $\begin{array}{l}\text { Number of Observations } \\
\text { R-squared }\end{array}$ & $\begin{array}{l}2,089 \\
0.075\end{array}$ & $\begin{array}{l}2,089 \\
0.021\end{array}$ & $\begin{array}{l}2,089 \\
0.075\end{array}$ & $\begin{array}{l}2,089 \\
0.018\end{array}$ \\
\hline
\end{tabular}

Standard errors in parentheses. ${ }^{* *}$ significant at $1 \%{ }^{*}$ significant at 5\%, + significant at 10\%. TFP, Employment, and Age are in logs. Dependent variables are averages over the period 1995-1999, while all the independent variables are averages over the period 1990-1994. Only plants that stayed in operation during the entire period 1990-1999 are included. Export Dummy = 1 if plant exported at least 3 years during the period $1990-1994$. 
TABLE A1: Impact effect of foreign tariffs on plant-level variables with plant fixed effects

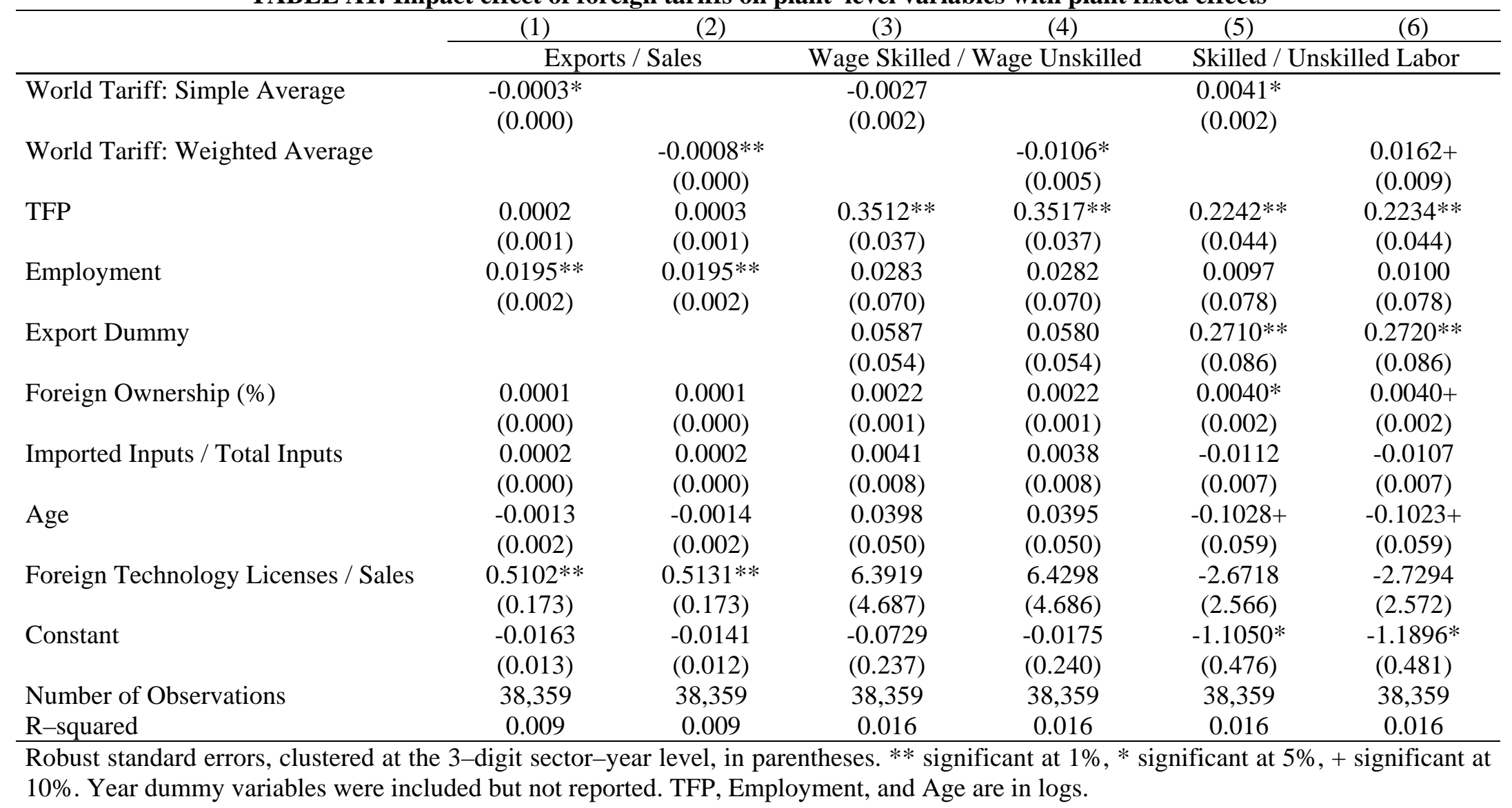


TABLE A2: Impact effect of foreign tariffs on plant-level variables with world imports

\begin{tabular}{|c|c|c|c|c|c|c|}
\hline & $(1)$ & $(2)$ & (3) & $(4)$ & $(5)$ & $(6)$ \\
\hline & \multicolumn{2}{|c|}{ Exports / Sales } & \multicolumn{2}{|c|}{$\begin{array}{c}\text { Wage Skilled / Wage } \\
\text { Unskilled }\end{array}$} & \multicolumn{2}{|c|}{ Skilled / Unskilled Labor } \\
\hline World Tariff: Simple Average & $\begin{array}{c}-0.0007^{* *} \\
(0.000)\end{array}$ & & $\begin{array}{c}-0.0060^{*} \\
(0.003)\end{array}$ & & $\begin{array}{l}0.0043^{*} \\
(0.002)\end{array}$ & \\
\hline World Tariff: Weighted Average & & $\begin{array}{c}-0.0016^{* *} \\
(0.000)\end{array}$ & & $\begin{array}{c}-0.0222 * * \\
(0.008)\end{array}$ & & $\begin{array}{l}0.0146 \\
(0.009)\end{array}$ \\
\hline World Imports & $\begin{array}{l}0.0210 \\
(0.015)\end{array}$ & $\begin{array}{l}0.0197 \\
(0.015)\end{array}$ & $\begin{array}{l}-0.0452 \\
(0.220)\end{array}$ & $\begin{array}{l}-0.0153 \\
(0.219)\end{array}$ & $\begin{array}{l}0.3639 \\
(0.249)\end{array}$ & $\begin{array}{l}0.3486 \\
(0.255)\end{array}$ \\
\hline TFP & $\begin{array}{l}0.0026 \\
(0.002)\end{array}$ & $\begin{array}{l}0.0026 \\
(0.002)\end{array}$ & $\begin{array}{c}0.2821^{* *} \\
(0.031)\end{array}$ & $\begin{array}{c}0.2825^{* *} \\
(0.031)\end{array}$ & $\begin{array}{c}0.2281^{* *} \\
(0.037)\end{array}$ & $\begin{array}{c}0.2278^{* *} \\
(0.037)\end{array}$ \\
\hline Employment & $\begin{array}{c}0.0552^{* *} \\
(0.005)\end{array}$ & $\begin{array}{c}0.0551 * * \\
(0.005)\end{array}$ & $\begin{array}{c}0.3437 * * \\
(0.030)\end{array}$ & $\begin{array}{c}0.3436 * * \\
(0.030)\end{array}$ & $\begin{array}{l}0.0008 \\
(0.023)\end{array}$ & $\begin{array}{l}0.0009 \\
(0.023)\end{array}$ \\
\hline Export Dummy & & & $\begin{array}{c}0.3040 * * \\
(0.054)\end{array}$ & $\begin{array}{c}0.3030^{* *} \\
(0.054)\end{array}$ & $\begin{array}{l}0.1084^{*} \\
(0.045)\end{array}$ & $\begin{array}{l}0.1090^{*} \\
(0.045)\end{array}$ \\
\hline Foreign Ownership (\%) & $\begin{array}{c}0.0006^{* *} \\
(0.000)\end{array}$ & $\begin{array}{c}0.0006^{* *} \\
(0.000)\end{array}$ & $\begin{array}{l}0.0019 \\
(0.001)\end{array}$ & $\begin{array}{l}0.0019 \\
(0.001)\end{array}$ & $\begin{array}{c}0.0041^{* *} \\
(0.001)\end{array}$ & $\begin{array}{c}0.0041^{* *} \\
(0.001)\end{array}$ \\
\hline Imported Inputs / Total Inputs & $\begin{array}{c}-0.0019+ \\
(0.001)\end{array}$ & $\begin{array}{c}-0.0019+ \\
(0.001)\end{array}$ & $\begin{array}{l}-0.0109 \\
(0.010)\end{array}$ & $\begin{array}{l}-0.0112 \\
(0.010)\end{array}$ & $\begin{array}{l}-0.0023 \\
(0.006)\end{array}$ & $\begin{array}{l}-0.0021 \\
(0.006)\end{array}$ \\
\hline Age & $\begin{array}{c}-0.0293 * * \\
(0.004)\end{array}$ & $\begin{array}{c}-0.0293^{* *} \\
(0.004)\end{array}$ & $\begin{array}{l}-0.0315 \\
(0.027)\end{array}$ & $\begin{array}{l}-0.0318 \\
(0.027)\end{array}$ & $\begin{array}{l}-0.0114 \\
(0.019)\end{array}$ & $\begin{array}{l}-0.0112 \\
(0.019)\end{array}$ \\
\hline Foreign Technology Licenses / Sales & $\begin{array}{l}0.1055 \\
(0.185)\end{array}$ & $\begin{array}{l}0.1102 \\
(0.185)\end{array}$ & $\begin{array}{l}0.9912 \\
(4.065)\end{array}$ & $\begin{array}{l}1.0797 \\
(4.063)\end{array}$ & $\begin{array}{l}4.9667+ \\
(2.693)\end{array}$ & $\begin{array}{l}4.9104+ \\
(2.697)\end{array}$ \\
\hline Constant & $\begin{array}{c}-0.4573^{*} \\
(0.221)\end{array}$ & $\begin{array}{c}-0.4356^{*} \\
(0.213)\end{array}$ & $\begin{array}{l}0.2571 \\
(3.141)\end{array}$ & $\begin{array}{l}-0.1082 \\
(3.132)\end{array}$ & $\begin{array}{c}-6.2848+ \\
(3.549)\end{array}$ & $\begin{array}{c}-6.1041+ \\
(3.615)\end{array}$ \\
\hline Number of Observations & 38,359 & 38,359 & 38,359 & 38,359 & 38,359 & 38,359 \\
\hline R-squared & 0.185 & 0.185 & 0.059 & 0.059 & 0.029 & 0.029 \\
\hline
\end{tabular}


TABLE A3: Impact effect of foreign tariffs - IV estimates

\begin{tabular}{|c|c|c|c|c|}
\hline & \multicolumn{2}{|c|}{ Instrument: Simple Average Tariff } & \multicolumn{2}{|c|}{ Instrument: Weighted Average Tariff } \\
\hline & $\begin{array}{c}\text { Wage Skilled / Wage } \\
\text { Unskilled }\end{array}$ & $\begin{array}{l}\text { Skilled Labor / } \\
\text { Unskilled Labor }\end{array}$ & $\begin{array}{c}\text { Wage Skilled / Wage } \\
\text { Unskilled }\end{array}$ & $\begin{array}{l}\text { Skilled Labor / } \\
\text { Unskilled Labor }\end{array}$ \\
\hline & (1) & $(2)$ & (3) & (4) \\
\hline Exports / Sales (Instrumented) & $\begin{array}{l}9.5060 * * \\
(2.893)\end{array}$ & $\begin{array}{c}-7.6404 * \\
(3.071)\end{array}$ & $\begin{array}{c}15.5171^{* *} \\
(5.179)\end{array}$ & $\begin{array}{c}-10.6895+ \\
(6.482)\end{array}$ \\
\hline TFP & $\begin{array}{c}0.2667^{* *} \\
(0.036)\end{array}$ & $\begin{array}{c}0.2518^{* *} \\
(0.040)\end{array}$ & $\begin{array}{c}0.2506^{* *} \\
(0.044)\end{array}$ & $\begin{array}{c}0.2600^{* *} \\
(0.044)\end{array}$ \\
\hline Employment & $\begin{array}{l}-0.1265 \\
(0.165)\end{array}$ & $\begin{array}{l}0.4413^{*} \\
(0.175)\end{array}$ & $\begin{array}{l}-0.4579 \\
(0.293)\end{array}$ & $\begin{array}{c}0.6094+ \\
(0.363)\end{array}$ \\
\hline Foreign Ownership (\%) & $\begin{array}{l}-0.0036 \\
(0.002)\end{array}$ & $\begin{array}{c}0.0092^{* *} \\
(0.002)\end{array}$ & $\begin{array}{c}-0.0075^{*} \\
(0.004)\end{array}$ & $\begin{array}{l}0.0111^{*} \\
(0.005)\end{array}$ \\
\hline Imported Inputs / Total Inputs & $\begin{array}{l}0.0106 \\
(0.014)\end{array}$ & $\begin{array}{l}-0.0152 \\
(0.011)\end{array}$ & $\begin{array}{l}0.0224 \\
(0.021)\end{array}$ & $\begin{array}{l}-0.0212 \\
(0.016)\end{array}$ \\
\hline Age & $\begin{array}{c}0.2407 * * \\
(0.087)\end{array}$ & $\begin{array}{c}-0.2378^{* *} \\
(0.092)\end{array}$ & $\begin{array}{c}0.4168^{* *} \\
(0.157)\end{array}$ & $\begin{array}{c}-0.3271+ \\
(0.191)\end{array}$ \\
\hline Foreign Technology Licenses / Sales & $\begin{array}{l}0.8552 \\
(4.473)\end{array}$ & $\begin{array}{c}5.9687+ \\
(3.117)\end{array}$ & $\begin{array}{l}0.2543 \\
(5.062)\end{array}$ & $\begin{array}{c}6.2735+ \\
(3.456)\end{array}$ \\
\hline First Stage Estimates for World Tari & & & & \\
\hline World Tariff: Simple Average & \multicolumn{2}{|c|}{$\begin{array}{c}-0.0007 * * \\
(0.000)\end{array}$} & & \\
\hline World Tariff: Weighted Average & & & \multicolumn{2}{|c|}{$\begin{array}{c}-0.0015 * * \\
(0.000)\end{array}$} \\
\hline F test Excluded Instruments & \multicolumn{2}{|c|}{$22.66^{* *}$} & \multicolumn{2}{|c|}{$15.03 * *$} \\
\hline Number of Observations & 38,359 & 38,359 & 38,359 & 38,359 \\
\hline
\end{tabular}


TABLE A4: Long-run effect of foreign tariffs on plant-level variables with plant fixed effects

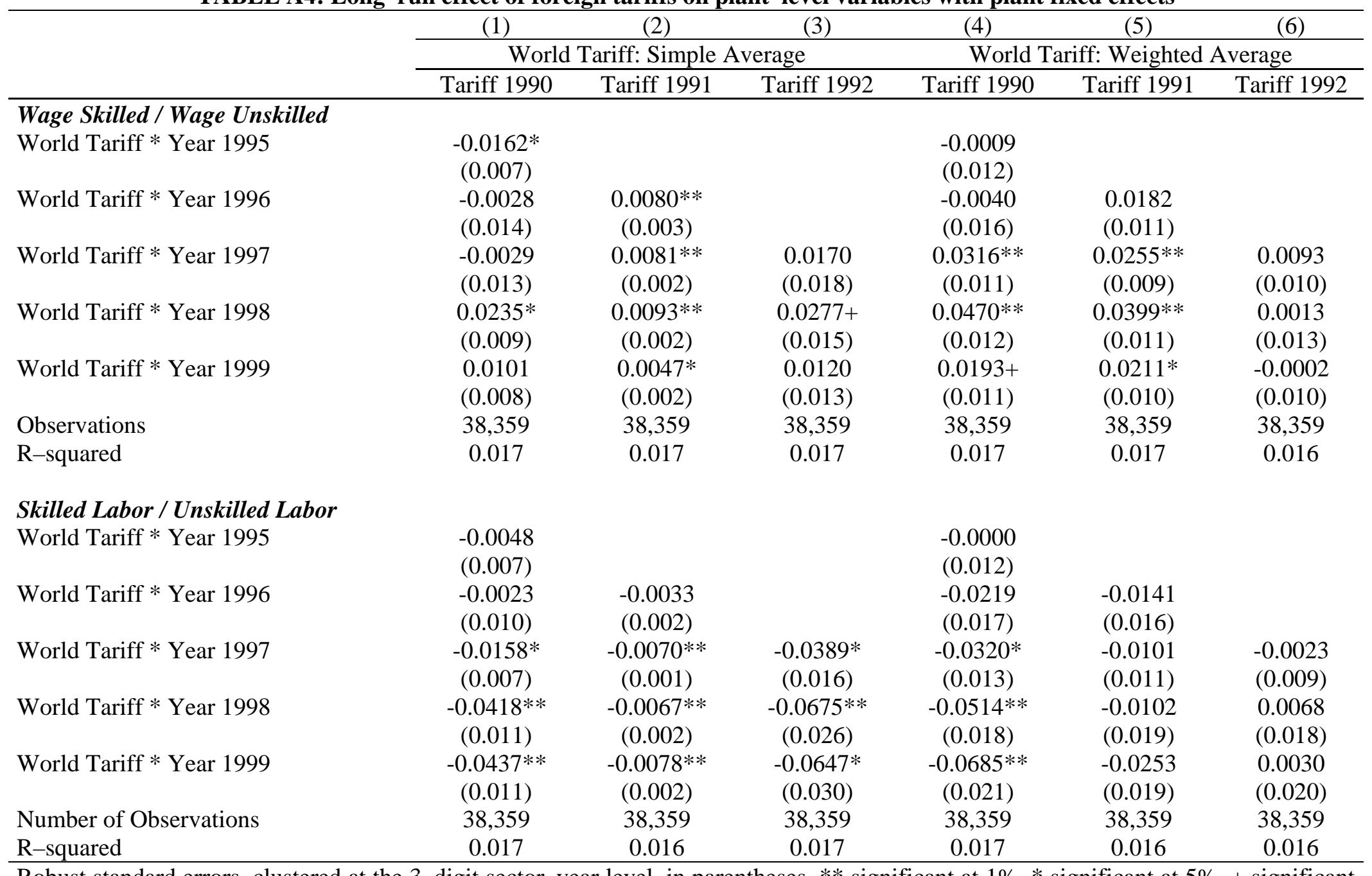

Robust standard errors, clustered at the 3-digit sector-year level, in parentheses. ** significant at 1\%, * significant at 5\%, + significant at $10 \%$. Year and 3-digit sector dummy variables were included but not reported. TFP, Employment, and Age are in logs. 
TABLE A5: Long-run effect of foreign tariffs on plant-level variables with world imports

\begin{tabular}{|c|c|c|c|c|c|c|}
\hline & \multicolumn{3}{|c|}{ World Tariff: Simple Average } & \multicolumn{3}{|c|}{ World Tariff: Weighted Average } \\
\hline & Tariff 1990 & Tariff 1991 & Tariff 1992 & Tariff 1990 & Tariff 1991 & Tariff 1992 \\
\hline & (1) & (2) & (3) & (4) & (5) & (6) \\
\hline \multicolumn{7}{|c|}{ Wage Skilled / Wage Unskilled } \\
\hline World Tariff * Year 1995 & $\begin{array}{c}-0.0122 \\
(0.009)\end{array}$ & & & $\begin{array}{l}0.0010 \\
(0.012)\end{array}$ & & \\
\hline World Tariff * Year 1996 & $\begin{array}{l}0.0009 \\
(0.018)\end{array}$ & $\begin{array}{c}0.0086^{* *} \\
(0.003)\end{array}$ & & $\begin{array}{l}0.0161 \\
(0.017)\end{array}$ & $\begin{array}{c}0.0220+ \\
(0.012)\end{array}$ & \\
\hline World Tariff * Year 1997 & $\begin{array}{l}-0.0017 \\
(0.014)\end{array}$ & $\begin{array}{c}0.0076^{* *} \\
(0.002)\end{array}$ & $\begin{array}{l}0.0037 \\
(0.028)\end{array}$ & $\begin{array}{c}0.0445^{* *} \\
(0.016)\end{array}$ & $\begin{array}{l}0.0168 \\
(0.013)\end{array}$ & $\begin{array}{c}-0.0018 \\
(0.017)\end{array}$ \\
\hline World Tariff * Year 1998 & $\begin{array}{c}0.0273^{* *} \\
(0.010)\end{array}$ & $\begin{array}{c}0.0104^{* *} \\
(0.003)\end{array}$ & $\begin{array}{c}0.0376^{*} \\
(0.015)\end{array}$ & $\begin{array}{c}0.0528 * * \\
(0.014)\end{array}$ & $\begin{array}{c}0.0431^{* *} \\
(0.011)\end{array}$ & $\begin{array}{l}0.0077 \\
(0.015)\end{array}$ \\
\hline World Tariff * Year 1999 & $\begin{array}{l}0.0434 \\
(0.028)\end{array}$ & $\begin{array}{c}0.0280^{* *} \\
(0.002)\end{array}$ & $\begin{array}{c}0.0899+ \\
(0.048)\end{array}$ & $\begin{array}{c}0.0528+ \\
(0.032)\end{array}$ & $\begin{array}{c}0.0499+ \\
(0.027)\end{array}$ & $\begin{array}{l}0.0092 \\
(0.014)\end{array}$ \\
\hline World Imports & $\begin{array}{l}0.1233 \\
(0.240)\end{array}$ & $\begin{array}{c}-0.0062 \\
(0.205)\end{array}$ & $\begin{array}{l}-0.0971 \\
(0.222)\end{array}$ & $\begin{array}{c}-0.1108 \\
(0.216)\end{array}$ & $\begin{array}{l}-0.0794 \\
(0.196)\end{array}$ & $\begin{array}{c}-0.1513 \\
(0.215)\end{array}$ \\
\hline Observations & 38,359 & 38,359 & 38,359 & 38,359 & 38,359 & 38,359 \\
\hline R-squared & 0.059 & 0.060 & 0.059 & 0.059 & 0.059 & 0.059 \\
\hline \multicolumn{7}{|c|}{ Skilled Labor / Unskilled Labor } \\
\hline World Tariff * Year 1995 & $\begin{array}{l}-0.0022 \\
(0.007)\end{array}$ & & & $\begin{array}{l}-0.0016 \\
(0.012)\end{array}$ & & \\
\hline World Tariff * Year 1996 & $\begin{array}{l}0.0015 \\
(0.010)\end{array}$ & $\begin{array}{l}-0.0035 \\
(0.002)\end{array}$ & & $\begin{array}{l}-0.0253 \\
(0.018)\end{array}$ & $\begin{array}{l}-0.0148 \\
(0.016)\end{array}$ & \\
\hline World Tariff * Year 1997 & $\begin{array}{c}-0.0135+ \\
(0.007)\end{array}$ & $\begin{array}{c}-0.0066^{* *} \\
(0.001)\end{array}$ & $\begin{array}{c}-0.0313+ \\
(0.016)\end{array}$ & $\begin{array}{c}-0.0288 * \\
(0.011)\end{array}$ & $\begin{array}{l}-0.0079 \\
(0.011)\end{array}$ & $\begin{array}{c}-0.0010 \\
(0.009)\end{array}$ \\
\hline World Tariff * Year 1998 & $\begin{array}{c}-0.0414^{* *} \\
(0.011)\end{array}$ & $\begin{array}{c}-0.0071^{* *} \\
(0.002)\end{array}$ & $\begin{array}{c}-0.0621 * \\
(0.026)\end{array}$ & $\begin{array}{c}-0.0509 * * \\
(0.018)\end{array}$ & $\begin{array}{l}-0.0018 \\
(0.018)\end{array}$ & $\begin{array}{l}0.0067 \\
(0.019)\end{array}$ \\
\hline World Tariff * Year 1999 & $\begin{array}{c}-0.0397^{* *} \\
(0.011)\end{array}$ & $\begin{array}{c}-0.0079 * * \\
(0.002)\end{array}$ & $\begin{array}{c}-0.0581^{*} \\
(0.028)\end{array}$ & $\begin{array}{c}-0.0492^{* *} \\
(0.018)\end{array}$ & $\begin{array}{l}-0.0214 \\
(0.017)\end{array}$ & $\begin{array}{l}-0.0011 \\
(0.017)\end{array}$ \\
\hline World Imports & $\begin{array}{l}0.1768 \\
(0.234)\end{array}$ & $\begin{array}{l}0.3642 \\
(0.245)\end{array}$ & $\begin{array}{c}0.4213+ \\
(0.239)\end{array}$ & $\begin{array}{c}0.4137+ \\
(0.243)\end{array}$ & $\begin{array}{l}0.3946 \\
(0.253)\end{array}$ & $\begin{array}{c}0.3994+ \\
(0.241)\end{array}$ \\
\hline Number of Observations & 38,359 & 38,359 & 38,359 & 38,359 & 38,359 & 38,359 \\
\hline R-squared & 0.030 & 0.030 & 0.030 & 0.030 & 0.029 & 0.029 \\
\hline
\end{tabular}

